University of Louisville

ThinkIR: The University of Louisville's Institutional Repository

Electronic Theses and Dissertations

8-2014

\title{
Putting the person first : an examination of thought disorder and personality heterogeneity in schizophrenia.
}

Catherine Rose Robertson

University of Louisville

Follow this and additional works at: https://ir.library.louisville.edu/etd

Part of the Psychology Commons

\section{Recommended Citation}

Robertson, Catherine Rose, "Putting the person first : an examination of thought disorder and personality heterogeneity in schizophrenia." (2014). Electronic Theses and Dissertations. Paper 1214.

https://doi.org/10.18297/etd/1214

This Doctoral Dissertation is brought to you for free and open access by ThinkIR: The University of Louisville's Institutional Repository. It has been accepted for inclusion in Electronic Theses and Dissertations by an authorized administrator of ThinkIR: The University of Louisville's Institutional Repository. This title appears here courtesy of the author, who has retained all other copyrights. For more information, please contact thinkir@louisville.edu. 
PUTTING THE PERSON FIRST: AN EXAMINATION OF THOUGHT DISORDER AND PERSONALITY HETEROGENEITY IN SCHIZOPHRENIA

By

Catherine Rose Robertson

B.A. University of Louisville, 2009

M.A. University of Louisville, 2011

\begin{abstract}
A Dissertation
Submitted to the Faculty of the

College of Arts and Sciences of the University of Louisville

in Partial Fulfillment of the Requirements

for the Degree of
\end{abstract}

Doctor of Philosophy

Clinical Psychology

Department of Psychological and Brain Sciences

University of Louisville

Louisville, Kentucky

August 2014 
Copyright 2014 by Catherine Rose Robertson

All rights reserved 

PUTTING THE PERSON FIRST: AN EXAMINATION OF THOUGHT DISORDER AND PERSONALITY HETEROGENEITY IN SCHIZOPHRENIA AND SCHIZOAFFECTIVE DISORDER

\author{
By \\ Catherine Rose Robertson \\ B.A. University of Louisville, 2009 \\ M.A. University of Louisville, 2011 \\ A Dissertation Approved on
}

May 22, 2014

by the Following Dissertation Committee:

Rich Lewine, Ph.D.

Dissertation Advisor

Manuel Casanova, M.D.

Jay Irby, Ph.D.

Suzanne Meeks, Ph.D. 


\section{DEDICATION}

This dissertation is dedicated to the family and friends who have provided me with unwavering support

and

to my mentor, Dr. Rich Lewine, for the inspiration and guidance to use my high

Openness to Experience as an asset, and for believing in my potential in spite of my low average Conscientiousness 


\section{ACKNOWLEDGEMENTS}

I would first like to express my gratitude to the lab which has served as a foundational support through my graduate school journey. Dr. Rich Lewine's commitment to mentoring and teaching style which emphasized not what, but how, to think fostered a collaborative learning environment and an ongoing source of inspiration. I would also like to thank my labmates, Rachel Waford, and Mara Hart. The struggles and successes we have shared as psychologists in training have been instrumental in my growth, both personally and professionally. Thank you for the hard work, the encouragement, the inspiration, and the friendship. I would also like to thank my committee members, Dr. Manuel Casanova, Dr. Jay Irby, and Dr. Suzanne Meeks for your time and thoughtful feedback related to this project. Lastly, I would like to thank those at the University of Louisville Hospital who made this project possible. In particular, I would like to thank the participants of the study. Working with each of these unique individuals strengthened my dedication to working on this project which highlights their individuality. 


\section{ABSTRACT \\ PUTTING THE PERSON FIRST: AN EXAMINATION OF THOUGHT DISORDER AND PERSONALITY HETEROGENEITY IN SCHIZOPHRENIA AND SCHIZOAFFECTIVE DISORDER}

Catherine Rose Robertson

May 22, 2014

The Recovery Model of mental illness, emerging as the new zeitgeist in regards to treatment, emphasizes the optimization of functioning for each individual, using personal strengths and preferences to drive the recovery process. Thought disorder has long been considered a core symptom of schizophrenia and has been implicated in multiple domains of functional outcome. In spite of its relationship to functioning and substantial heterogeneity of the phenomenon, little to no research has examined potential factors which may be related to these differences in thought disorder and its related domains of functioning. The current study proposes that "normal" personality traits, such as those captured by the widely accepted Five-Factor Model (FFM), may be of particular utility in understanding the differences among individuals with schizophrenia, consistent with the Recovery Model's attention to individual differences.

This dissertation specifically explores the relationship between personality and thought disorder in schizophrenia. Participants in the study were assessed for thought disorder and personality via the Thought Disorder Index and the Big Five Inventory, respectively. It was hypothesized that 1) personality would be related to the severity of 
thought disorder, and 2) personality would be related to the characteristics of thought disorder observed. It was also hypothesized that significant personality differences within the sample would emerge.

Hypotheses were partially supported. Three clusters with significant personality differences emerged within the sample. While personality and the severity of thought disorder were not related, personality was related to the quality of thought disorder. Results suggest that personality may be related to the heterogeneity of thought disorder within the schizophrenia population. Additionally, results indicate those with a diagnosis of schizophrenia demonstrate distinct personalities which distinguish them as individuals, may be relevant to functional outcome, and inform intervention. 


\section{TABLE OF CONTENTS}

\begin{tabular}{|c|c|}
\hline & PAGE \\
\hline DEDICATION... & $\ldots$...ii \\
\hline $\begin{array}{l}\text { ACKNOWLEDGEMENTS... } \\
\text { ABSTRACT } \ldots \ldots \ldots \ldots \ldots \ldots \ldots\end{array}$ & 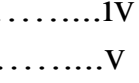 \\
\hline
\end{tabular}

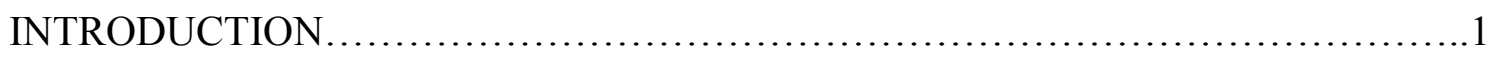

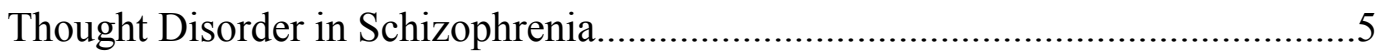

Five-Factor Theory of Personality ........................................ 12

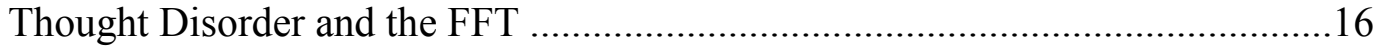

Support for the FFT in Schizophrenia....................................... 18

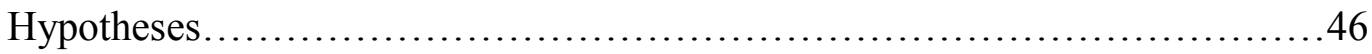

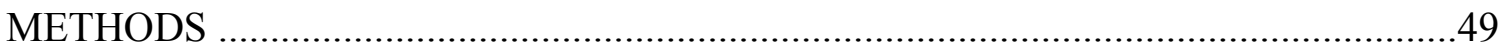

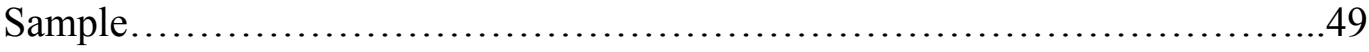

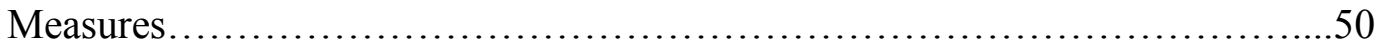

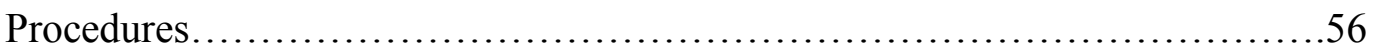

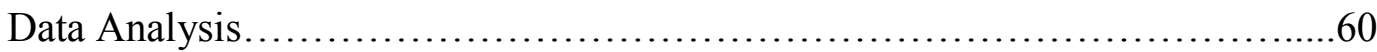

Participant Sample and Statistical Power......................................63

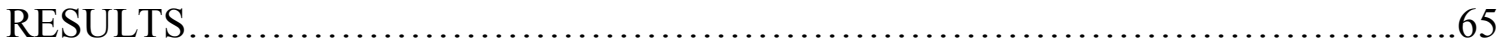

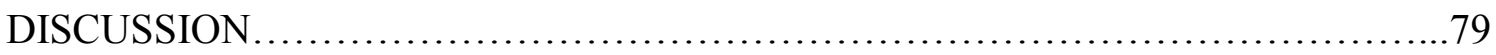

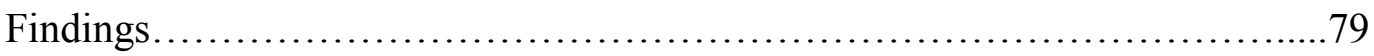

Limitations and Future Directions........................................... 86 
Summary and Implications......................................... 89

REFERENCES...........................................................93

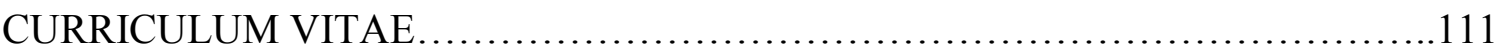




\section{LIST OF TABLES}

TABLE

PAGE

1. Sample and Descriptive Characteristics of Reviewed Studies of FFM and

Schizophrenia

2. Definitions and Examples of TDI categories

$.57-58$

3. Participant Sociodemographic Characteristics...................................66

4. Correlations for BFI and TDI and Sociodemographic Variables....................68

5. Sample Characteristics for BFI Factor Scores and TDI Total Score.....................69

6. Correlation analyses for BFI and TDI total.................................... 71

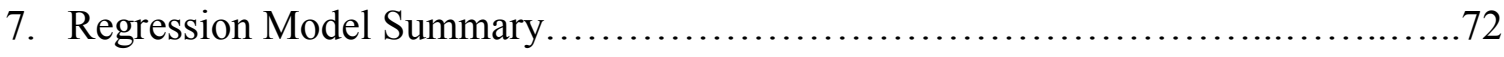

8. Hierarchical Cluster Analysis ANOVA Results...................................73

9. K-Means Cluster Analysis ANOVA Results.......................................74

10. Tukey's Post-Hoc Test for K-Means Cluster ANOVA............................75

11. Sociodemographic and Descriptive Sample Characteristics By Cluster...............76

12. Correlations for BFI Scores and TDI Categories and Severity Levels...............78 


\section{INTRODUCTION AND AIMS}

Although the term schizophrenia has only existed for just over a century, evidence suggests that the constellation of features which define this diagnosis have been present across cultures through the history of humankind. The Book of Hearts from the Eber's Papyrus, believed to be written in $1500 \mathrm{BC}$ contains detailed descriptions of dementialike symptoms, breakdown in thought processes, and depression (Kyziridis, 2005). Throughout the written history of symptoms associated with schizophrenia, there has been a significant focus on the characteristics which differentiate the individuals experiencing these symptoms from others. Unfortunately, highlighting these areas of deviance and using them to define "groups" can inadvertently exaggerate the differences between groups while also occluding the differences that exist within the defined groups(Goffman, 1963). Within this context, the characteristics which differentiate individuals with schizophrenia from one another as well as the characteristics they share with other individuals are virtually ignored.

Contrary to beliefs inherently promoted by this approach, schizophrenia is a psychiatric diagnosis marked by striking behavioral heterogeneity (Seaton, Goldstein, \& Allen, 2001). Given the current diagnostic criteria provided in the DSM-5 (American Psychiatric Association, 2013), the presentation of individuals sharing a diagnosis of schizophrenia can differ greatly from one person to the next. In addition to highly variable clinical presentation there is considerable inconsistency in the premorbid 
functioning, course of illness, and treatment response within the disorder (Buchanan \& Carpenter, 1994). Individuals who share a diagnosis of schizophrenia may have little in common other than this diagnostic label.

While there has long been a focus on what makes individuals with schizophrenia different from non-psychiatric individuals or those with other Axis I disorders, the attempts to define and clarify what makes those with schizophrenia different from one another in clinically relevant ways has been largely unsuccessful (Seaton et al., 2001). Within the schizophrenia literature, a significant goal has been to find ways to decrease this heterogeneity with the assumption that the discovery of meaningful differentiating factors related to these areas of variability will assist in the identification and development of more focused intervention strategies. Numerous attempts have been made over time to identify variables that reliably differentiate individuals with schizophrenia and account for the considerable heterogeneity. These attempts have included a focus on pathophysiology (Buchanan \& Carpenter, 1994), neurocognitive factors (Green, 1996), expressed symptomatology, genetics, and development and trajectory of illness, among others (see Goldstein \& Tsuang, 1988 for full review). In spite of this array of strategies, no system is generally accepted in the field at this time.

The past decade has seen a substantial transformation in the mental health field, characterized by a shift in the standard approach to treatment and assessment of outcomes. The medical model, which emphasizes reduction of symptoms and generally views a specific mental illness as the primary treatment target is being replaced by recovery-oriented approaches. A fundamental aspect of the Recovery Model is placing the person, not a diagnosis, at the center of treatment and recognizing that each individual 
has needs, differences, values, and an identity that extends beyond their mental illness (U.S. Department of Health and Human Services, 2009).Within this framework, addressing factors which impact quality of life and functioning are prioritized over symptom reduction. This changing zeitgeist demands a shift in the focus of research towards factors which highlight individuality and those which may be relevant to social and occupational functioning and other domains which may be relevant to meaningful personal roles (Bartholomeu z\& Allot, 2012).

The first account explicitly characterizing schizophrenia as a specific mental illness was written by Emil Kraepelin in 1896 (Kraepelin, 1919). In his early descriptions of dementia praecox, Kraepelin identified anomalies in linguistic expression and illogical ordering of thoughts as prominent features of the disorder. Eugen Bleuler $(1911 / 1950)$ identified "loosening of associations "or the peculiar pattern and structure of thought as the core defining feature of the disorder. He believed that this splitting of associations was so integral to the disorder, he chose to name the syndrome schizophrenia, Latin for "to split", to emphasize what he believed to be the cardinal feature of the syndrome (Andreasen \& Carpenter, 1993). These early descriptions of divergent expressions in speech, peculiar alterations of language, incongruous associations, and other related phenomena are now collectively referred to as thought disorder. Though long considered an essential symptom of schizophrenia, it is a remarkably heterogeneous phenomenon and is not found in all individuals with schizophrenia. Thought disorder can present as a wide variety of thought processes and varies widely in severity and course. It also occurs across the psychiatric spectrum, 
appearing in individuals who meet criteria for a variety of psychiatric diagnoses as well as "healthy" controls (Andreasen, 1979a).

Research has supported relationships between thought disorder and multiple functional domains, potentially implicating thought disorder in the heterogeneous functional outcomes observed in the schizophrenia population (Marengo\& Harrow, 1997). In spite of this evidence, the majority of thought disorder research has focused on the identification of diagnostically relevant features of disordered thinking by exploring differences in thought disorder between diagnostic groups. This approach inherently fails to recognize the within-group heterogeneity and neglects to examine specific factors which could help to explain the associations between thought disorder and outcome. An increased understanding of this relationship could inform treatment planning by illuminating potential targets of intervention to promote optimal functional outcome.

In the current study, we examine the potential role of personality as factor which may be related to the heterogeneity of thought disorder, in the schizophrenia population. The recognition that personality traits are associated with specific affective processes, patterns of behavior, and styles of thinking (Costa \& McCrae, 2000) has contributed to an increased attention towards the study of personality within the schizophrenia population. A review by Dinzeo and Docherty (2007) suggests that specific personality traits are related to etiology, symptom severity, occupational functioning, and various clinical phenomena in individuals with schizophrenia. These areas are all marked by substantial heterogeneity within the schizophrenia population, suggesting differences in underlying personality traits may be related to the observed differences across multiple domains within the schizophrenia population. To date, the potential relationship between 
personality traits and thought disorder has not been examined. The aim of the current study is to begin exploration of the possible relationships between personality and thought disorder heterogeneity. This research is within the context of examining the Five-Factor theory of personality as a valuable framework from which to begin addressing other questions relevant to the heterogeneity problem. Lastly, the current research aims to emphasize person-centered approaches to the study of schizophrenia and other psychiatric diagnoses to facilitate the incorporation of research findings into recovery-based approaches to treatment.

\section{Thought Disorder in Schizophrenia}

Historically considered by many to be an essential and defining feature of schizophrenia, (Levy et al., 2010) thought disorder is believed to reflect atypical organization in the structure or form of thought and is manifested by peculiar and sometimes incoherent patterns of speech. The speech anomalies can be challenging for others to comprehend, thus interfering with communication (Assaf et al., 2006). Recent reviews of the thought disorder literature have drawn attention to the problems which arise from a lack of general agreement in functional definition and conceptual models of thought disorder (see Levy et al., 2010, and Waford, 2013). Multiple attempts to operationalize thought disorder have done little to clarify the ambiguity surrounding the construct.

In spite of inconsistent functional definitions and discrepancies in the measure of thought disorder, some consistent findings relevant to the phenomenon have emerged. It is generally accepted that thought disorder is a multifaceted construct which spans a continuum of severity and is characterized by a number of many potential features (Levy 
et al., 2010; Waford, 2013). Once believed to be a phenomenon restricted to those with a diagnosis of schizophrenia, thought disorder is now recognized as occurring across the psychiatric spectrum, in the context of multiple other psychiatric diagnoses as well as non-psychiatric controls (Andreasen, 1979a; Andreasen, 1979b; Andreasen \& Grove, 1986; Harrow \& Marengo, 1986; Harrow, Marengo, \& McDonald, 1986; Harvey, Docherty, Serper, \& Rasmussen, 1990; Marengo \& Harrow, 1997). Evidence also suggests that while the presence of thought disorder is not diagnostically specific, there may be certain features of thought disorder with diagnostic utility based on their frequent occurrences in different psychiatric syndromes (Andreasen \& Grove, 1986; Harrow \& Marengo, 1986; Holzman, Shenton, \& Solovay, 1986; Marengo \& Harrow, 1985; Solovay, Shenton, \& Holzman, 1987).That these features tend to cluster in families of individuals with particular psychiatric diagnoses and manifest regardless of psychiatric illness or treatment suggests these characteristics have a strong genetic basis and may serve as an endophenotype identifying risk of particular syndromes (Levy et al., 2010). Both within and across disorders, thought disorder is heterogeneous in terms of course, severity, and characteristic features. Thought disorder may manifest in transient forms which are commonly found in the acute phases of psychosis. This type of thought disorder differs in severity over time and is responsive to antipsychotic medications (Hurt, Holzman, \& Davis, 1983; Spohn et al., 1986). It has been suggested that this may represent a "state-like" form of thought disorder. Individuals who exhibit this type of thought disorder have a varied clinical course (Harrow \& Marengo, 1986; Marengo \&Harrow, 1987). Evidence also suggests many individuals demonstrate thought disorder which persists beyond the acute phase of illness that does not respond to treatment and 
generally follows a chronic course (Andreasen \& Grove, 1986; Harvey, Docherty, Serper, \& Rasmussen, 1990; Marengo \& Harrow, 1997). This has been conceptualized as a more "trait-like" form of thought disorder.

Relationships have also been supported between thought disorder and outcomes in multiple functional domains, with the more persistent and severe forms of disordered thinking demonstrating particularly salient relationships with outcome. Specifically, high levels of thought disorder persisting beyond the acute stages of illness have consistently been associated with a particularly negative clinical course and poorer functional prognosis (Andreasen \& Grove, 1986; Bowie \& Harvey, 2008; Harrow \& Marengo, 1986; Harrow, Silverstein, \& Marengo, 1983; Harvey et al., 1990; Marengo \& Harrow, 1987; Marengo, Harrow, M., Lanin-Kettering, \&Wilson, 1986). Longitudinal studies have reported significant relationships between higher levels of thought disorder at baseline and higher rates of rehospitalization (Harrow, Marengo, \& McDonald, 1986; Harrow \& Marengo, 1986) and duration of illness (Maeda et al., 2007). Research has also suggested a strong positive relationship between thought disorder and delusional severity, across diagnostic lines (Harrow, Silverstein, and Marengo 1983; Harrow, Marengo, \& McDonald 1986; Marengo \& Harrow, 1997). However, thought disorder, particularly the more chronic trait-like forms are independent of psychosis (Marengo \& Harrow, 1985; Marengo \& Harrow, 1997). Finally, negative relationships have been reported between thought disorder and longitudinal occupational functioning (Harrow \& Marengo, 1986; Harrow, Silverstein, \&Marengo, 1983; Maeda et al., 2007, Marengo \&Harrow, 1997; Racenstein, Penn, Harrow, \& Schleser, 1999) as well as social areas of functioning (Bowie \& Harvey, 2008; Harrow \& Marengo, 1986; Racenstein et al., 1999). 
In spite of a lengthy history and expansive body of research (see Levy et al., 2010 and Waford, 2013 for a thorough review of the thought disorder literature), several findings in the thought disorder literature have remained at the forefront of the field and appear to guide ongoing research. Specifically, the findings that individuals with psychotic disorders tend to have higher levels of thought disorder than non-psychotic individuals (Andreasen, 1979b; Holzman et al., 1986), a chronic and unremitting course of thought disorder is more commonly found in schizophrenia than other psychiatric disorders (Harrow \& Marengo, 1986; Marengo \& Harrow, 1987; Marengo \& Harrow, 1997), and that specific features of thought disorder appear to be diagnostically meaningful (Andreasen\& Grove, 1986; Harrow \& Marengo, 1986; Holzman et al., 1986; Levy et al., 2010) have emerged as prominent findings.

While we recognize the practical necessity in streamlining nuanced results, these summaries inaccurately represent the heterogeneity of thought disorder both within and across diagnostic lines. Overlooked by these general summaries are robust findings which illuminate valuable areas in need of additional research. For example, the relationships between thought disorder severity and poor general prognosis were found across diagnostic lines (Harrow \& Marengo, 1986; Harrow, Silverstein, \&Marengo, 1983; Marengo \& Harrow, 1987; Racenstein et al., 1999). The other functional relationships, including poorer work functioning and increased psychopathology, were also found regardless of diagnosis (Harrow \& Marengo, 1986; Harrow, Silverstein, \&Marengo, 1983; Maeda et al., 2007, Marengo \& Harrow, 1997; Racenstein et al., 1999). Also, though more common in schizophrenia, the persistent forms of thought disorder are found in other diagnoses and demonstrate the same temporal stability across diagnostic 
lines (Harvey et al., 1990). This suggests that the mechanisms which determine or sustain chronic thought disorder may be independent of diagnosis.

Although it has been suggested that thought disorder may be related to the heterogeneous functional outcomes observed in the schizophrenia population (Marengo \& Harrow, 1997), the field at large has continued to examine thought disorder through a lens which emphasizes between group differences and factors which differentiate the schizophrenia population from other groups. The emphasis on between group differences and prevalence in schizophrenia shifts the focus away from the remarkable within group differences demonstrated in the literature. For example, the positive/negative dichotomy suggested by Andreasen (1976b) emphasized the finding that negative thought disorder occurs at a higher rate in individuals with schizophrenia than bipolar disorder and that positive thought disorder is commonly found in individuals with bipolar disorder suggesting diagnostic utility. This overshadows the fact that positive thought disorder occurs in both bipolar disorder and schizophrenia at equal or even higher rates than negative thought disorder (Andreasen \& Grove, 1986; Harvey et al., 1990; Harvey, EarleBoyer \& Wielgus, 1984).

A thorough examination of the results reported in several Chicago Follow-up Study reports also reveals notable heterogeneity in the course and severity of thought disorder within the schizophrenia population. For example, Marengo and Harrow (1997) examined the longitudinal course of thought disorder in a schizophrenia sample and found that in a sample of 45 inpatient participants with schizophrenia, $71 \%$ demonstrated thought disorder. They were re-evaluated post discharge at 2 years, 4.5 years, and 7 years. An infrequent episodic course (TD present at one follow up) of thought disorder 
was demonstrated in $18 \%$ of the sample, while $40 \%$ displayed a frequent episodic course (TD present at two follow ups). There was no thought disorder present at any follow-up in $18 \%$ of the sample and a persistent unremitting course was found in $24 \%$ of the sample (Marengo \& Harrow, 1997). This information is lost in a summary which concludes that thought disorder in schizophrenia follows a generally unremitting and chronic course. While this course may be more common in schizophrenia than other disorders, this course of thought disorder was not even the most common within the schizophrenia samples examined in the reported studies.

Neglected in general discussions of thought disorder is the recognition that many individuals with a diagnosis of schizophrenia, though in the minority, do not demonstrate any level of identifiable thought disorder (Harrow \& Marengo, 1986; Marengo \& Harrow, 1985). Among the individuals who do display thinking disturbances, the severity, quality, and course of thought disorder varies substantially. While the theoretical and measurement differences pervading the study of thought disorder could be argued to contribute to this heterogeneous presentation, heterogeneity is consistently observed within and across studies utilizing the same measures. Although specific features, courses, or severity levels may occur at higher rates in particular syndromes, there is no currently identified feature of thought disorder which occurs solely in the context of one disorder, nor is there a specific characteristic displayed by every individual with a shared diagnosis. The various relationships between functional outcomes and thought disorder course and severity which occur across diagnostic lines highlights the need to explore factors which may influence thought disorder. 
If, as Marengo and Harrow (1997) suggest, thought disorder may account for some of the functional heterogeneity within the schizophrenia population, highlighting the group level differences based on diagnostic categories does little to clarify this issue. The relationship between thought disorder and outcomes demands explicit attention on variables which may be related to the expression of thought disorder. Such research could provide valuable information clarifying these relationships and potentially be used to more effectively tailor interventions aimed at optimizing functioning.

In the Recovery Model, psychiatric diagnosis is recognized as one of many aspects relevant to functioning. Within this framework, an increased understanding of differences within diagnostic groups could be of particular benefit. The literature summarized in this brief review indicates that thought disorder is a heterogeneous phenomenon both within and across diagnostic lines. This suggests that factors independent of psychiatric status may be implicated in the expression of thought disorder. Additionally, research suggests that the stable forms of thought disorder may have a strong heritability (Levy et al., 2010). Based on these findings, we suggest that a variable which exists independent of psychiatric status, sustains a generally stable course, and is genetically based may be of particular utility in examining these relationships. We suggest that personality, which has largely been ignored in the study of schizophrenia, may be one factor which is related to the heterogeneous presentation of thought disorder. Furthermore, we propose that personality may also be an appropriate framework to more broadly account for heterogeneity within the schizophrenia population. 


\section{The Five-Factor Theory of Personality (FFT)}

Recent research has suggested that "normal" personality traits within the schizophrenia population are related to clinical presentation, course of illness, and functioning. As of this time, the potential association between personality and thought disorder has not been examined. As the general personality literature is far more advanced than the personality literature specific to schizophrenia, models within the general literature can serve as a foundation for understanding potential relationships to be explored within schizophrenia. The literature which directly examines personality in the schizophrenia population is still in the early stages but will be reviewed to provide additional context and support for the proposed relationship.

The field of personality is remarkably expansive, consisting of numerous theories, models, and conceptual frameworks that attempt to define and explicate the dynamic processes and interactions that we describe as personality. The construct of personality itself is highly complex and can be conceptualized and defined in numerous ways across theories. A comprehensive review of the entire personality literature is clearly not within the scope of this paper, thus we have chosen to examine personality as defined by the Five-Factor Theory of personality (FFT; McCrae \& Costa, 1996; McCrae \& Costa, 1999; McCrae \& Costa, 2008). The Five-Factor Theory (FFT) attempts to describe an entire system of personality and provide an account of the essential psychological features and mechanisms of human nature. A figure depicting the theoretical model is presented in Figure 1(McCrae \& Costa, 1996). The Five Factor Model of personality (FFM; McCrae \& Costa, 1996; McCrae \& Costa, 2008; McCrae \& John, 1992) is a component of the FFT with a substantial evidence base and served as the foundation for the FFT. The FFM 
posits that five broad personality traits: neuroticism $(\mathrm{N})$, extraversion $(\mathrm{E})$, openness $(\mathrm{O})$, agreeableness (A), and conscientiousness (C), represent the basic dimensions of personality which are biologically based and occur across cultures. According to the FFM, personality traits are defined as measurable, relatively stable, and consistent patterns of behaviors, emotions, and thoughts and explain dispositional individual differences. This position has been supported by extensive research that not only validates the existence of these traits, but also suggests that the constructs discussed in alternative models of personality can actually be subsumed under the FFM (McCrae \& John, 1992). The FFM was chosen as the conceptual personality framework for this paper based on the extensive research supporting this model. The traits in the FFM were originally derived from non-clinical samples, but empirical research has supported its utility in psychiatric samples as well (Bagby et al., 1999). Additionally, several researchers have started examining the five factors within the schizophrenia population and their relation to outcome and various clinical phenomena, as will be reviewed in detail. Lastly, the traits discussed in the FFM reflect the basic dimensions of personality, suggesting that everyone falls somewhere within these dimensions. In other words, the study of personality traits reflects the exploration of individual differences that exist on a continuum in individuals whether or not they demonstrate personality or general psychopathology. 
Figure 1.Conceptual representation of the Five Factor Theory. From McCrae \& Costa (1996)

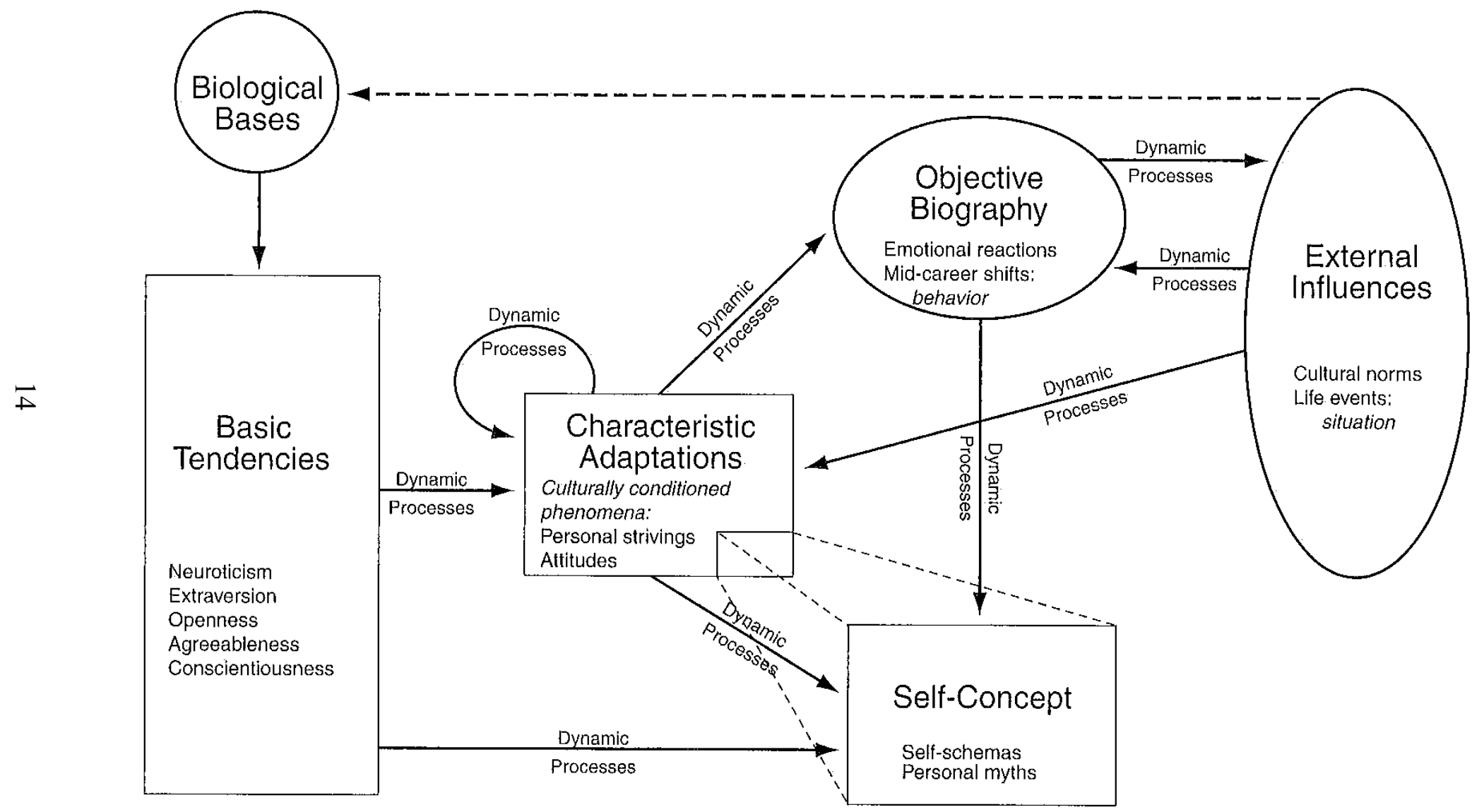


In the FFT, personality traits are conceptualized as basic tendencies. Basic tendencies represent the endogenous abstract core of the personality which cannot be directly observed. The theory also posits that these biologically based traits cannot be affected by the environment, with the exception of environmental changes which directly impact biology (McCrae \& Costa, 2008). The observable components of the personality system, believed to reflect the enduring core traits, are called characteristic adaptations. Although strongly influenced by basic tendencies, characteristic adaptations are also influenced by the environment. They represent the interplay of stable core traits with the demands of an individual's cultural and social environment over time.

They are expressed as a variety of both intrapersonal and interpersonal characteristics such as general attitudes, skills, desires, and habits (McCrae \& Costa, 1996; McCrae \& Costa, 1999; McCrae \& Costa, 2008).The relationship between characteristic adaptations and basic tendencies can be compared to the concept of phenotype and genotype. Although two organisms may share an identical genotype, the observable expression, or phenotype, can differ. Similarly, two individuals may have the same "level" of neuroticism (basic tendency) and it may be manifested as rumination (characteristic adaptation) in one individual and avoidance (characteristic adaptation) in another individual. It is well supported that the variations in trait levels have distinct associations with certain behaviors, styles of thinking, and emotional tendencies(Costa \& McCrae, 2000). As each of these domains is relevant to the study of psychopathology, personality traits have been suggested as a potential means for examining differences in symptomatology of psychiatric syndromes. Psychiatric symptoms themselves have been characterized as characteristic adaptations within this model (McCrae \& Costa, 2008). 


\section{Thought Disorder and the FFT}

In spite of extensive research, thought disorder remains a poorly understood construct with ongoing debate regarding its functional definition and precise nature (Barrera, McKenna,\& Berrios, 2005). The model of thought disorder which we adopt in the current study was proposed by Holzman and colleagues (1986) and conceptualizes thought disorder as aberrance in the pattern or form of thinking which can be assessed through speech. The FFT posits that the development of our patterns of thinking, feeling, and behaving (characteristic adaptations) are influenced by underlying trait facets (McCrae \& Costa, 1999). Research has supported the idea that personality is related to the characteristic way in which individuals perceive, process, and understand their environment. We suggest that the conceptualization of thought disorder as a reflection of abnormalities in the form of thought, or the manner in which thoughts are linked together (Holzman, Levy, \& Johnston, 2005; Levy et al., 2010; Solovay et al., 1986) is congruent with the FFT and its conceptualization of a characteristic adaptation. According to the FFT, it is then feasible that heterogeneity in severity, course, and characteristics of thought disorder may be accounted for, in part, by differences in underlying levels of the core personality traits defined by the FFM.

Also consistent with the FFT is the substantial evidence supporting genetic underpinnings and substantial heritability rates for both thought disorder (Levy et al., 2010) and personality (McCrae \& Costa, 1996; McCrae \& Costa, 2008). Levy and colleagues (2010) found the heritability of thought disorder to be $39.85 \%$ in clinically non-affected siblings of individuals with schizophrenia. The heritability of schizophrenia itself in siblings is approximately $8.9 \%$ (Slater, 1968), suggesting that the heritability of 
thought disorder is much higher than the heritability rate of schizophrenia. Research has also found that particular qualities of thought disorder aggregate in clinically unaffected relatives of individuals with a diagnosis of schizophrenia. Studies using the TDI have also found qualitative similarities in responses between individuals with mania and their clinically unaffected relatives. The qualitative profiles of each group were distinctly different, suggesting a genetic component of thought disorder which occurs independent of disease or treatment (Levy et al., 2010; Shenton, Solovay, Holzman, Coleman, \& Gale, 1989). From this evidence, it may be that the different manifestations of thought disorder are related to differences in other factors which aggregate in families and have a supported genetic component. Research has also found consistent heritability evidence for each of the five factor personality traits. Twin studies have found that the heritability of each trait is nearly equitable, ranging from approximately 40-55\% (Loehlin, McCrae, Costa, \& John, 1998). This evidence is compatible with the genetic evidence of thought disorder, suggesting that the FFT may serve as a useful model in the understanding of thought disorder.

Finally, this model is also accordant with the observed differences in thought disorder which occur across the psychiatric spectrum. As personality is something which is present in everyone, independent of psychiatric status, the model could potentially be applied to any population to examine the thought disorder spectrum. A simple representation of the proposed model is presented in Figure 2. 
Figure 2. Proposed model linking personality and thought disorder. Adapted from McCrae \& Costa (1996).

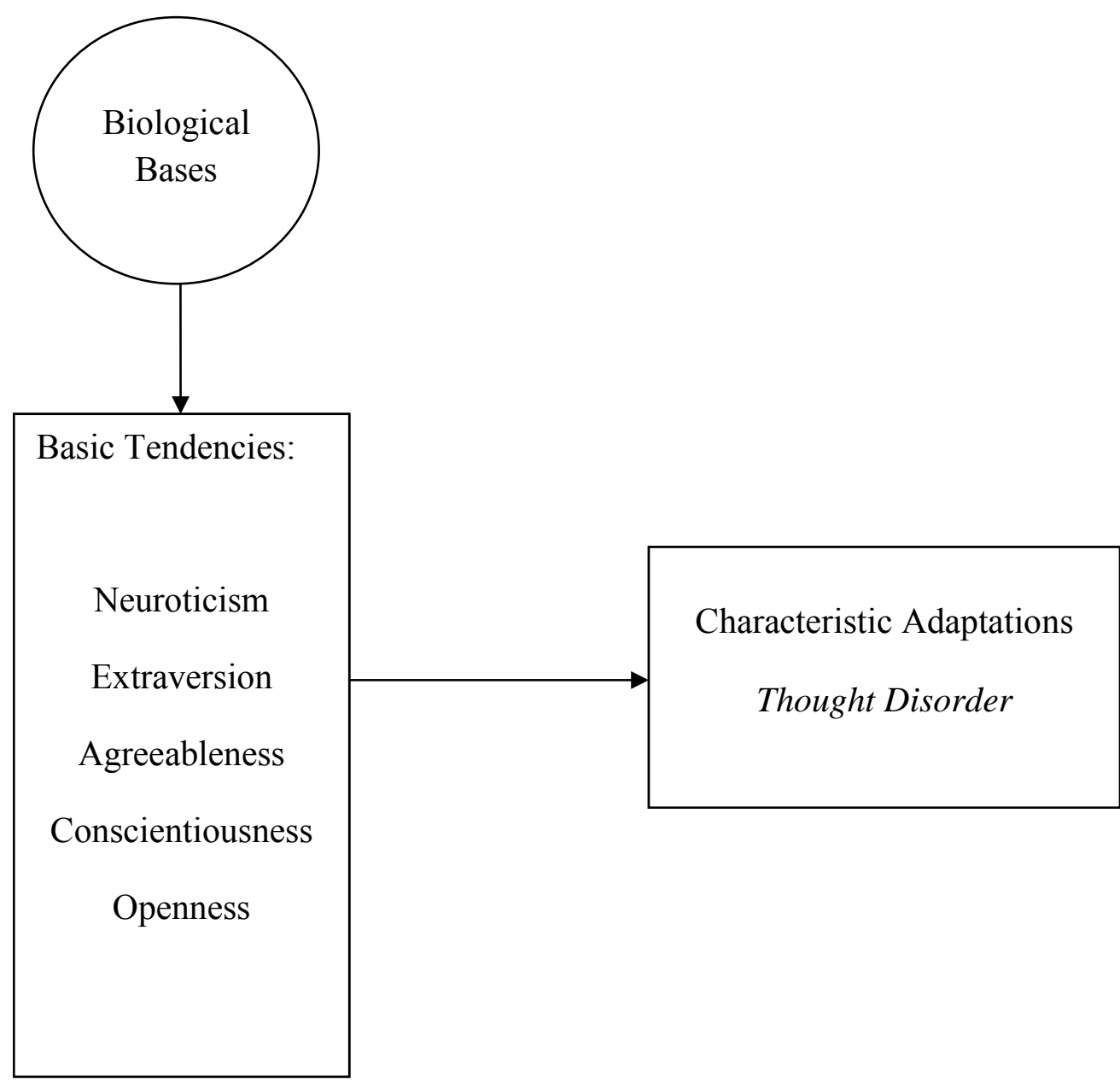

\section{Support for FFT in Schizophrenia}

In order to support the efficacy for utilizing the FFT in forming hypotheses, it is first crucial that we review support for the appropriateness of using the FFT within the schizophrenia population. First, we will briefly discuss the history of personality research within the schizophrenia population. Next, the research examining personality characteristics in schizophrenia at the group level will be presented. Finally, studies 
which have examined five factor traits and their relation to various factors within schizophrenia will be reviewed.

History of personality in schizophrenia. The understanding that personality factors are intimately linked to the presentation and course of schizophrenia has been recognized since early characterization of the disorder. Historically, the conventional belief concerning this relationship was that along with the development of psychosis came the destruction of the personality (Bleuler, 1911/1915; Kraepelin, 1919). In essence, psychosis itself represented a personality that was either disorganized beyond recognition or completely shattered. As the absence of an identifiable personality was considered a core feature in the early conceptualization of schizophrenia, to study personality in this population subsequent to the emergence of psychosis would have been to examine a null construct. Although there is evidence to suggest that the development of schizophrenia and other psychotic processes may have an impact on personality (DiLalla \& Gottesman, 1995) empirical research as well as clinical observation, suggests that persons with schizophrenia regularly exhibit stable individual differences, traits, and patterns of behavior, emotion, and thought that might be defined as personality (Horan et al., 2005; Smith et al., 1995). In addition there are no extant data to support the historical view that psychotic processes cause the personality to cease existence, nor is it clear what this would mean.

In spite of the early dismissal of the study of personality in schizophrenia, the topic has not been completely ignored. Until recently, the research related to personality in the schizophrenia literature emphasized comorbid personality disorders or pathological traits characteristic of these disorders, as opposed to the continuum of personality 
characteristics found independent of Axis II psychopathology (Berenbaum \& Fujita, 1994). One particularly salient example is the extensive research on schizotypy. Schizotypy broadly refers to schizophrenia spectrum personality characteristics, such as the traits observed in schizotypal personality disorder. Conceptualized as a latent personality framework resulting from social learning and genetics, (Meehl, 1962) schizotypy has been proposed as the "common core" to schizophrenia. Although referred to as a shared personality framework, it is important to note that schizotypy is also marked by significant heterogeneity (Lenzenweger, 2006). The study of schizotypal traits has long been a strategy for studying "personality" in schizophrenia (Asai et al., 2011). However, schizotypy represents only one dimension of personality and is focused on specific abnormalities (Meehl, 1962). In the current study, our focus is on the "normal" aspects of personality which are proposed to be present in the entire human population and vary only in degree. This is markedly different from the study of deviant aspects of personality present only in specific groups. As such, schizotypy will not be discussed in this review.

The role of "normal" personality traits in the manifestation, presentation, and course of the disorder has largely been overlooked in spite of empirical evidence supporting relationships between typical variations in personality and specific behavioral patterns and emotional tendencies (Costa \& McCrae, 2000) as well as the influence of personality features and treatment response in both non-psychiatric (Herbert \& Powell, 1989) and psychiatric (Beauchamp et al., 2011) populations. The recognition that personality is related to multiple factors relevant to treatment outcome and functioning has led to a recent increase in the examination of "normal" personality traits within the 
schizophrenia population. The literature suggests that underlying differences in personality traits may be related to the variations in symptom profile, course of illness, functional outcome, and treatment response within the population (Beauchamp et al., 2011; Dinzeo \& Docherty, 2007).

Schizophrenia and the FFM at the between group level. The most widely used method for assessing FFM traits are the NEO-Personality Inventories (NEO-PI, NEOFFI, NEO-PI-R, NEO-PI-S; Costa \& McCrae, 1992). The NEO inventories are selfreport measures designed to evaluate levels of trait dimensionality in each domain of the FFM. Participants are presented with items on a Likert scale (options range from strongly disagree to strongly agree) that describe general outlook and behaviors. Answers generate a profile representing scores along a spectrum in which individuals exhibit levels of a particular trait. The 5-factor structure of the NEO has been reliably replicated in psychiatric samples supporting its clinical utility (Bagby et al., 1999). Additionally, the NEO has demonstrated test-retest reliability and good internal consistency in samples of individuals with schizophrenia (Gurrera, Nestor, \& O'Donnell, 2000; Kentros et al., 1997).

Unless otherwise noted, all studies referred to in the following section evaluated personality traits using one of the NEO Personality Inventories (Costa \& McCrae, 1992). The only exception to this are a few of the studies discussed in the Neuroticism and Extraversion section. Neuroticism and Extraversion are the most recognized and widely researched five-factor traits and have appeared in multiple personality theories other than the FFM. Detailed information on the studies reviewed in the following section is presented in Table 1. 
Neuroticism. Broadly, the neuroticism (N) dimension within the FFM captures trait levels of emotional stability and adjustment, moodiness, irritability, impulse control, anxiety, and depression. Individuals who score high on $\mathrm{N}$ are generally more prone to global psychological distress and negative mood states in stressful situations (Costa \& McCrae, 1992). When compared to the other domains of the FFM, the findings on $\mathrm{N}$ in schizophrenia have been the most consistent. As a group, those with schizophrenia consistently exhibit statistically significant higher levels of $\mathrm{N}$ than non-psychiatric control groups (Berenbaum \& Fujita, 1994; Camisa et al., 2005; Gurrera et al., 2000; Gurrera, Nestor, O'Donnell, Rosenberg, \& McCarley, 2005; Herrán, Sierra-Biddle, Cuesta, Sandoya, \& Vazquez-Barquero, 2006; Kentros et al., 1997), or when compared to a normative sample (Bagby et al., 1997; Reno, 2004). Higher levels of $\mathrm{N}$ have also been found in relatives of individuals with schizophrenia who score high on measures of schizotypy (Bora \& Veznedaroglu, 2007). Based on the consistency of the findings that higher levels of $\mathrm{N}$ are found in schizophrenia on the group level and that higher levels of $\mathrm{N}$ are present in schizotypal individuals, there has been an interest in the role of $\mathrm{N}$ in the etiology of schizophrenia. 
Table 1

Sample and Descriptive Characteristics of Reviewed Studies of FFM and Schizophrenia

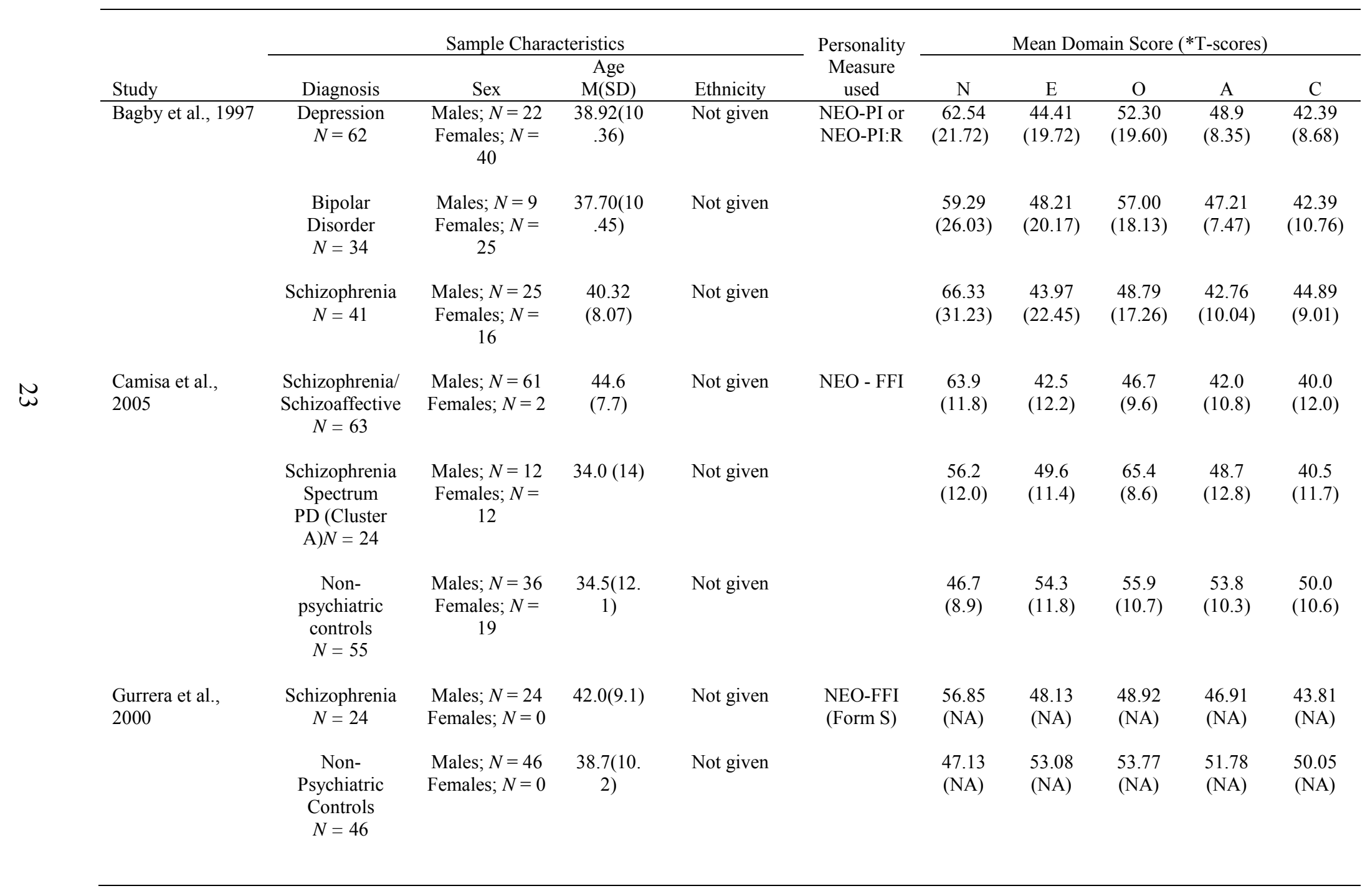




\begin{tabular}{|c|c|c|c|c|c|c|c|c|c|c|}
\hline $\begin{array}{l}\text { Gurrera et al., } \\
2005\end{array}$ & $\begin{array}{c}\text { Non- } \\
\text { Psychiatric } \\
\text { Controls } \\
\text { Non- } \\
\text { Psychiatric } \\
\text { Controls }\end{array}$ & $\begin{array}{c}\text { Males; } N=46 \\
\text { Females; } N=0 \\
\text { Total; } N=46 \\
\text { Males; } N=24 \\
\text { Females; } N= \\
19 \\
\text { Total; } N=43\end{array}$ & $\begin{array}{c}38.7(10 . \\
2) \\
34.8(\text { not } \\
\text { given) }\end{array}$ & $\begin{array}{l}\text { Not given } \\
\text { Not given }\end{array}$ & & & & & & \\
\hline \multirow[t]{2}{*}{$\begin{array}{l}\text { Herrán et al., } \\
2006\end{array}$} & $\begin{array}{l}\text { Schizophrenia } \\
\quad N=62\end{array}$ & $\begin{array}{c}\text { Males; } N=33 \\
\text { Females; } N= \\
29\end{array}$ & $\begin{array}{c}37.6(11 . \\
4)\end{array}$ & Not given & $\begin{array}{c}\text { EPQ } \\
\text { (measures } \\
\mathrm{N} \text { and } \mathrm{E} \text { ) }\end{array}$ & & & & & \\
\hline & $\begin{array}{c}\text { Non- } \\
\text { Psychiatric } \\
\text { Controls } \\
N=43\end{array}$ & $\begin{array}{c}\text { Males; } N=24 \\
\text { Females; } N= \\
19\end{array}$ & $\begin{array}{l}34.8 \text { (not } \\
\text { given) }\end{array}$ & Not given & & & & & & \\
\hline \multirow[t]{2}{*}{$\begin{array}{l}\text { Kentroset al., } \\
1997\end{array}$} & $\begin{array}{c}\text { Schizophrenia/ } \\
\text { Schizoaffective } \\
\quad N=21\end{array}$ & $\begin{array}{l}\text { Males; } N=15 \\
\text { Females; } N=6\end{array}$ & $\begin{array}{l}33.91(7 . \\
80)\end{array}$ & Not given & NEO-PI & $\begin{array}{c}69.19 \\
(10.63)\end{array}$ & $\begin{array}{c}47.00 \\
(12.71)\end{array}$ & $\begin{array}{l}48.43 \\
(9.34)\end{array}$ & $\begin{array}{c}42.00 \\
(11.49)\end{array}$ & $\begin{array}{c}34.67 \\
(12.45)\end{array}$ \\
\hline & & & & & & $\begin{array}{c}69.19 \\
(12.03)\end{array}$ & $\begin{array}{c}48.19 \\
(10.61)\end{array}$ & $\begin{array}{c}49.48 \\
(11.78)\end{array}$ & $\begin{array}{c}41.19 \\
(10.65)\end{array}$ & $\begin{array}{c}36.52 \\
(13.14)\end{array}$ \\
\hline $\begin{array}{l}\text { Lysaker et al., } \\
1998\end{array}$ & $\begin{array}{l}\text { Schizophrenia/ } \\
\text { Schizoaffective }\end{array}$ & $\begin{array}{c}\text { Males; } N=41 \\
\text { Females; } N=2 \\
\text { Total; } N=43\end{array}$ & $43.3(8.1)$ & $\begin{array}{c}\text { African- } \\
\text { American: } 15 \\
\text { Hispanic: } 3 \\
\text { White: } 25\end{array}$ & $\begin{array}{c}\text { EPQ } \\
\text { (measures } \\
\mathrm{N} \text { and } \mathrm{E} \text { ) }\end{array}$ & & & & & \\
\hline $\begin{array}{l}\text { Lysaker et al., } \\
1999\end{array}$ & $\begin{array}{l}\text { Schizophrenia/ } \\
\text { Schizoaffective }\end{array}$ & $\begin{array}{c}\text { Males; } N=113 \\
\text { Females; } N=0 \\
\text { Total; } N=113\end{array}$ & $43.0(8.4)$ & $\begin{array}{c}\text { African- } \\
\text { American: } 36 \\
\text { Hispanic: } 6 \\
\text { White: } 71\end{array}$ & $\begin{array}{c}\text { EPQ } \\
\text { (measures } \\
\mathrm{N} \text { and } \mathrm{E} \text { ) }\end{array}$ & & & & & \\
\hline $\begin{array}{l}\text { Lysaker\& Davis, } \\
2004\end{array}$ & $\begin{array}{l}\text { Schizophrenia/ } \\
\text { Schizoaffective }\end{array}$ & $\begin{array}{c}\text { Males; } N=65 \\
\text { Females; } N=0 \\
\text { Total; } N=65\end{array}$ & $47.5(9.0)$ & $\begin{array}{c}\text { African } \\
\text { American: } 28 \\
\text { Hispanic: } 1 \\
\text { White: } 36\end{array}$ & $\begin{array}{l}\text { NEO-FFI: } \\
\text { form S }\end{array}$ & & & & & \\
\hline $\begin{array}{l}\text { Lysaker\& Taylor, } \\
2007\end{array}$ & $\begin{array}{l}\text { Schizophrenia/ } \\
\text { Schizoaffective }\end{array}$ & $\begin{array}{c}\text { Males; } N=45 \\
\text { Females; } N=1 \\
\text { Total; } N=46\end{array}$ & $\begin{array}{c}45.89(5 \\
65)\end{array}$ & $\begin{array}{c}\text { African- } \\
\text { American: } 25 \\
\text { Hispanic: } 0\end{array}$ & $\begin{array}{l}\text { NEO-FFI: } \\
\text { form S }\end{array}$ & & & & & \\
\hline
\end{tabular}




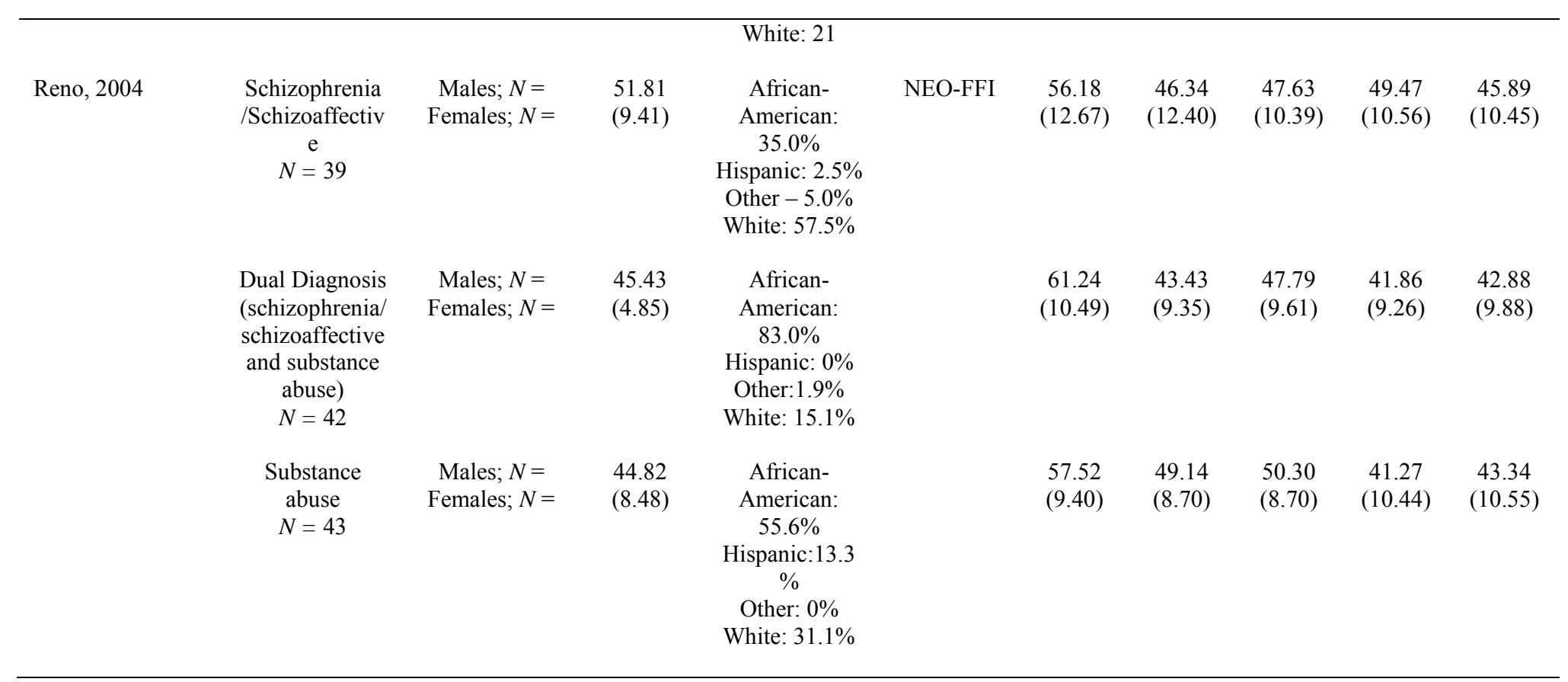


Within the general population, several studies have found higher premorbid levels of $\mathrm{N}$ in individuals who later develop schizophrenia or other psychotic symptoms suggesting $\mathrm{N}$ as a possible risk factor for psychosis (Goodwin, Fergusson, \& Horwood, 2003, Krabbendam et al., 2002; Lönnqvist et al., 2009; Van Os \& Jones, 2001). However, there are several areas of critique concerning the literature on which this hypothesis has been proposed. First, all of these studies have used differing assessment measures to determine levels of N. Although the term "neuroticism" may be consistently used, we cannot be sure that the various measures are tapping into the same construct. The instruments were developed from distinct personality theories which may conceptualize or define neuroticism in different ways. In addition, possible confounds also associated with $\mathrm{N}$ are not generally considered. In at least one study the association between levels of $\mathrm{N}$ and later development of schizophrenia was reduced when confounding variables such as childhood risk factors (i.e. childhood sexual abuse, maternal education, and interparental violence) and comorbid mental illness were controlled for statistically (Goodwin et al., 2003). Also, as discussed by Van os and Jones (2001), higher levels of $\mathrm{N}$ are consistently found in women. If $\mathrm{N}$ is a risk factor for psychosis, this would suggest that women are at a higher risk for the development of the disorder; however there is not a higher rate of schizophrenia in women than men. Lastly, there is at least one study that did not find associations between high premorbid levels of $\mathrm{N}$ and the subsequent development or level of psychosis, using prospective data (Angst \& Clayton, 1986).

Furthermore, there is substantial evidence to suggest that $\mathrm{N}$ may occur at higher levels not only in schizophrenia, but also in other types of psychopathology. Bagby and 
colleagues (1997) examined FFM traits in individuals with major depressive disorder, bipolar disorder, and schizophrenia. They found that each of the three groups scored significantly higher than the normative sample on $\mathrm{N}$, but no significant differences were present among the groups. Similarly, in groups of individuals diagnosed with schizophrenia, substance abuse, or with a dual diagnosis of schizophrenia and substance abuse, all deviated from the normative sample on $\mathrm{N}$, but levels did not differ among the diagnostic groups (Reno, 2004). Results from a meta-analysis that included over 15 different Axis I diagnoses including schizophrenia indicated that all disorders were marked by a characteristic profile that included high neuroticism scores (Malouff, Thorsteinsson, \& Schutte, 2005). Trull and Sher (1994) also reported that all Axis I disorders in their study (which did not include schizophrenia) were characterized by a profile that included high levels of $\mathrm{N}$, suggesting that $\mathrm{N}$ may simply reflect general psychopathology. There is convergent evidence in the research on premorbid personality as well. $\mathrm{N}$ has been studied as a general risk factor for psychopathology, such as depression (Van os \& Jones, 2001). High $\mathrm{N}$ was found to distinguish psychiatric patients from controls, but not differentiate among diagnoses in a study of premorbid personality conducted by Furukawa and colleagues (1998). Although the studies summarized above have suggested baseline levels of $\mathrm{N}$ are a risk factor for psychosis, the data are inconclusive and it is currently unclear whether or not increased levels of $\mathrm{N}$ represent a consequence of or a risk factor for schizophrenia and other types of psychopathology.

Extraversion. The trait of extraversion (E), sometimes referred to as surgency, measures level of sociability, emotional expressiveness, and general preference for interpersonal interactions. Those who score high on $\mathrm{E}$ often exhibit characteristics such 
as talkativeness, assertiveness, and excitability. Individuals who score lower on E tend to be more reserved and quiet (Costa \& McCrae, 1992).

Similar to $\mathrm{N}$, the findings on levels of $\mathrm{E}$ in schizophrenia have been fairly consistent. Individuals with schizophrenia tend to obtain lower scores on E than nonpsychiatric comparison groups (Berenbaum \& Fujita, 1994; Camisa et al., 2005; Gurrera, Nestor, \& O’Donnell, 2000; Gurrera et al., 2005; Hérran et al., 2006) and a normative sample (Bagby et al., 1997; Reno et al., 2004). Similar levels of E have been found in major depressive disorder (Bagby et al., 1997), substance use, and dual diagnosis groups (Reno, 2004). Individuals with schizophrenia have also scored lower on E than individuals with cluster A personality disorders (Camisa et al., 2005). Only one study to our knowledge found that individuals with schizophrenia did not differ from the normative sample on scores of E (Kentros et al., 1997).

Also similar to the trait of $\mathrm{N}$, there has been some interest in the role of $\mathrm{E}$ in proneness to psychosis. Those who exhibit low levels of $\mathrm{E}$ have a tendency to be more withdrawn. One study found that high levels of social withdrawal as measured by the Chapman Psychosis Proneness Scales (CPPS) were associated with psychotic proneness, consistent with recent literature that has found higher levels of social withdrawal in schizophrenia prodromes (Bolinskey \& Gottesman, 2010). Similarly, Angst \& Clayton (1986) found that within a sample of Swiss conscripts, those who later developed schizophrenia tended to score somewhat lower on E than other individuals although the difference was not significant. In other literature examining premorbid personality, Van os and Jones (2001) as well as Lönnqvist and colleagues (2009) found that lower levels of premorbid $\mathrm{E}$ were linked to a later diagnosis of schizophrenia. To propose that low 
levels of E indicate a risk factor for schizophrenia, suggests that anyone who exhibits traits associated with low $\mathrm{E}$ is at risk for this disorder. While it may be that low levels of E interact with more substantial risk factors to increase the likelihood of developing schizophrenia, based on the low prevalence of the disorder, it is unlikely that low levels of E independently represent a vulnerability to schizophrenia.

Openness. The findings related to schizophrenia and openness $(\mathrm{O})$ have been less consistent than those of $\mathrm{N}$ and $\mathrm{E}$. High scorers on $\mathrm{O}$ are characterized by a willingness to seek out and appreciate new experiences, novel ideas, and unconventional values. High scores are also linked to high levels of imagination, flexibility, and a more broad experience of emotions while low scores on $\mathrm{O}$ are associated with more conventional values and beliefs and behavioral and emotional rigidity. Several studies have found that those with schizophrenia as a group tend to score lower than control groups on $\mathrm{O}$, although the differences have not been statistically significant (Camisa et al., 2005; Gurrera, Nestor, \&O'Donnell, 2000; Gurrera et al., 2005). When compared to the normative sample, however, studies have shown no differences on $\mathrm{O}$ (Kentros et al., 1997; Reno, 2004). Bagby et al. (1997) examined scores on the individual facets of O to further examine what might be driving these differences. Of interest, the study found that individuals with schizophrenia obtained scores similar to a non-psychiatric comparison group and individuals with major depression on the feelings and values facets of the $\mathrm{O}$ domain. However, those with schizophrenia scored one standard deviation below nonpsychiatric, bipolar, and depressed individuals on the actions facet of openness. This suggests that as a group, individuals with schizophrenia tend to be less willing to go new places or try new activities. The authors suggest that this difference could be the result of 
negative symptoms; however, this may also reflect the development of a protective factor in response to the illness itself (Bagby et al., 1997). All of the individuals with schizophrenia in this study were in a residual phase of the illness. The preference for maintaining a stable environment and restricting change could conceivably reflect an effort to reduce the chances of relapse.

Camisa and colleagues (2005) suggested that higher levels of O may actually serve as a protective factor from the development of schizophrenia. In this study, individuals with schizophrenia, schizophrenia spectrum personality disorders, and nonpsychiatric controls were examined and those with schizophrenia exhibited lower levels of openness than both groups. The schizophrenia spectrum group, however, scored significantly higher than the comparison group on O. Similarly, high levels of O have been linked to positive schizotypy symptoms (Ross et al., 2002). We must not discount the fact that many of the traits encompassed within the $\mathrm{O}$ domain are traits commonly associated with schizotypy such as divergent thinking and creativity (Berenbaum \& Fujita, 1994). Although it is possible that O serves as a protective factor from the development of full-blown psychosis (Camisa et al., 2005), it may simply be that the traits measured in $\mathrm{O}$ are more common among individuals with Cluster A personality disorders. Alternatively, when considered along with the findings of Bagby and colleagues (1997), the emergence of psychosis may be the antecedent to a subsequent and potentially adaptive decrease in levels of openness.

Agreeableness. Agreeable individuals are characterized by a trusting nature, cooperativeness, kindness, and altruistic tendencies. Those who score low in this domain tend to be cynical, uncooperative, and possibly even manipulative (Costa \& McCrae, 
1992). Similar to O, the research on agreeableness (A) in individuals with schizophrenia is not as prominent or consistent as the research on $\mathrm{N}$ and $\mathrm{E}$. Some studies have found that individuals with schizophrenia score significantly lower on A when compared to control groups (Bagby et al., 1997; Camisa et al., 2005; Gurrera et al., 2005) as well as individuals with major depression and bipolar disorder (Bagby et al., 1997) and individuals with cluster A personality disorders (Camisa et al., 2005). Gurrera, Nestor, and O'Donnell (2000) found no differences in scores on agreeableness between individuals with schizophrenia and a comparison group. Similarly, when compared to normative samples, other studies have found no differences between this sample and the schizophrenia group (Kentros et al., 1997; Reno, 2004). Of interest, Reno (2004) found that individuals with schizophrenia scored significantly higher on A than either a dual diagnosis or substance abuse group.

Conscientiousness. Common features associated with high scores on this domain include good impulse control, goal-directedness, good organization and achievementoriented behaviors. Characteristics such as unreliability, laziness, and negligence are associated with low scores on this dimension (Costa \& McCrae, 1992). Regarding conscientiousness $(\mathrm{C})$, the general trend is that individuals with schizophrenia score lower than comparison groups (Camisa et al., 2005; Gurrera et al., 2000; Gurrera et al., 2005) as well as the normative sample (Bagby et al., 1997; Kentros et al., 1997; Reno, 2004). Bagby and colleagues (1997) found no group differences on C among individuals with schizophrenia, bipolar, and major depression. Camisa and colleagues (2005) found that individuals with schizophrenia scored lower on this domain than individuals diagnosed with a Cluster A personality disorder. Reno (2004) found that although 
individuals with schizophrenia did not deviate from the substance use and dual diagnosis group, on $\mathrm{C}$ scores, they deviated from the normative sample. Of particular interest however, older individuals with schizophrenia in this study obtained significantly higher scores on $\mathrm{C}$ than the younger individuals with the same diagnosis. This suggests a possible impact of age or experience on the $\mathrm{C}$ domain and warrants further investigation.

Summary and Critique. Research has consistently shown that as a group, individuals with schizophrenia tend to exhibit higher levels of $\mathrm{N}$ and lower levels of $\mathrm{E}$ when compared to non-psychiatric individuals in a comparison group or a normative sample. There is also some evidence to suggest that higher levels of $\mathrm{N}$ and lower levels of E may be present prior to the development of psychosis leading some to suggest that this may represent a risk factor for the disorder (Goodwin, Fergusson, \& Horwood, 2003; Krabbendam, et al., 2002; Lönnqvist et al., 2009; Van os \& Jones, 2001). The results regarding the $\mathrm{O}$ domain have shown a tendency for lower scores in studies that have used comparison groups, but these differences have not been as consistent when compared to a normative sample. There is also some evidence to suggest that the tendency towards somewhat lower scores on $\mathrm{O}$ may largely be the result of certain facets of the domain (Bagby et al., 1997). Extant research on the A domain in schizophrenia at the group level is mixed and currently inconclusive. Although some studies have shown lower scores in A for those with schizophrenia than non-psychiatric comparison groups as well as other diagnoses (Bagby et al., 1997; Camisa et al., 2005; Gurrera et al., 2005), this difference has not been found when compared to a normative sample (Kentros et al., 1997; Reno, 2004) and in one study was also not found when compared to a non-psychiatric group (Gurrera et al., 2000). In yet another study, those with schizophrenia obtained higher 
levels of A than individuals with a diagnosis of substance abuse, and those with a dual diagnosis of schizophrenia and substance abuse (Reno, 2004). Reno (2004) found an interesting age difference in $\mathrm{C}$ scores, highlighting a significant within group difference. Lastly, the data indicate that individuals with schizophrenia generally obtain lower scores in the $\mathrm{C}$ domain when compared to non-psychiatric individuals both in comparison groups (Camisa et al., 2005; Gurrera et al., 2000; Gurrera et al., 2005) and the normative sample (Bagby et al., 1997; Kentros et al., 1997; Reno, 2004), although they typically do not differ from other psychiatric groups (Bagby et al., 1997, Reno, 2004).

Although this summary provides us with some information regarding the role of FFM traits in those with schizophrenia as a whole, this research, like the previously reviewed thought disorder research, does not address the prevalent heterogeneity in personality within schizophrenia. This literature suggests that on average, individuals with schizophrenia tend to deviate from non-psychiatric individuals as a whole on trait dimensionality within the FFM. Within the psychiatric population, however, individuals with schizophrenia did not differ consistently from any other diagnostic group, indicating that personality traits do not differentiate among Axis I diagnoses (Donat, Geczy, Helmrich, \& Lemay, 1992).

Furukawa and colleagues (1998) examined premorbid personality in a group of psychiatric patients with a diagnosis of organic disorders, schizophrenic disorders (consisting of schizophrenia, schizotypal, and delusional disorders), mood disorders, or neurotic disorders using retrospective data collected from their families. This study was designed to see if any premorbid traits from the FFM distinguished the psychiatric patients from the normal controls and if any particular trait differentiated among the 
diagnostic groups. The psychiatric patients as a whole displayed higher levels of $\mathrm{N}$ and lower levels of $\mathrm{C}$ when a non-psychiatric group was used as comparison, but there was no trait which reliably distinguished the groups from one another, nor was there any correlation with premorbid $\mathrm{N}$ and schizophrenia. Although this study relies on retrospective data and examines premorbid personality, the results remain striking. Similar results were found in a meta-analysis conducted by Malouff, Thorsteinsson, and Schutte (2005), that examined current FFM profiles across multiple studies and disorders and found that all psychiatric disorders were characterized by high N, low C, low A, and low E. N had a particularly large effect size of $d=0.92$, a medium effect size of $d=-$ 0.66 was found for $\mathrm{C}$, and small effect sizes of $d=-0.41$ and $d=-0.38$ were found for $\mathrm{E}$ and A, respectively. There was no significant effect found for $\mathrm{O}$. As a similar pattern of FFM characteristics was observed in individuals with an Axis I disorder (or symptoms of a disorder), this again suggests that personality may not differentiate among diagnoses, but may indicate psychopathology in general.

Although no individuals with schizophrenia were included in the study, Trull and Sher (1994) found that all Axis 1 disorders in a non-clinical sample of 468 young adults were characterized by a personality profile of High $\mathrm{N}$ and $\mathrm{O}$, and lower E, A, and C. Also of particular interest, scores on FFM traits accounted for variance on several of the diagnoses beyond the variance accounted for by current symptom severity.

The findings that individuals with schizophrenia as a group tend to exhibit higher levels of $\mathrm{N}$ and lower levels of $\mathrm{E}$ represent the most robust finding in the literature on schizophrenia and the FFM. However, evidence suggests that this pattern is also found in other psychiatric diagnoses and personality traits do not consistently differentiate 
schizophrenia from other diagnostic categories. Not only does the examination of between group personality differences in schizophrenia inherently ignore the heterogeneity problem, the current literature provides a very limited understanding of how personality interacts with other facets of the disorder, even at the group level.

Although clinical observations clearly suggest that personality differences exist among individuals with schizophrenia (Smith et al., 1995), the first step in supporting the FFT as a framework for addressing the problem of heterogeneity is establishing the existence of distinct and stable personality differences in the population. Also, in order to be an efficacious method, these traits would need to reliably differentiate individuals on characteristics such as symptoms, level of functioning, or trajectory of the disorder. In the following section, the small body of literature examining personality traits within groups of individuals diagnosed with schizophrenia will be reviewed. A summary of these studies is also provided in Table 1. Relationships between personality traits and specific phenomena have also been explored and this will be discussed and reviewed within the context of the heterogeneity problem.

\section{Schizophrenia and the FFM at the within diagnosis level.}

Quality of Life. There is preliminary evidence to suggest a relationship between personality and reported subjective quality of life (QoL) in individuals with schizophrenia. Kentros, Terkelsen, Hull, Smith, and Goodman (1997) examined the possible associations between global QoL and each of the FFM domains and found that global ratings of QoL were negatively correlated with $\mathrm{N}(r=-0.63, p<0.001)$ while $\mathrm{E}$ ( $r=$ $0.45, p<0.05)$ and $\mathrm{A}(r=0.77, p<0.001)$ were positively correlated with QoL ratings. This suggests that individuals with low levels of $\mathrm{N}$ who also score higher on $\mathrm{E}$ and $\mathrm{A}$ 
tend to report that they are more satisfied with their life across several domains. This is the only study to our knowledge that has examined FFM traits and QoL, however, another study found that among individuals with schizophrenia, lower levels of harm avoidance and higher levels of self-directedness were associated with higher levels of QoL (Hansson et al., 2001). In this study, harm avoidance was negatively correlated with global subjective QoL $(r=-0.41, p<0.05)$ as well as interviewer rated global QoL $(r=$ $0.38, p<0.05)$ while self-directedness was positively correlated with both global subjective $(r=0.49, p<0.05)$ and interviewer rated global $(r=0.53, p<0.05)$ QoL scores. Additionally, multiple regression analyses revealed that after controlling for age, sex, and psychopathology, higher levels of self-directedness were associated with better QoL and explained $4.1 \%$ of the variance concerning both global subjective and interviewer rated global QoL (Hansson et al., 2001). Although this model did not use the FFM, harm avoidance has been correlated with $\mathrm{N}$ and self-directedness has been correlated with $\mathrm{C}$ (Hiroaki et al., 2008) which provides further support for the relationship between $\mathrm{N}$ and QoL.

Lastly, although the study did not examine relationships between traits and global QoL ratings, Lysaker and Davis (2004) reported the results of correlational analyses between FFM traits and some of the subscales on the Quality of Life Scale (QOLS; Heinrichs, Hanlon, \& Carpenter, 1984). N $(r=-0.40, p<0.01)$ and A $(r=0.51, p<$ 0.001) were both significantly correlated with the Interpersonal Relations subscale which measures the frequency of social contacts. The quality of interpersonal relationships is measured in the Intrapsychic Foundations subscale and scores on this subscale were also correlated with $\mathrm{N}(r=-0.37, p<0.01)$ and A $(r=0.50, p<0.001)$, as well as $\mathrm{O}(r=0.40$, 
$p<0.01)$. None of the traits were correlated with scores on the Common Objects and Activities Subscale which measures general community involvement (Lysaker\& Davis, 2004). Additionally, multiple regression analyses revealed that several of the FFM personality variables accounted for statistically significant proportions of variance in the QoL subscales. On the Interpersonal Relations subscale, A accounted for $22 \%$ of the variance and also accounted for $20 \%$ of the variance on the Intrapsychic Foundations subscale, as did $\mathrm{C}$ and $\mathrm{O}$ at $7 \%$ and $5 \%$, respectively. Taken together, these results suggest that personality variables, specifically N, may have a substantial impact on an individual's perceived life satisfaction and may also account for some of the differences found among individuals with schizophrenia on such measures. Furthermore, the results reported by Lysaker and Davis (2004) pertaining to the relationship between personality traits and QoL are clearly based on social constructs. This suggests that personality may also be implicated in social functioning in schizophrenia. This relationship is further explored in the following section.

Social Functioning. A common characteristic of schizophrenia is deficient social functioning which likely contributes to the popularity of psychosocial based treatment programs for the disorder. One could speculate that personality factors impact social functioning. Thus, the relationship between social functioning and personality symptoms in schizophrenia may be of particular importance in determining the most appropriate intervention strategy for an individual. One study found that $\mathrm{N}$ was negatively correlated with social functioning $(r=-.60, p<0.01)$ while $\mathrm{E}(r=0.48, p<0.05), \mathrm{O}(r=0.54$, $p<0.05)$, and A $(r=0.47, p<0.05)$ were positively correlated with social functioning (Kentros, et al., 1997). These results are somewhat consistent with the results of Lysaker 
and Davis (2004) presented in the previous section. They found that patients with a greater number of social ties generally had lower levels of $\mathrm{N}$ and higher levels of $\mathrm{A}$. In addition, those with greater capacities for intimacy had lower levels of $\mathrm{N}$, higher levels of O, A, and C. However, unlike Kentros and colleagues (1997) there was no significant relationship between levels of $\mathrm{E}$ and social functioning. This may be an artifact of differences in the instruments used to assess social functioning, but further research is necessary to clarify this inconsistency.

Symptoms. Systematic examination of the possible link between personality traits and various clinical symptoms in schizophrenia has also emerged. Lysaker and colleagues (1999) examined relationships among negative, positive, and emotional discomfort symptoms and levels of $\mathrm{E}$ and $\mathrm{N}$ as measured by the Eysenck Personality Questionnaire (EPQ; Eysenck \& Eysenck, 1975). The authors first divided participants into High $\mathrm{E}(N=36)$ and Low $\mathrm{E}(N=77)$ groups based on Extraversion scores on the EPQ. High E individuals were classified as those whose scored $\geq 50^{\text {th }}$ percentile according to EPQ norms, and Low E individuals were those who scored $<50^{\text {th }}$ percentile. The two groups were then compared on PANSS scores using a multivariate analysis of variance (MANOVA) which revealed significant group differences, $F(5,105)$ $=8.83, p<.0001 . T$-tests revealed that when compared to the Low E group, the High E group had significantly lower positive $(t=2.20, p<.05)$, negative $(t=2.15, p<.05)$, and emotional discomfort symptoms $(t=4.84, p<.0001)$ indicating lower levels of global symptomatology. For the next set of analyses, subjects were classified as either High N $(N=78)$ or Low $\mathrm{N}(N=35)$ using the same criteria as the High $\mathrm{E}$ and Low E groups with Neuroticism scores in place of Extraversion scores. PANSS scores were compared 
between the two groups using a multivariate analysis of covariance which revealed significant group differences, $F(5,105)=8.48, p<.01 . T$-tests comparing the High $\mathrm{N}$ and Low $\mathrm{N}$ groups revealed that the High $\mathrm{N}$ groups had significantly higher positive $(t=2.10$, $p<.05)$ and emotional discomfort $(t=3.93, p<.0001)$ scores. No differences were found regarding negative symptoms scores.

This suggested relationship was later examined by Lysaker and Taylor (2007) with the inclusion of A. In this study, N, E, and A, were assessed using the NEO-FFI (form $S$ ) and symptoms were again assessed using the PANSS. Using correlational analyses, they found a positive correlation between $\mathrm{N}$ and emotional discomfort symptoms $(r=0.53, p<.01)$ and a negative correlation between $\mathrm{E}$ and emotional discomfort symptoms $(r=-0.30, p<.05)$. $\mathrm{N}$ was not linked to positive symptoms as it was in the previous study, however results revealed a negative correlation between positive symptoms and scores on $\mathrm{A}(r=-.31, p<.05)$ (Lysaker \& Taylor, 2007).

Horan and colleagues (2005) also suggested a link between personality and clinical symptoms based on a study of personality characteristics in participants with recent onset schizophrenia. In this study, systematic relationships emerged between five personality characteristics derived from the MMPI-168 and clinical symptoms. Of important note, the same participants were assessed twice over the next 15 months and these relationships, as well as the personality scores, remained stable. As this study defined personality characteristics outside of the FFM that have not been correlated with FFM traits, we can assume no precise relationship. However, this study does support the stability of meaningful individual personality differences in individuals with schizophrenia. 
The state-trait interactions of positive and negative symptoms on the stability of NEO profiles over a 6 months period was also examined by Kentros and colleagues (1997). They found significant test-retest correlations for personality profiles, indicating significant stability in spite of unstable positive symptom profiles $\mathrm{N}(r=0.84, p<.001)$; $\mathrm{E}(r=0.90, p<.001) ; \mathrm{O}(r=0.84, p<.001) ; \mathrm{A}(r=0.43, p<.05) ; \mathrm{C}(r=0.86, p<.001)$. While positive symptoms were not related to stability scores on the NEO, the finding that negative symptoms also remained stable suggests a potential trait interaction between negative symptoms and NEO profile stability. While the evidence regarding precise relationships between personality traits and expressed symptoms is inconclusive, the findings reported in these studies indicate that some of the variation in symptom severity and presentation in schizophrenia can be accounted for by personality.

Other functional domains. Personality traits have also been implicated in general psychosocial functioning in individuals with schizophrenia. High levels of Neuroticism, for example, have been found to globally contribute to the long-term deficits found in patients with schizophrenia. Although negative symptoms were the strongest predictor of disability, neuroticism was also found to contribute substantially to disability ratings in the case of overall behavior $(\beta=0.211, \mathrm{p}<.001)$ and global judgment $(\beta=0.237$, $\mathrm{p}<.001)$. Negative symptoms and neuroticism combined explained $35.2 \%$ of the variance in overall behavior and $44 \%$ of variance in the case of global judgment (Herrán et al., 2006). Vocational abilities have also been linked to specific personality traits. One study found that higher levels of $\mathrm{E}\left(R^{2}=0.13, p<.01\right)$ and higher levels of $\mathrm{N}\left(R^{2}=0.09, p<\right.$ .05 ) as measured by the EPQ predicted poorer work performance based on several areas (Lysaker et al., 1998). 
In the general population, high levels of $\mathrm{E}$ are associated with increased social support seeking while $\mathrm{N}$ has been shown to predict a coping style marked by passive and avoidant strategies. The relationship between personality traits, coping style, and neurocognition was explored in a 2004 study by Lysaker and colleagues. The authors found that both neurocognitive factors and personality traits were related to coping styles in the participants. Of important note, the relationship found between coping style and personality in individuals with schizophrenia and schizoaffective disorder was remarkably similar to the pattern found in the healthy population. That is, passive and avoidant strategies were linked to high levels of $\mathrm{N}$ while individuals who scored high on E tended to more actively seek more social support. Additionally, as the participants in the study had diagnoses of either schizophrenia or schizoaffective disorders, possible between diagnostic group differences were explored. Consistent with previous research, no differences were found.

Summary and critique of personality traits within schizophrenia. From the studies reviewed above, there is evidence to suggest that personality traits may account for some within diagnosis heterogeneity across several domains. Higher levels of $\mathrm{N}$ are associated with lower QoL ratings (Hansson et al., 2001, Kentros et al., 1997), more deficient social functioning (Kentros et al., 1997; Lysaker\& Davis, 2004), and poorer work performance (Lysaker et al., 1998). It has also been linked to higher levels of disability (Herran et al., 2006) and passive and avoidant coping strategies (Lysaker et al., 1999). There is also some evidence to suggest that $\mathrm{N}$ may possibly be related to emotional discomfort symptoms (Lysaker et al., 1999; Lysaker\& Taylor, 2007). High levels of E have been associated with higher QoL ratings (Kentros, Terkelsen, et al., 
1997), lower negative symptoms (Kentros et al., 1997.; Lysaker et al., 1999), and lower emotional discomfort symptoms (Lysaker et al., 1999; Lysaker\& Taylor, 2007). In one study high extraversion was found to predict better social functioning (Kentros et al., 1997) as well as increased social support seeking (Lysaker et al., 2004), but also poorer work performance (Lysaker et al., 1998). Based on these findings, we can assert that higher levels of $\mathrm{N}$ appear to globally predict more negative functioning, while other than work performance, higher levels of E may predict better global functioning.

Although not as prominent in the research literature as neuroticism and extraversion, the domains of $\mathrm{O}, \mathrm{C}$, and $\mathrm{A}$ have also been implicated in certain outcomes. The combination of high levels of $\mathrm{O}, \mathrm{C}$, and $\mathrm{A}$ have been found in individuals who exhibit a greater capacity for intimacy (Lysaker \& Davis, 2004). Higher levels of C have been linked to higher QoL ratings (Hansson et al., 2001) as have higher levels of A when found alongside high scores on E (Kentros, Terkelsen et al., 1997). Openness has been positively correlated with better social functioning (Kentros et al., 1997), as has agreeableness (Kentros et al., 1997; Lysaker \& Davis, 2004). There is also some evidence to suggest links between $\mathrm{O}, \mathrm{A}$, and symptomatology. Kentros and colleagues (1997) found that both O and A were negatively correlated with negative symptoms, while Lysaker and Davis (2004) found that A was positively correlated with positive symptoms.

One of the most striking issues in the small body of literature examining fivefactor traits within individuals with schizophrenia is the limited composition of the research samples as summarized in Table 1. Given these characteristics, there is a clear inability to generalize the results. Females are markedly underrepresented in these 
studies, and in several cases, not represented at all. In addition to the generalizability problem, this lack of information about females prevents us from examining possible sex differences. This is of particular significance based on the large body of literature examining sex differences in schizophrenia (Goldstein \& Lewine, 2002) and the consistent sex differences found in the personality literature (Costa, Terracciano, \& McCrae, 2001; Feingold, 1994). That sex differences have been neither explored nor acknowledged may largely be a result of the lack of females in the study samples.

Only one study to our knowledge has addressed sex differences in personality traits in individuals with schizophrenia. The investigators found that males showed greater personality alterations than females on several of the personality domains assessed. The personality domains examined in this study are not FFM domains, which prevents us from making explicit hypotheses about which, if any, domains could differ between men and women. In addition, the study was conducted in Japan and the results could be an artifact of cultural factors (Hiroaki et al., 2008). However, these results in conjunction with the reliable sex differences found throughout the personality literature demand explicit consideration of sex differences when examining personality traits in schizophrenia.

In addition to the potential confound of sex, the samples in these studies are also comprised primarily of individuals in their forties. As discussed previously, Reno (2004) found a significant age difference in $\mathrm{C}$ scores within individuals with schizophrenia suggesting a moderating effect of age on this domain. In spite of the lack of further evidence suggesting this relationship, we cannot rule out the possibility that age and experience could impact levels of $\mathrm{C}$ as well as other FFM domains. Even if there is no 
effect on traits themselves, the relationships found among personality traits and other phenomena could vary with age. Although high levels of $\mathrm{N}$ may be linked to poorer social functioning in mostly middle-aged individuals with schizophrenia (Lysaker et al., 2004), this relationship may not exist in younger individuals. This could be the case with any of the variables linked to specific personality traits. Adjusting to life after the development of schizophrenia clearly requires adaptation in a variety of functional domains. High levels of a particular trait or pattern of traits may not impact functional domains or clinical phenomena in a twenty year old with schizophrenia in the same manner that it might impact a forty year old with the disorder.

Also in need of further attention are the possible roles of race, ethnicity, and cultural factors when examining personality within a sample of individuals with schizophrenia. As the prevalence rate of schizophrenia is similar across all ethnic groups throughout the world, these factors are of particular importance when studying this disorder. Research has shown that the five-factor structure of personality is universal and has been identified across cultures (McCrae \& Costa, 1997). However, the majority of the attention given to race and culture in the personality literature focuses on the similarities in general personality structure across cultures while ignoring the differences both within and between different groups. As demonstrated in Tables 1, a majority of the literature fails to even mention the race of the participants in the study. The studies that do report race as part of the demographic information do not explicitly examine the possible relationship between race and personality traits. Even if there are no racial differences in the level of certain personality traits, it is possible that race and a variety of 
other cultural factors could interact with specific traits to impact a variety of areas that are observed to be heterogeneous in the schizophrenia population.

Lastly, each of these studies recruited participants from outpatient day programs. In light of the hypotheses that could be made from the results of these studies regarding treatment and intervention, this highlights a serious problem with sample bias. We can postulate from previous research (Herbert \& Powell, 1989) that the individuals who are actively participating in outpatient treatment may represent a specific subsample of individuals with the diagnosis. For the purposes of generalizability, these relationships would also need to be examined in inpatient populations.

In spite of the notable limitations existing in the body of literature outlined previously, these studies provide support for the applicability of the FFT within the schizophrenia population. The finding that discrete personality differences have been found among individuals with schizophrenia (Horan et al., 2005) and that these differences have been implicated in a variety of functional outcomes and clinical phenomena begins to offer an explanation for how personality may account for some of the heterogeneity found in the disorder. Following from the evidence previously summarized, we suggest that personality may be related to the manifestation of thought disorder and underlying differences in personality features may be associated with the heterogeneous presentation of the phenomenon. Given the novelty of the research, the current study seeks to explore the most basic level of the proposed relationships. Hypotheses were developed from the available literature and represent a largely exploratory approach. We propose that personality traits will be related to the expression 
of thought disorder. Specifically, we hypothesize that personality traits will be related to thought disorder both quantitatively and qualitatively.

\section{Hypotheses}

Hypothesis 1. The Big Five personality traits as measured by the Big Five Inventory (BFI) will predict severity of thought disorder as measured by total TDI score on the Thought Disorder Index. Although it is hypothesized that all five factors will contribute to total thought disorder severity, we believe that this contribution is differential. We predict that two traits in particular will significantly contribute to this relationship.

Hypothesis 1a. Neuroticism scores on the BFI will be positively related to global thought disorder severity. Thought disorder in healthy individuals is found most frequently during periods of psychological distress (Solovay et al., 1986), suggesting psychological distress may exacerbate thought disorder. As individuals who score high on $\mathrm{N}$ are more prone to general psychological distress, they may exhibit more severe levels of thought disorder. In addition, sustained psychological distress (Castaneda et al., 2008) and high levels of N (Gurrera et al., 2005) have both been linked to thought processes. Finally, high levels of $\mathrm{N}$ and high levels of thought disorder have independently been found to be associated with more negative global outcomes and functioning.

Hypothesis 1b. Conscientiousness scores on the BFI will be negatively related to overall thought disorder severity. As thought disorder represents difficulty in the appropriate organization and ordering of thoughts, individuals with general strengths in this area may display less severe levels of thought disorder. We might also expect 
thought disorder to be affected by variables which are related to other cognitive

processes. Good organization skills, planning, and goal-directed behaviors are common in individuals who score high in the $\mathrm{C}$ domain. Brain imaging studies have linked conscientiousness to the lateral prefrontal cortex, the brain area involved in planning and voluntary control of behavior (DeYoung, et al., 2010) suggesting that the tendencies associated with this trait have strong neuropsychological underpinnings.

\section{Hypothesis 2. The Big Five personality traits as measured by the Big Five} Inventory (BFI) will be related to quality of thought disorder. Thought disorder is expressed in multiple ways. For example, high scores can result from a few occurrences at a high level, or multiple low level scores. Also, thought disorder in one individual may be characterized by combinatory processes, where another individual may display peculiar word usage and disorganization. We hypothesize that personality will be related to the different manifestations of thought disorder. In addition, we recognize that the characteristic adaptations of the personality system within an individual are under the influence of all five underlying facets at any given time, and thus the overall trait levels are likely to interact in ways which will influence observable manifestations of the factors (McCrae\& John, 1992). Following from this consideration, for this hypothesis we will examine the relationship between thought disorder quality and personality using empirically derived clusters of traits as opposed to individual factors. This method also allows us to evaluate personality differences within the sample. Although this hypothesis is largely exploratory, based on the available literature and clinical experience, we make the following predictions: 
1) Statistically valid clusters which differ significantly on personality traits will emerge.

2) A cluster differentiated from other clusters by significantly higher $\mathrm{N}$ and significantly lower E will emerge. Compared to other clusters, this cluster will display higher levels of thought disorder than other groups, and this high score will largely result from disorganized thought processes.

3) If a cluster marked by significantly high $\mathrm{N}$ is also marked by high levels of $\mathrm{O}$, individuals in this cluster will exhibit disordered thinking characterized by combinatory responses.

4) A cluster differentiated from other clusters by significantly higher levels of $O$, $\mathrm{A}$, and $\mathrm{C}$, as well as significantly lower $\mathrm{N}$ will emerge. We predict that this cluster will have the lowest TDI totals of all groups.

5) A cluster will emerge which is differentiated from other clusters by significantly higher levels of $\mathrm{C}$ and significantly lower N. The mean levels of $\mathrm{C}$ and $\mathrm{N}$ will be high and low, respectively, compared to the normative sample. Regardless of total TDI score, most scorable instances of thought disorder in this group will be the result of deviant verbalizations. 


\section{METHODS}

The methods outlined in this section were originally submitted jointly with and approved as part of IRB protocol number 11.0453. The methods presented here contain some alterations, but largely represent the original work contained in the protocol.

\section{Sample}

The following criteria were met by all study participants : (1) Axis I diagnosis of schizophrenia or schizoaffective disorder;(2) native English speaker; (3) ability to provide informed consent; (4) no visual or hearing impairments without corrective treatment, and (5) no diagnosis of dementia or other known cognitive or neurological dysfunction. Adequate sample size recruitment is a significant challenge in schizophrenia research (Loughland, Carr, \& Lewin, 2001). To increase recruitment probability, it is common practice in schizophrenia research to combine participants diagnosed with schizoaffective disorder and schizophrenia (Mathalon et al., 2010) as demonstrated in the review of studies in Table 1. Furthermore, diagnoses of participants in the current study were taken from medical charts. Research has demonstrated poor diagnostic reliability for schizoaffective disorder and suggests that clinicians are more likely to inaccurately diagnose schizophrenia as schizoaffective disorder (Maj et al., 2000; Tandon \& Maj, 2008). As this study was interested in the role of personality and thought disorder within the diagnostic group, no comparison group was used. 


\section{Measures}

Sociodemographic form. The following sociodemographic data was identified via thorough review of the medical chart and confirmed by the patient, with the understanding that information from the medical chart was determined as the most accurate in light of any discrepancies given the extensive medical and psychiatric information obtained by the unit social workers:

1. Race

2. Ethnicity

3. Age

4. Diagnosis

5. Date of birth

6. Marital Status

7. Educational attainment

8. Employment status

9. Employment history

10. Living arrangements prior to hospitalization

11. Current medications

12. Medication history

13. Medication adherence

14. Number of previous hospitalizations

15. Other current treatment

16. Age of first hospitalizations

17. Age of first episode

18. Family psychiatric history

19. Substance abuse history

20. Numbers of days on hospital unit

21. Number of previous suicide attempts

Big Five Inventory. The Big Five Inventory (BFI, John, Donahue, \& Kentle, 1991) is a 44-item measure of the "Big Five" domains of personality. On this self-report form, participants are asked to rate the extent to which they agree with personal statements ("I see myself as someone who...") on a 5-point scale: 1 (disagree strongly) 5 (agree strongly). Each item reflects traits or preferences associated with one of the five domains of the Five-Factor model of personality: Neuroticism, Extraversion, Openness, 
Agreeableness, \& Conscientiousness. A completed BFI yields scores in each of these five domains. The BFI was developed to address problems which had been raised in personality research regarding the need for brief inventories to assess the Big Five while avoiding problems inherent in abbreviated versions of pre-existing measurements (John, Neumann, \& Soto, 2008).

Strong reliability has consistently been shown for the BFI domain scales. For example, Benet-Martinez \& John (1998) found strong internal consistency with a $M_{\alpha}$ of 0.83, ranging from $\alpha=0.79$ for the Agreeableness scale to $\alpha=0.88$ for the Extraversion scale. Results of a second study were reported in the same manuscript with similar reliability scores $\left(M_{\alpha}=0.85\right.$, range $\alpha=0.80-\alpha=0.87$ for Agreeableness and Extraversion, respectively). Strong convergent validity was also seen between the BFI and the NEO-FFI (Costa \& McCrae, 1992) with correlations ranging from 0.69 to 0.86 $(M=0.77)$, and principal factor analyses revealed the expected five-factor structure (Benet-Martinez \& John, 1998.) These results are consistent with other studies that show high reliability, clear factor structure, and strong convergent validity with other longer Big Five measures (John, Naumann, \& Soto, 2008; Soto, John, Gosling, \& Potter, 2008). As such, the BFI was chosen over other measures of the Big Five to minimize participant fatigue.

In addition to scores on the five primary domains, facet scales for the BFI have recently been developed. Each of the five domains contains two facet scales, identified as follows: Assertiveness \& Activity (Extraversion), Altruism \& Compliance (Agreeableness), Order \& Self-Discipline (Conscientiousness) Anxiety \& Depression (Neuroticism), and Aesthetics \& Ideas (Openness) (Soto \& John, 2009). These facets 
have also demonstrated moderate to strong reliabilities. Soto \& John (2009) developed and examined these facet scales and obtained mean alpha reliabilities of .72 (range $=.63-$ .84 ) and .70 (range $=.53-.83$ ), in a community and student sample, respectively, with an average test-retest reliability of 0.80 . These facet scales also showed strong convergence with the longer NEO PI-R (Costa \& McCrae, 1992) facet scales. The alpha corrected correlations averaged .82 (range $=.72-.90)$ in the community sample and in the student sample corrected correlations averaged .93 (range $=.87-1.00$ ). Facet scales will not be used in this particular study, but will be examined in later follow-up studies.

Thought Disorder Index. The Thought Disorder Index (TDI, Johnston \& Holzman, 1979; Johnson et al., 1986) is a method applied to verbal samples to assess the severity and quality of thought disorder. Although speech samples are examined, the TDI was developed specifically to assess the thinking patterns believed to be the primary disturbance underlying formal thought disorder (Johnston \& Holzman, 1979; Solovay et al., 1986). This is in contrast to other measures which emphasize the assessment of linguistic or communication disturbances, such as the TLC (Andreasen, 1979a) and the Communication Disturbances Index (CDI:Docherty, DeRosa, \& Andreasen 1996).

The TDI assesses both quality and quantity of thought disorder, allowing for a multifaceted exploration of the construct (Johnston \& Holzman, 1979). The TDI was also designed to measure an extremely broad range of thought disorder and is sensitive to even subtle examples of cognitive slippage (Coleman et al, 2003). The verbal samples used for TDI scoring are most commonly responses from the Rorschach Inkblot Test (Rorschach, 1921/1942), although other verbal samples, such as verbal samples from the Weschsler Adult Intelligence Scale can be used. However, responses from the Rorschach 
are considered to be the optimal sample for use with the TDI as it avoids the potential restriction of responses observed with standardized questions. The novelty and openended prompts of the Rorschach are not prone to the learned responses often generated in the face of discrete questions and thus more effectively elicits thought disorder (Johnston \& Holzman,1979; Spohn et al., 1986). For use with the TDI, the Rorschach is administered using the Rapaport instructions (Rapaport, Gill, \& Schafer, 1968), which allow for inquiry as soon as an individual has finished responding to a card rather than after all ten cards have been shown as is required in other scoring systems (e.g. Exner scoring system, Exner, 1993). Administration and scoring of the TDI are standardized, and scoring requires extensive training (Johnston \& Holzman, 1979). Although Rapaport administration is utilized, TDI scoring is distinct from Rorschach scoring and does not require traditional clinical scoring of the protocols.

All individuals who administered the Rorschach and scored the TDI in the current study completed training (with D. Levy) and held regular follow-up meetings to maintain skills. For the current study, all Rorschach administrations were tape-recorded and then transcribed for scoring purposes. Responses were retained and de-identified, for later analyses. Each completed Rorschach protocol was scored by consensus by at least three researchers using the TDI.

The TDI divides the severity of thinking disturbances into four levels: 0.25 (minor cognitive slippage); 0.50 (some loss of reality stability); 0.75 (clear disturbance in thought and reality constraint); and 1.0 (complete loss of reality). In addition to degree of severity, 23 scoring categories are provided to summarize the types of thought disturbance that could be exhibited. Examples and descriptions of each category and 
their respective severity levels are provided in Table 2 . The 23 scoring categories are organized into four larger categories: deviant verbalizations, associative, combinatory, and disorganized. These categories represent higher order factors which characterize the general domains of thinking disturbance by specific processes or features (Johnston \& Holzman 1979; Solovay et al., 1986).

Thought disorder within the deviant verbalizations category is characterized by instances of idiosyncratic language use, ranging from the unusual usage of words or phrases to severe cases in which novel nonsensical words are manufactured. Disordered thinking categorized under the associative domain reflects the tendency to make associations between internal and external stimuli in an inappropriate manner. In this category, irrelevant, bizarre, and idiosyncratic relationships are identified which suggests difficulty in maintaining contextually appropriate lines of thought. Associative forms of thought disorder are frequently discussed in terms of "distance" from the task at hand and associations may be loose, disconnected, or personalized. The combinatory category encompasses instances of thought disorder which suggest a tendency to merge thoughts and percepts in a manner which is not compatible with reality. The inappropriate combinations manifest in a variety of ways and include the inappropriate combination of images, details, and ideas into one as well as overgeneralization and excessive elaboration given the context. Lastly, blatant confusion and complete disconnection of thoughts is captured by the disorganized category. These instances of thought disorder generally lack meaning and are markedly difficult to understand (Johnston \& Holzman 1979; Solovay et al., 1986). 
A scored protocol provides the number of responses at each level of severity, the number of responses for each category, and a thought disorder severity total score (Johnston et al., 1986). A total TDI score is derived from the sum of each instance of thought disorder weighted by its severity level and divided by the number of total responses to control for verbal production. This value is then multiplied by 100 .

The use of the Rorschach with the TDI for measuring thought disorder has shown good internal consistency using the Spearman-Brown formula with a value of .78 (Johnston \& Holzman, 1979). In addition, reliability analyses have shown strong interrater reliability for individual and group raters across varying levels of psychopathology. Johnston and Holzman (1979) found strong inter-rater reliability for TDI total score with two independent raters for a sample of individuals with schizophrenia $(r=.90)$, nonpsychotic patients $(r=.93)$ and nonpsychiatric controls $(r=.82)$. Similarly, Solovay, Shenton, and Holzman (1987) examined a sample of individuals with schizophrenia, bipolar disorder and healthy controls, and showed strong inter-rater reliability using the Spearman-Brown formula for two independent raters for TDI total score $(r=.89)$, severity level $(r=.79)$, and categories $(r=.81)$. Coleman et al. (1993) used four independent teams of raters to examine thought disorder severity in a sample of individuals with schizophrenia, schizoaffective disorder, or bipolar disorder, as well as first-degree relatives of these patients. Coleman et al. (1993) found strong inter-rater reliability for TDI total scores ranging from $r_{s}=.80$ to .90 . Furthermore, Coleman et al. (1993) showed intraclass correlations of .77, .72, and .77 for levels $0.25,0.5$, and 0.75 , respectively (there were not enough responses at the 1.0 level to calculate reliability), and intraclass correlations of $.58, .76$, and .86 for idiosyncratic verbalizations, combinatory 
thinking, and irrelevant intrusions, respectively (these were the only categories for which there were enough instances to calculate reliability). Finally, it should be noted that the TDI has been shown to be unrelated to race and socioeconomic status(Haimo \& Holzman, 1979; Johnston \& Holzman, 1979) and use of the Rorschach in assessing thought disorder has received support even from strong critics of the Rorschach (Lillienfeld, Wood, \& Garb, 2000).

\section{Procedures}

Recruitment. Recruitment for the current study was approved by the University of Louisville, the University of Louisville Hospital Institutional Review Board, and the director of nursing of the inpatient psychiatric unit at University of Louisville hospital. Attempts were made to recruit at the University of Louisville outpatient psychiatric clinic after approximately one year of inpatient data collection. This was approved by the IRB and the director of the outpatient clinic, Outpatient recruitment was attempted through the use of flyers and direct contact with providers who agreed to aid with recruitment. No eligible individuals from this site participated in the current study. All recruitment for the inpatient site took place on the inpatient unit. A partial waiver was approved by the University of Louisville Hospital Institutional Review Board allowing us to review chart notes to identify eligible participants. Unit nursing staff members were then consulted to confirm eligibility for participants who seemingly met all inclusion criteria.

Eligible participants were then approached to inquire about their interest in the study. Each of these individuals was provided with pertinent study information such as purpose of the study, their role as a participant, the risks and benefits of the study, and 
Table 2

Definitions and Examples of TDI categories (Holzman, Levy, \& Johnston, 2005; Solovay et al., 1986)

\begin{tabular}{|c|c|c|c|}
\hline $\begin{array}{l}\text { Severity } \\
\text { Level }\end{array}$ & General TDI Category & Definition & Example \\
\hline & Associative & & \\
\hline \multirow[t]{4}{*}{0.25} & Inappropriate Distance & $\begin{array}{l}\text { The "psychological distance" an individual places } \\
\text { between him/herself and a task }\end{array}$ & "I can't stand looking at it." \\
\hline & Flippant Response & $\begin{array}{l}\text { Absence of seriousness during the task/wisecracks } \\
\text { during task }\end{array}$ & "I see another vagina, I guess I'm a sex maniac..." \\
\hline & Clangs & Rhyming or alliteration to play with words & "Really busy, Busy Lizzie." \\
\hline & Perseveration & $\begin{array}{l}\text { Response with poor form repeated at least three } \\
\text { times }\end{array}$ & An airplane on cards I, II, and III \\
\hline \multirow[t]{2}{*}{0.50} & Relationship Verbalization & Repeats or relates a response to an earlier card & "The previous bat in flight" \\
\hline & Looseness & Responses that are arbitrary or unrelated to task & $\begin{array}{l}\text { "It could be a bow for your hair, if you've got any. Most } \\
\text { people do have a lot of hair, it grows, so they should know } \\
\text { how to take care of it." }\end{array}$ \\
\hline \multirow[t]{2}{*}{0.75} & Fluidity & A response that indicates loss of object constancy & $\begin{array}{l}\text { "When I first looked at it, it looked like a bat flying away, } \\
\text { then I looked again and it looked like a bat flying towards } \\
\text { me." }\end{array}$ \\
\hline & Combinatory & & \\
\hline 0.25 & Incongruous Combinations & Single details merged into one response & "Two rats climbing a dress" \\
\hline \multirow[t]{3}{*}{0.50} & Fabulized Combinations & $\begin{array}{l}\text { Percepts are merged into unrealistic relationships } \\
\text { that violate reality }\end{array}$ & "two fetal bears on a coral reef" \\
\hline & Playful Confabulations & $\begin{array}{l}\text { Fabulized combinations that are overelaborated and } \\
\text { humorous or playful }\end{array}$ & "a butterfly on steroids" \\
\hline & Idiosyncratic Symbolism & $\begin{array}{l}\text { Interpretation of either color/images to represent } \\
\text { abstract ideas }\end{array}$ & $\begin{array}{l}\text { "red it trouble and Africa being red symbolizes that maybe } \\
\text { the origin of man was in Africa and that's why it's red." }\end{array}$ \\
\hline 0.75 & Confabulations & $\begin{array}{l}\text { Extreme elaboration or generalization of a small } \\
\text { detail in the blot }\end{array}$ & $\begin{array}{l}\text { "two people looking at each other and feeling something } \\
\text { heart-to-heart." }\end{array}$ \\
\hline
\end{tabular}




\begin{tabular}{|c|c|c|c|}
\hline & Autistic Logic & $\begin{array}{l}\text { Rationalization of a response based on illogical } \\
\text { private reasoning }\end{array}$ & $\begin{array}{l}\text { "Pant legs" (Why?) "Because it wasn't the skull it's gotta be } \\
\text { the pants legs." }\end{array}$ \\
\hline \multirow[t]{2}{*}{1.0} & Contamination & $\begin{array}{l}\text { Two separate, unrelated percepts are merged into } \\
\text { one }\end{array}$ & "dog-men" \\
\hline & Deviant Verbalizations & & \\
\hline 0.25 & Peculiar & Unusual expression or combinations of words & "a reverse reflection" \\
\hline 0.50 & Queer & $\begin{array}{l}\text { Similar to peculiar but more severe. Meaning is } \\
\text { generally uncertain. }\end{array}$ & "the feet are going together unitedly" \\
\hline 0.75 & Absurd & $\begin{array}{l}\text { A response with no resemblance to objective reality } \\
\text { in which the scorer cannot form any idea about the } \\
\text { source of the response }\end{array}$ & " and this white space...looks like part of a pentagon." \\
\hline \multirow[t]{2}{*}{1.0} & Neologisms & Invented words & "A firmabone" \\
\hline & Disorganized & & \\
\hline \multirow[t]{2}{*}{0.25} & Vague & A response that carries no clear meaning & $\begin{array}{l}\text { "they all could be animals, I-I, it's too much in general. I } \\
\text { don't know... }\end{array}$ \\
\hline & Word-Finding Difficulty & $\begin{array}{l}\text { Blocking in the search for a word that subject is } \\
\text { familiar with }\end{array}$ & $\begin{array}{l}\text { "It's a... what is it...it's a...not a beetle, but oh, it's a } \\
\text { sca...it's in the desert. I can't think of it." }\end{array}$ \\
\hline \multirow[t]{2}{*}{0.50} & Confusion & $\begin{array}{l}\text { Indicates disorientation in which subject seems } \\
\text { unsure of what they are seeing or saying }\end{array}$ & “...some people smoking matches and burning cigarettes" \\
\hline & Fragmentation & $\begin{array}{l}\text { The inability to appropriately organize and } \\
\text { integrate information }\end{array}$ & $\begin{array}{l}\text { "They....act...just like friends. Act like friends, children } \\
\text { (inquiry) Their feet. That would be two feet. That's when } \\
\text { they are close together...because they seem so playful. }\end{array}$ \\
\hline 1.0 & Incoherence & $\begin{array}{l}\text { Responses are completely unrelated to the task and } \\
\text { completely impossible for examiner to understand } \\
\text { in any context }\end{array}$ & $\begin{array}{l}\text { "(What makes it look like a duck?)" "Their disarrangement. } \\
\text { They follow out together, meeting one another. They jacked } \\
\text { up in back like spinal cord being broken" }\end{array}$ \\
\hline
\end{tabular}


their compensation for participation. They were also told that their verbal responses to the Rorschach would be tape-recorded for transcription and these responses would be retained, and de-identified for later analyses. Finally they were told that all data would be coded with an identification number that would be secured separately from each participant's identifying information (i.e. name, age, race, and date of birth), and provided information regarding confidentiality. Patients had the opportunity to ask any additional questions and were then given the option to proceed through the informed consent process, consider participation with the option to proceed with informed consent and participate at a later time, or decline participation altogether. Because the average length of stay on this particular unit is six days, all attempts were made to conduct testing on the day interested patients provided consent to do so. For participants who requested a break or who were interrupted by a unit activity, testing was completed within 24 hours of the stopping point.

Informed consent. Individuals who expressed interest in study participation at after that point were introduced to the informed consent process. Each individual who provided consent was assessed for understanding of the consenting process and the requirements of participation. The following questions were answered correctly by each participant to ensure an adequate level of understanding: (a) "What are you being asked to do as a participant in this project;" (b) "Who should you ask if you have questions about any part of the project;" (c) "What should you do if you no longer want to participate" and (d) "Do you have to participate?" After consent was obtained, each participant was briefed about the hospital HIPAA policy and asked to sign a form 
indicating their understanding of the policy and how their protected health information may be used.

Completion of measures. A majority of the sociodemographic information was obtained from the patient chart including physician, nursing, and social work notes. Additional information was obtained and/or corroborated with patient report, as needed. Following receipt of consent for participation and access to the medical chart and completing the sociodemographic questionnaire, each participant was individually administered the Rorschach and the BFI. As this was part of a larger study, participants were also administered the Positive and Negative Affect Schedule (PANAS), the Beck Depression Inventory -II (BDI-II), the Beck Anxiety Inventory (BAI), and the WTAR (Weschler Test of Adult Reading).The administration of these assessments was counterbalanced across participants to control for order effects. Following the administration of all measures, participants were engaged in a short, neutral conversation to provide a distraction from any distress that may have been caused by the assessment battery. The average length of time for study completion was approximately 1.5 hours. All participants who completed the entire battery were reimbursed $\$ 5$ for their time and participation.

\section{Data Analyses}

Descriptive analyses. Descriptive analyses were completed for clinical and sociodemographic variables using IBM SPSS Statistics 21. To explore potential relationships between sociodemographic variables and clinical variables, correlation analyses were conducted for BFI scores in each domain, TDI total score, and the following socio-demographic variables: age, years of education, age at first 
hospitalization, age at first psychotic episode, and total number of hospitalizations. The remainders of the sociodemographic variables were excluded from analyses due to large discrepancies in sample size across categories.

\section{Hypothesis 1}

Multiple regression analysis. Multiple regression analysis was used to examine the relationship between thought disorder severity and personality as assessed from the BFI. Scores on all five domains of the BFI were entered into the regression model as independent predictors of total TDI score. These predictors were entered into the regression equation using the forced entry method based on its appropriateness for theory testing (Field, 2009). Significance was determined at the $\alpha=0.05$ level. The fit of each predictor was explored in addition to the overall model.

Multiple regression was chosen over other more sophisticated modeling techniques based on the current stage of model development. Path analysis was considered as an alternative or additional analysis, however, the lack of specific theory regarding indirect effects of variables suggests that multiple regression is more appropriate method (Mertler, \&Vannatta, 2009: Streiner, 2005). Furthermore, conducting a path analysis with the proposed model results in path coefficients which are identical to beta coefficients provided in the regression results. Multiple regression is therefore the most parsimonious approach in the current analysis. 
Hypothesis 1a and 1b.Univariate correlations from the regression model were calculated to determine directionality of relationships, as well as appropriateness of each variable as an independent predictor. A cut-off value of $r<0.80$ was used.

\section{Hypothesis 2.}

Cluster analysis/ANOVA/MANOVA. Scores on all five domains of the BFI were subjected to a cluster analysis to empirically generate personality subtypes. Cluster analysis is a classification technique used to identify homogenous groups within a sample. This method has shown previous utility in psychiatric populations by identifying subgroups (Seaton, Goldstein, \& Allen, 2001) or subtypes of impairment within a disorder (Turetsky, Moberg, Mozley, Moelter, Agrin, Gur, \&Gur, 2002).To provide evidence for the validity of the clusters, the sample was subjected to two clustering methods to assess the appropriateness of cluster assignment.

First, Ward's method of hierarchical agglomerative clustering was employed to group the data. In this analysis, each participant begins as a separate cluster and the two most similar clusters are merged at each successive step in the process until one cluster containing all subjects remains. Ward's method generates clusters by computing means for each cluster, calculating the squared Euclidian distance to the cluster mean for each case, and summing these distances for all cases. The overall sum of squares within cluster distances is then used to combine clusters with the smallest increase at each stage (Borgen \& Barnett, 1987). In addition to its ability to minimize within cluster variance, this method was chosen for its utility in determining the initial number of clusters and cluster centroids (Donat et al., 1992).After each case was assigned to a cluster, a one-way ANOVA was conducted to determine which variables differentiated the clusters. 
Next, the data was subjected to the K-means method of clustering. This method maximizes between cluster variation to within cluster variation. Using a preselected number of groups, all cases are allocated to their closest cluster centroid. The mean values of all of the variables for all of the cases in a cluster (the cluster centroid) are then updated based on the points assigned. This assignment is repeated until no allocations or centroids change and the clusters are stable. The initial centroids were determined by the hierarchical agglomerative cluster analysis (Hartigan \& Wong, 1979). A one-way ANOVA was also conducted to determine which grouping variables differentiated the clusters. The clusters generated from both of these methods were then compared to determine the appropriate number of clusters to retain for further analysis.

These empirically derived personality subgroups were then compared using both univariate (ANOVA) and multivariate analysis of variance techniques (MANOVA). First a univariate ANOVA was conducted to determine group differences on thought disorder severity based on total TDI score. A MANOVA was then conducted to compare the groups on specific aspects of thought disorder. A previously described, the TDI is divided into four severity levels and four broad qualitative domains (see Table 2). Frequency counts for each of these variables were used to compare the groups.

\section{Participant Sample and Statistical Power}

Field (2009) suggests a minimum sample size of 10-15 participants per predictor variable for adequate power in a regression analysis. Based on this suggestion, a minimum sample size of 75 participants would be necessary for sufficient power in the regression analysis. There is currently no standard sample size requirement for cluster analysis (Dolcinar, 2002). However, Dolcinar suggests that the minimum sample size of 
$2^{\mathrm{k}}(\mathrm{k}=$ number of variables $)$ suggested for latent class analysis may be an acceptable estimate based on the similar issues in dimensionality that arise between this and cluster analysis. Based on this calculation, 32 participants would be a minimum requirement. Given the proposed analyses, a larger sample size would have been ideal to address the hypotheses in the current study. Obtaining adequately sized samples is an ongoing challenge in working with the schizophrenia population due to a number of general barriers to participant recruitment (Loughland, Carr, \&Lewin, 2001). Recruitment for the current study took place over a period of approximately 17 months, during which 151 individuals were identified as eligible through initial chart review and approached regarding their interest in the study. Of the 151 individuals, 34 agreed to participate and completed the consent process, (6 withdrew), 82 declined to participate, and 29 were deemed unable to consent and thus ineligible. 


\section{RESULTS}

\section{Sample Characteristics and Descriptive Analyses}

Of the 28 participants in the current sample, $23(82.1 \%)$ had a diagnosis of schizophrenia and $5(17.8 \%)$ had a diagnosis of schizoaffective disorder.

Sociodemographic and descriptive information for the total sample is provided in Table 3. Potential relationships between sociodemographic variables and clinical variables were explored through correlation analysis. The following socio-demographic variables were examined: age, years of education, age at first hospitalization, age at first psychotic episode, and total number of hospitalizations. The remainder of the socio-demographic variables were excluded from analyses due to large discrepancies in sample size across categories. Due to non-normal distribution of the socio-demographic variables, Spearman's correlations were utilized for this analysis and coefficients are provided in Table 4. There were no significant correlations between any of the variables explored and TDI total score and BFI scores on each facet. Age at time of testing was positively correlated with age at first hospitalization as well as age at first psychotic episode. Age at first psychotic episode and age at first hospitalization were also positively correlated. 
Table 3

$\underline{\text { Participant Sociodemographic Characteristics }}$

\begin{tabular}{|c|c|c|}
\hline & Frequency & Percentage $(\%)$ \\
\hline \multicolumn{3}{|l|}{ Sex } \\
\hline Males & 24 & 85.7 \\
\hline Females & 4 & 14.3 \\
\hline \multicolumn{3}{|l|}{$\underline{\text { Race }}$} \\
\hline$\overline{\text { White }}$ & 18 & 64.3 \\
\hline African-American & 9 & 32.1 \\
\hline Asian & 0 & 0 \\
\hline Biracial/Multiracial & 0 & 0 \\
\hline First Nations & 1 & 3.6 \\
\hline \multicolumn{3}{|l|}{ Diagnosis } \\
\hline Schizophrenia & 23 & 82.1 \\
\hline Schizoaffective & 25 & 17.9 \\
\hline \multicolumn{3}{|l|}{ Marital Status } \\
\hline Married & 2 & 7.1 \\
\hline Single & 26 & 92.9 \\
\hline \multicolumn{3}{|l|}{ Living Status } \\
\hline $\begin{array}{l}\text { Unsupervised In } \\
\text { House/Apartment }\end{array}$ & 16 & 57.1 \\
\hline $\begin{array}{l}\text { Unsupervised In } \\
\text { Rooming or } \\
\text { Boarding House }\end{array}$ & 2 & 7.1 \\
\hline $\begin{array}{l}\text { Supervised In } \\
\text { Halfway House, } \\
\text { etc. }\end{array}$ & 2 & 7.1 \\
\hline Homeless/Shelter & 7 & 25.1 \\
\hline Other & 1 & 3.6 \\
\hline \multicolumn{3}{|l|}{ Medication } \\
\hline \multicolumn{3}{|l|}{ Compliance } \\
\hline Never as Prescribed & 3 & 10.7 \\
\hline $\begin{array}{r}\text { Self-medicate By } \\
\text { Own Criteria }\end{array}$ & 2 & 7.1 \\
\hline $\begin{array}{l}\text { Sometimes as } \\
\text { Prescribed }\end{array}$ & 4 & 14.3 \\
\hline $\begin{array}{c}\text { Usually Takes as } \\
\text { Prescribed }\end{array}$ & 6 & 21.4 \\
\hline
\end{tabular}




\begin{tabular}{lcccccc}
\hline $\begin{array}{l}\text { Always as prescribed } \\
\text { First Time on Meds }\end{array}$ & \multicolumn{2}{c}{9} & \multicolumn{2}{c}{32.1} & & \\
\hline & $N$ & Range & $M$ & $S D$ & $\begin{array}{c}\text { Skewness } \\
(S E)\end{array}$ & $\begin{array}{c}\text { Kurtosis } \\
(S E)\end{array}$ \\
\hline Age & 28 & $18-73$ & 35.04 & 15.07 & $1.30(.44)$ & $.95(.86)$ \\
Years of education & 28 & $9-15$ & 12.11 & 1.52 & $-.19(.44)$ & $.09(.86)$ \\
$\begin{array}{l}\text { Age at First } \\
\text { Hospitalization }\end{array}$ & 26 & $9-50$ & 19.52 & 7.92 & $2.33(.46)$ & $8.34(.89)$ \\
$\begin{array}{l}\text { Age at First } \\
\text { Psychotic Episode }\end{array}$ & 21 & $5-34$ & 18.95 & 7.40 & $.13(.50)$ & $.49(.97)$ \\
$\begin{array}{l}\text { Total Number of } \\
\text { Hospitalizations }\end{array}$ & 24 & $2-100$ & 15.42 & 21.39 & $3.12(.47)$ & $10.92(.92)$ \\
\hline
\end{tabular}

Sample characteristics for predictor and criterion variables are summarized in Table 5. Mean BFI scores on each domain were as follows: $\mathrm{N}(M=2.77, S D=0.98), \mathrm{E}(M=3.21$, $S D=0.63), \mathrm{A}(M=3.60, S D=0.88), \mathrm{C}(M=3.60, S D=0.91)$, and $\mathrm{O}(M=3.73, S D=$ 0.64). These scores are similar to the results from a large sample of individuals from the general population $(N=132,515)$ described in Srivastava, John, Gosling, \& Potter (2003), $\mathrm{N}(M=3.13, S D=0.86), \mathrm{E}(M=3.25, S D=0.90), \mathrm{A}(M=3.82, S D=0.68)$, and $\mathrm{C}(M=$ 3.73, $S D=0.71), \mathrm{O}(M=3.90, S D=0.69)$.The mean total TDI score for our sample was similar to other published means $(M=37.11$, S.D. $=34.24)$. 
Table 4

Correlations for BFI and TDI and Sociodemographic Variables

\begin{tabular}{|c|c|c|c|c|c|}
\hline & Age & $\begin{array}{l}\text { Years of } \\
\text { education }\end{array}$ & $\begin{array}{c}\text { Age at First } \\
\text { Hospitalizati } \\
\text { on }\end{array}$ & $\begin{array}{c}\text { Age at First } \\
\text { Psychotic } \\
\text { Episode }\end{array}$ & $\begin{array}{c}\text { Total } \\
\text { Number of } \\
\text { Hospitalizati } \\
\text { ons }\end{array}$ \\
\hline$\overline{\text { Age }}$ & - & & & & \\
\hline $\begin{array}{l}\text { Years of } \\
\text { education }\end{array}$ & .17 & -- & & & \\
\hline $\begin{array}{l}\text { Age at First } \\
\text { Hospitalization }\end{array}$ & $.50^{* *}$ & .07 & -- & & \\
\hline $\begin{array}{l}\text { Age at First } \\
\text { Psychotic } \\
\text { Episode }\end{array}$ & $.48^{*}$ & .41 & $.58^{* *}$ & -- & \\
\hline $\begin{array}{l}\text { Total Number of } \\
\text { Hospitalizations }\end{array}$ & .15 & .12 & .11 & .08 & -- \\
\hline Extraversion & .13 & .21 & -.03 & .27 & -.17 \\
\hline Agreeableness & .27 & .14 & -.06 & .01 & -.22 \\
\hline $\begin{array}{l}\text { Conscientiousnes } \\
\text { S }\end{array}$ & .30 & .20 & .02 & .21 & -.03 \\
\hline Neuroticism & -.19 & -.19 & -.11 & -.26 & -.03 \\
\hline Openness & .06 & .20 & -.08 & .02 & .21 \\
\hline TDI total & .04 & .13 & .22 & -.23 & -.01 \\
\hline
\end{tabular}


In a sample of inpatients, Holzman and colleagues (1986) reported a mean TDI score of $34.60(S D=38.80)$ and $22.80(S D=21.40)$ for the participants with schizophrenia and schizoaffective disorder, respectively. Four separate rating teams scored 20 protocols from an inpatient sample and found mean total TDI scores ranging from $18.79(S D=29.15)$ to $37.92(S D=47.29)($ Coleman et al.,1993.) This sample consisted of combined protocols from individuals with a diagnosis of schizophrenia, schizoaffective disorder, and bipolar disorder.

\section{Table 5}

$\underline{\text { Sample Characteristics for BFI Factor Scores and TDI Total Score }}$

\begin{tabular}{lcccccc} 
Clinical Variables & $N$ & Range & $M$ & SD & Skewness (SE) & Kurtosis (SE) \\
\hline Extraversion & 28 & $1.88-4.63$ & 3.21 & .63 & $.05(.44)$ & $.21(.86)$ \\
Agreeableness & 28 & $1.00-4.89$ & 3.60 & .88 & $-1.14(.44)$ & $1.55(.86)$ \\
Conscientiousness & 28 & $1.78-5.00$ & 3.60 & .91 & $-.27(.44)$ & $-.77(.86)$ \\
Neuroticism & 28 & $1.00-4.88$ & 2.77 & .98 & $.28(.44)$ & $-.49(.86)$ \\
Openness & 28 & $2.50-4.90$ & 3.73 & .64 & $.03(.44)$ & $-.97(.86)$ \\
TDI Total & 28 & $4.17-128.75$ & 37.11 & 34.24 & $1.70(.44)$ & $1.89(.86)$ \\
& & & & & &
\end{tabular}

Normality distribution was assessed by examining skewness and kurtosis $\mathrm{Z}$ scores and visual inspection of a histogram. Field (2009) has suggested that scores greater than 2.58 are significant for small sample sizes. TDI total score was significantly positively skewed. Log transformation of TDI total scores were conducted. Transformed TDI total 
score fell within the acceptable range for normal distribution and were used for subsequent analyses.

\section{Hypothesis Testing}

\section{Hypothesis 1.}

A multiple regression analysis was conducted to predict thought disorder severity from personality traits using total TDI score as the criterion variable. All five facets on the BFI: N, E, A, C, and O, were entered into the model as predictor variables. Our sample demonstrated several significant correlations between scales. $\mathrm{N}$ was significantly correlated with $\mathrm{E}(r=-0.72, p<.0001), \mathrm{A}(r=-0.40, p=.034)$, and $\mathrm{C}(r=-.805, p<$ $.0001)$. There were also significant correlations between $\mathrm{E}$ and $\mathrm{C}(r=0.68, p<.0001)$ as well as A \& $\mathrm{C}(r=0.39, p=.019)$. The scale intercorrelations in our group are substantially higher than what would be expected from previous research. In the sample previously referenced, Svrivastava, John, Gosling, and Potter (2003) reported 0.29 as their highest correlation in general population samples. In another study using the BFI, John and Svrivastava's (1999) highest scale correlation was 0.33. These correlations are provided in Table 6. Regression model summary is provided in Table 7 . The model failed to reach significance for Hypothesis 1. Due to non-significant results of overall model, no additional modeling techniques were utilized.

\section{Hypothesis 1a.}

A univariate analysis by Pearson's correlation coefficient suggests little to no relationship between $\mathrm{N}$ and TDI total score $(r=.06)$. 


\section{Hypothesis $1 b$.}

A univariate analysis by Pearson's correlation coefficient suggests little to no relationship between $\mathrm{C}$ and TDI total score $(r=.02)$. Examination of other correlation coefficients indicate little to no relationship between TDI severity and any of the BFI facet scores.

\section{Table 6}

Correlation analyses for BFI and TDI total

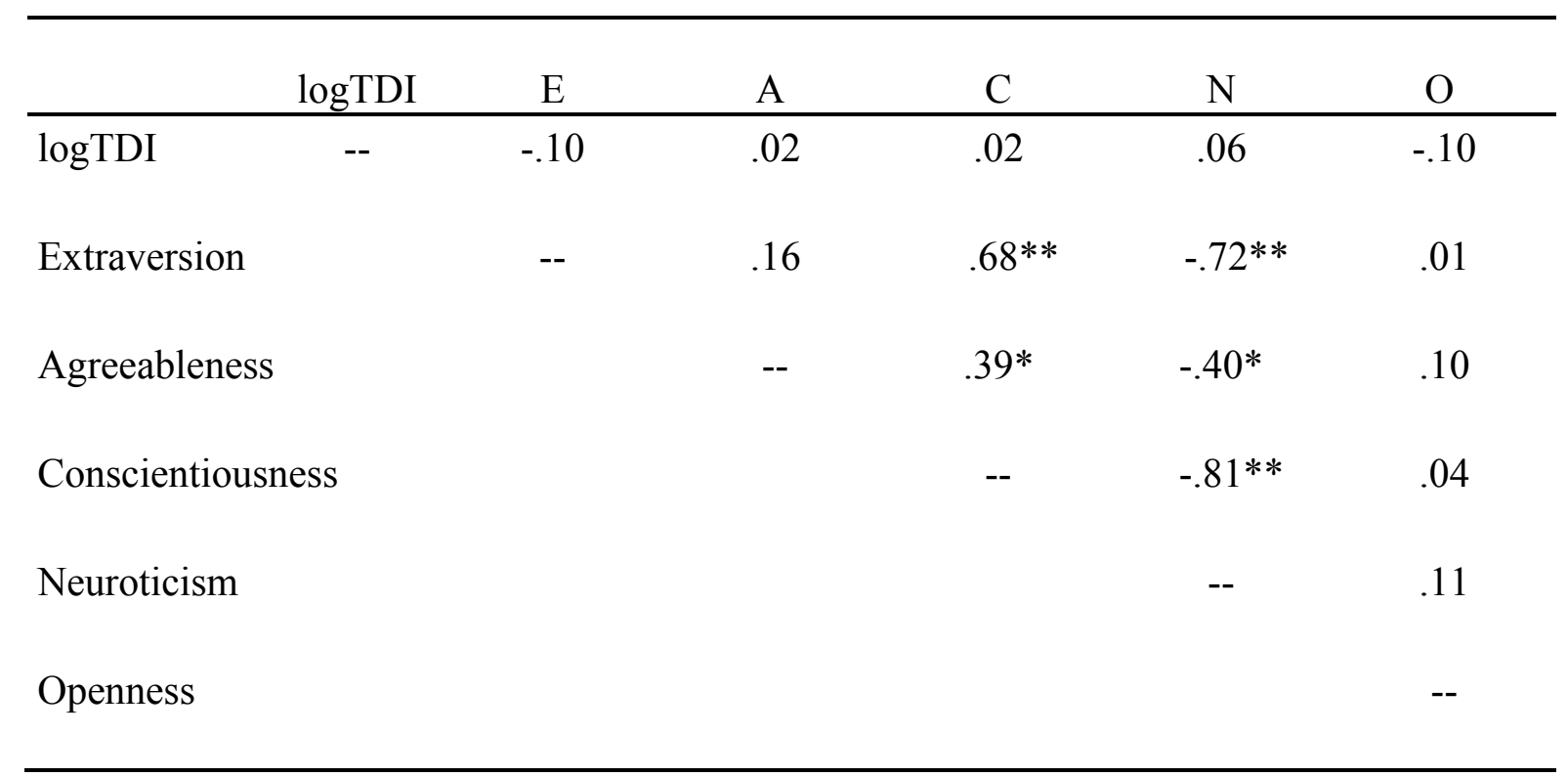

Note: Correlations marked $(*)$ were significant at $p<.05$., marked $(* *)$ were significant at $\mathrm{p}<.01 . \mathrm{E}=$ Extraversion, $\mathrm{A}=$ Agreeableness, $\mathrm{C}=$ Conscientiousness, $\mathrm{N}=$ Neuroticism, $\mathrm{O}=$ Openness $* *=\mathrm{p}<.01, *=\mathrm{p}<.05)$ 
Table 7

$\underline{\text { Regression Model Summary }}$

\begin{tabular}{|c|c|c|c|c|c|c|}
\hline Variable & $B$ & $S E B$ & $\beta$ & Sig. & Tolerance & VIF \\
\hline$\overline{\mathrm{E}}$ & -.086 & .185 & -.149 & .646 & .423 & 2.365 \\
\hline A & .010 & .100 & .024 & .920 & .758 & 1.319 \\
\hline $\mathrm{C}$ & .111 & .150 & .278 & .465 & .311 & 3.219 \\
\hline $\mathrm{N}$ & .073 & .152 & .197 & .634 & .260 & 3.841 \\
\hline $\mathrm{O}$ & -.075 & .124 & -.132 & .551 & .913 & 1.095 \\
\hline$R^{2}$ & & .046 & & & & \\
\hline$F$ & & .210 & & & & \\
\hline$p$ & & .955 & & & & \\
\hline
\end{tabular}

\section{Hypothesis 2.}

All 28 participant cases were subjected to a two-step cluster analysis as described by Burns and Burns (2009). This analysis was used to identify naturally occurring subgroups of individuals with similar personality traits. A hierarchical agglomerative cluster analysis using Ward's method was used to identify the optimum number of clusters and resulted in a three cluster solution. A one-way ANOVA was conducted to determine which variables significantly differentiated the clusters. Personality differences between clusters were determined to be statistically significant for E, C, N, and O. A did not significantly differ between the clusters. ANOVA table is summarized in Table8. 


\section{Table 8}

Hierarchical Cluster Analysis ANOVA Results

\begin{tabular}{lcccc}
\hline BFI Factor & $D f$ & $F$ & $p$ & $\eta_{\mathrm{p}}{ }^{2}$ \\
\hline Extraversion & $(2,25)$ & 20.380 & .000 & .620 \\
Agreeableness & $(2,25)$ & 1.370 & .272 & .099 \\
Conscientiousness & $(2,25)$ & 35.300 & .000 & .738 \\
Neuroticism & $(2,25)$ & 48.396 & .000 & .795 \\
Openness & $(2,25)$ & 8.166 & .002 & .395 \\
\hline
\end{tabular}

The cases were then subjected to a K-means cluster analysis with a forced 3 cluster solution entry, based on the results of the hierarchical cluster analysis. This iterative method of clustering is designed to optimize cluster assignments. A one-way ANOVA was conducted to determine which grouping variables differentiated the clusters. Results indicated statistically significant cluster differentiation for $\mathrm{N}, F(2,25)$ $=49.6, p<.0001 ; \mathrm{E}, F(2,25)=19.00, p<.0001 ; \mathrm{C}, F(2,25)=42.23, p<.0001 ;$ and $\mathrm{O}, F$ $(2,25)=5.72, p<.009$. A did not significantly differentiate the clusters. A summary of these results is provided in Table 9. Tukey's post-hoc comparisons of the clusters are summarized in Table 10and indicate that Cluster 1 is marked by low E, low $\mathrm{C}$ and high $\mathrm{N}$ when compared to other groups, Cluster 2 demonstrated in-between scores on all traits, and Cluster 3 is differentiated from the other clusters by high $\mathrm{E}$, high $\mathrm{C}$, and high $\mathrm{N}$. Cluster 3 also had the highest scores of all the clusters on A and O, although A did not significantly differentiate among the clusters. The composition of the clusters suggests the clusters obtained represent useful homogenous subgroups marked by meaningful differences on four factors. This suggests cluster validity. Descriptive characteristics of 
the clusters are found in Table 11. A visual representation of mean cluster personality profiles is provided in Figure 3.

\section{Table 9}

K-Means Cluster Analysis ANOVA Results

\begin{tabular}{lcccc}
\hline BFI Factor & $D f$ & $F$ & $p$ & $\eta_{\mathrm{p}}{ }^{2}$ \\
\hline Extraversion & $(2,25)$ & 19.004 & .000 & .603 \\
Agreeableness & $(2,25)$ & 1.734 & .197 & .122 \\
Conscientiousness & $(2,25)$ & 42.247 & .000 & .772 \\
Neuroticism & $(2,25)$ & 49.593 & .000 & .799 \\
Openness & $(2,25)$ & 5.719 & .009 & .314 \\
\hline
\end{tabular}

Based on support for cluster validity, all three clusters generated from the Kmeans analysis were retained for further analysis. Results from a univariate ANOVA revealed no statistically significant differences between clusters in TDI severity $(F(2,25)$ $=0.47, p=0.63)$ ). A MANOVA was then conducted to examine potential cluster differences in specific features of thought disorder. The features were chosen based on the existing TDI categories (associative, combinatory, deviant verbalizations, and disorganization) and levels of severity $(0.25,0.50,0.75$, and 1.0$)$. 


\section{Table 10}

Tukey's Post-Hoc Analysis for K-Means Cluster ANOVA

\begin{tabular}{|c|c|c|c|c|c|}
\hline Dependent Variable & $\begin{array}{l}\text { (I) Cluster } \\
\text { Number }\end{array}$ & $\begin{array}{l}\text { (J) Cluster } \\
\text { Number }\end{array}$ & $\begin{array}{c}\text { Mean } \\
\text { Difference (I-J) }\end{array}$ & SE & Sig. \\
\hline \multirow[t]{6}{*}{ BFI Extraversion } & 1 & 2 & $-.83654^{*}$ & .18670 & .000 \\
\hline & & 3 & $-1.28571^{*}$ & .21503 & .000 \\
\hline & 2 & 1 & $.83654^{*}$ & .18670 & .000 \\
\hline & & 3 & -.44918 & .19478 & .073 \\
\hline & 3 & 1 & $1.28571^{*}$ & .21503 & .000 \\
\hline & & 2 & .44918 & .19478 & .073 \\
\hline \multirow[t]{6}{*}{ BFI Agreeableness } & 1 & 2 & -.43803 & .38456 & .500 \\
\hline & & 3 & -.82143 & .44292 & .173 \\
\hline & 2 & 1 & .43803 & .38456 & .500 \\
\hline & & 3 & -.38339 & .40121 & .611 \\
\hline & 3 & 1 & .82143 & .44292 & .173 \\
\hline & & 2 & .38339 & .40121 & .611 \\
\hline BFI & 1 & 2 & $-1.22650^{*}$ & .20383 & .000 \\
\hline \multirow[t]{5}{*}{ Conscientiousness } & & 3 & $-2.13492^{*}$ & .23476 & .000 \\
\hline & 2 & 1 & $1.22650^{*}$ & .20383 & .000 \\
\hline & & 3 & $-.90842^{*}$ & .21265 & .001 \\
\hline & 3 & 1 & $2.13492^{*}$ & .23476 & .000 \\
\hline & & 2 & $.90842^{*}$ & .21265 & .001 \\
\hline \multirow[t]{6}{*}{ BFI Neuroticism } & 1 & 2 & $1.39423^{*}$ & .20574 & .000 \\
\hline & & 3 & $2.32143^{*}$ & .23696 & .000 \\
\hline & 2 & 1 & $-1.39423^{*}$ & .20574 & .000 \\
\hline & & 3 & $.92720^{*}$ & .21464 & .001 \\
\hline & 3 & 1 & $-2.32143^{*}$ & .23696 & .000 \\
\hline & & 2 & $-.92720^{*}$ & .21464 & .001 \\
\hline \multirow[t]{6}{*}{ BFI Openness scale } & 1 & 2 & .58846 & .24914 & .065 \\
\hline & & 3 & -.22143 & .28695 & .724 \\
\hline & 2 & 1 & -.58846 & .24914 & .065 \\
\hline & & 3 & $-.80989^{*}$ & .25992 & .012 \\
\hline & 3 & 1 & .22143 & .28695 & .724 \\
\hline & & 2 & $.80989^{*}$ & .25992 & .012 \\
\hline
\end{tabular}




\section{Table 11}

$\underline{\text { Socio-demographic and Descriptive Sample Characteristics By Cluster }}$

\begin{tabular}{|c|c|c|c|}
\hline & Cluster 1 & Cluster 2 & Cluster 3 \\
\hline$N$ & 8 & 13 & 7 \\
\hline Male & 7 & 10 & 7 \\
\hline Female & 1 & 3 & 0 \\
\hline White & 6 & 8 & 4 \\
\hline Black & 2 & 4 & 3 \\
\hline Native American & 0 & 1 & 0 \\
\hline schizophrenia & 8 & 9 & 6 \\
\hline \multirow[t]{2}{*}{ schizoaffective } & 0 & 4 & 1 \\
\hline & $\mathrm{M}(S D)$ & $\mathrm{M}(S D)$ & $\mathrm{M}(S D)$ \\
\hline BFI Extraversion & $2.50(0.39)$ & $3.34(0.29)$ & $3.79(0.61)$ \\
\hline BFI Agreeableness & $3.19(1.17)$ & $3.63(0.74)$ & $4.02(0.61)$ \\
\hline BFI Conscientiousness & $2.50(0.48)$ & $3.73(0.52)$ & $4.63(0.21)$ \\
\hline BFI Neuroticism & $4.00(0.50)$ & $2.61(0.43)$ & $1.68(0.46)$ \\
\hline BFI Openness & $3.95(0.67)$ & $3.36(0.53)$ & $4.17(0.45)$ \\
\hline TDI total score & $38.01(31.68)$ & $35.56(40.11)$ & $38.94(29.61)$ \\
\hline LogTDI total & $1.47(0.33)$ & $1.35(0.43)$ & $1.50(0.29)$ \\
\hline Associative & $2.63(3.89)$ & $1.08(1.66)$ & $1.86(1.57)$ \\
\hline Combinatory & $5.25(3.33)$ & $3.08(3.15)$ & $3.29(3.35)$ \\
\hline Deviant Verbalizations & $2.88(2.70)$ & $8.54(12.64)$ & $4.57(2.15)$ \\
\hline Disorganized Responses & $1.63(2.39)$ & $2.46(4.01)$ & $3.14(2.61)$ \\
\hline
\end{tabular}




\begin{tabular}{llcc}
\hline TDI \# of .25 & $3.63(2.56)$ & $10.0(12.29)$ & $7(5.60)$ \\
TDI \# of .50 & $4.88(4.45)$ & $2.31(2.18)$ & $3.14(2.27)$ \\
TDI \# of .75 & $3.00(2.45)$ & $1.77(2.65)$ & $2.43(3.64)$ \\
TDI \# of 1.0 & $0.88(1.81)$ & $1.08(2.50)$ & $0.43(1.13)$ \\
\hline
\end{tabular}

Preliminary descriptive analyses also revealed significant positive skewness based on Field's suggested cutoff (2009) on the following variables: associative, deviant verbalizations, disorganized, TDI 0.25, TDI 0.50, TDI 0.75, and TDI 1.0. Log transformations were conducted on the variables, producing a roughly normal distribution of each of the variables. Transformed scores were used in the MANOVA. Results from this MANOVA indicated a multivariate effect for the relationship between group and quality of TDI responses which approached statistical significance, Pillai's Trace $(2,25)$ $\left.=1.85, p=.06, \eta_{\mathrm{p}}{ }^{2}=.44\right)$. Univariate analysis revealed no significant effects. However, the effect for TDI 0.25 approached conventional statistical significance $(F(2,25)=2.68, p$ $\left.\left.=.08, \eta_{\mathrm{p}}{ }^{2}=0.18\right)\right)$. Correlation analyses were also conducted between BFI scores and each of the thought disorder categories and severity levels to examine potential relationships between independent personality traits and characteristics of thought disorder. Results revealed no significant relationships and are summarized in Table 12. 
Figure 3.Mean Cluster Personality Profiles

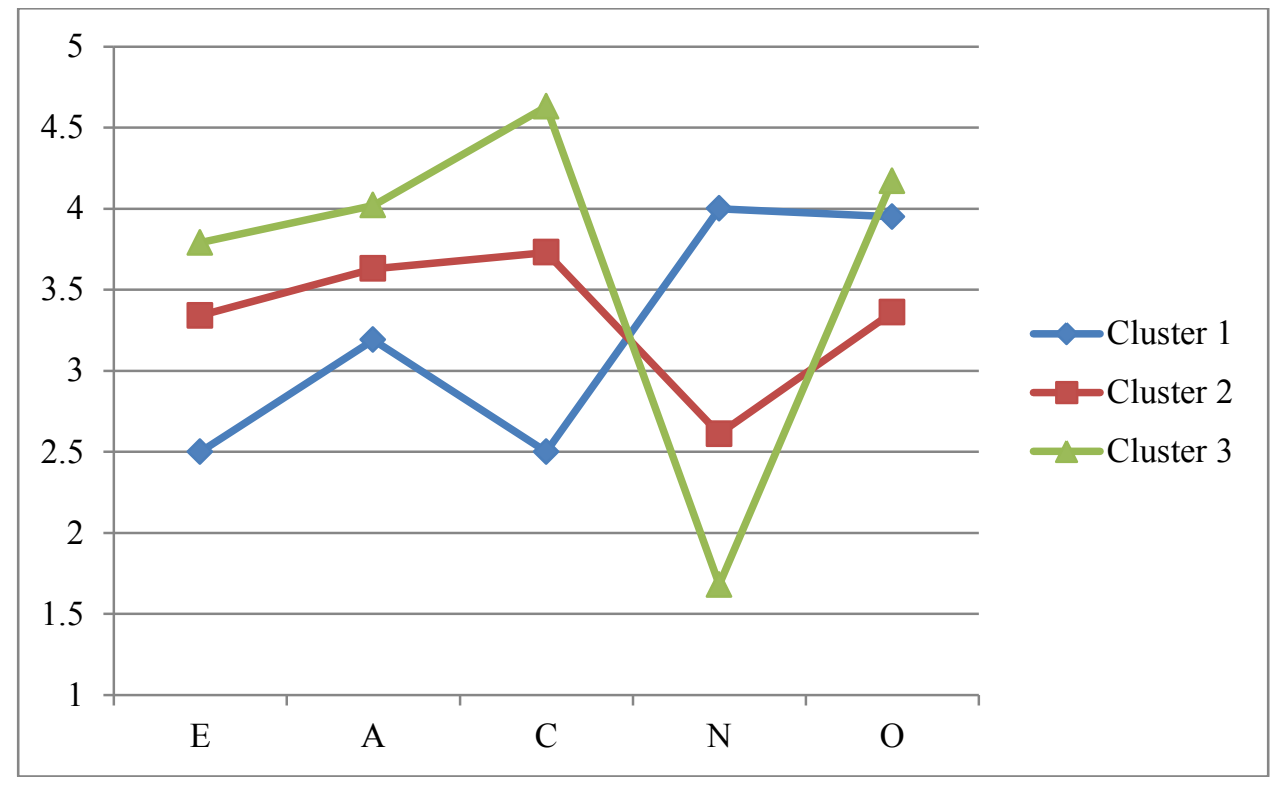

Table 12

Correlations for BFI Scores and TDI Categories and Severity Levels

\begin{tabular}{|c|c|c|c|c|c|c|c|c|}
\hline & $\begin{array}{c}\text { Combin } \\
\text { atory }\end{array}$ & $\begin{array}{c}\text { Associat } \\
\text { ive }\end{array}$ & $\begin{array}{c}\text { Deviant } \\
\text { Verbaliz } \\
\text { ations }\end{array}$ & $\begin{array}{c}\text { Disorga } \\
\text { nized }\end{array}$ & $\begin{array}{c}0.25 \\
\text { Severity } \\
\text { Level } \\
\end{array}$ & $\begin{array}{c}0.50 \\
\text { Severity } \\
\text { Level } \\
\end{array}$ & $\begin{array}{c}0.75 \\
\text { Severity } \\
\text { Level } \\
\end{array}$ & $\begin{array}{c}1.0 \\
\text { Severity } \\
\text { Level } \\
\end{array}$ \\
\hline $\mathrm{E}$ & -.319 & -.166 & .213 & .403 & .264 & -.362 & -.220 & .042 \\
\hline A & .000 & .110 & .089 & .311 & .227 & -.130 & .065 & .146 \\
\hline $\mathrm{C}$ & -.165 & .038 & .309 & .250 & .349 & -.057 & -.153 & -.043 \\
\hline $\mathrm{N}$ & .317 & -.018 & -.231 & -.308 & -.339 & .230 & .255 & .111 \\
\hline $\mathrm{O}$ & .069 & .137 & .120 & .055 & .139 & .221 & .009 & -.018 \\
\hline
\end{tabular}




\section{DISCUSSION}

The current study examined the potential relationship between personality and formal thought disorder in schizophrenia and represents the initial step in examining personality as a variable which may help to explain thought disorder's heterogeneous presentation. This is within the context of a larger framework which seeks to explore the applicability of the FFT of personality as a model to account for the heterogeneity problem within the schizophrenia population. Driving the current research is the underlying goal to highlight the remarkable heterogeneity within the schizophrenia population and draw attention to the unique individuality demonstrated within the group. It was hypothesized that personality would be related to both the quality and the severity of thought disorder in the sample and that significant within group differences in personality traits would emerge.

\section{Findings}

Hypothesis 1. Hypothesis 1 was not supported; personality was not related to the severity of thought disorder in our sample. The contribution of each individual personality trait was also examined. Hypothesis $1 \mathrm{a}$ and $1 \mathrm{~b}$ were also not supported. The data indicated weak to no relationship between any of the five factor traits and thought disorder. This was not consistent with our predictions based on the FFT and the available literature. 
All participants were in an inpatient setting during the time of data collection, suggesting current or recent acute phase of illness. The model proposed by the FFT suggests that the manifestation of symptoms may be impacted by personality traits (McCrae \& Costa, 1996; McCrae \& Costa, 1999; McCrae \& Costa, 2008). It may be that personality has an impact on quality of thought disorder, but a negligible effect on severity of thought disorder. Also, we examined total thought disorder severity on one specific measure of thought disorder. It is possible that personality may be related to total thought disorder severity on a number of other measures of thought disorder, or that personality is related to the severity of particular types or aspects of thought disorder. This is consistent with the research that suggests certain aspects of thought disorder may be non-specific indicators of psychosis (Harrow \& Marengo, 1986; Levy et al., 2010).These aspects may potentially overshadow potential thought disorder differences related to personality.

Furthermore, evidence has suggested that in addition to the state related exacerbations in thought disorder associated with acute psychosis, there are also more chronic, trait related forms of thought disorder (Andreasen \& Grove, 1986; Harvey, Docherty, Serper, and Rasmussen, 1990; Marengo \& Harrow, 1997). These trait-like forms, independent of illness state, are the ones which have been largely associated with functional outcome (Andreasen \& Grove, 1986; Bowie \& Harvey, 2008; Harvey, Docherty, Serper, and Rasmussen, 1990; Harrow \& Marengo, 1986; Harrow, Silverstein, \& Marengo, 1983; Marengo et al., 1986; Marengo \& Harrow, 1987). Our results may be a consequence of state-like exacerbations in thought disorder severity, occluding our ability to examine more trait-like manifestations of thought disorder. It may be that 
personality is related to severity of thought disorder over time or in the more trait-like, stable conditions.

Hypothesis 2.Results from the current study partially supported the hypothesis that personality is related to the quality of thought disorder. Three valid clusters differentiated from one another by specific aspects of personality were compared on several characteristics of thought disorder using MANOVA. Results from this analysis reached conventional statistical significance for this relationship, suggesting a relationship between personality and the features of thought disorder which is displayed. Subsequent univariate analyses indicated group differences in TDI 0.25 severity level responses which approached conventional statistical significance.

Examination of mean cluster differences generated by descriptive analyses also revealed that some of the predicted patterns of personality and thought disorder features emerged, suggesting the need for further exploration of these relationships and potential clinical significance. Regarding specific cluster predictions, the emergence of a cluster differentiated by significantly high $\mathrm{N}$ and low E did emerge (Cluster 1). While this cluster was present, it did not display the highest levels of thought disorder as predicted. It was also predicted that the thought disorder of individuals within this cluster would be characterized by disorganization. In addition to high $\mathrm{N}$ and low $\mathrm{E}$, Cluster 1 is marked by high levels of $\mathrm{O}$. Although not consistent with the prediction of prevalent disorganization in high $\mathrm{N}$ and low $\mathrm{E}$ categories, this cluster is consistent with the prediction that clusters characterized by high $\mathrm{N}$ and high $\mathrm{O}$ would be marked by combinatory responses. Combinatory responses include the following categories: Incongruous Combinations, Idiosyncratic Symbolism, Fabulized Combinations, Confabulation, Autistic Logic, 
and Contamination. This category is marked by a process in which ideas and perceptions are combined in way which violate reality (Solovay et al, 1986). It is possible that combinations of high $\mathrm{N}$ and low $\mathrm{E}$ are related to disorganized responses in the absence of high levels of $\mathrm{O}$. High levels of $\mathrm{O}$, or high levels of $\mathrm{O}$ alongside high levels of $\mathrm{N}$ may have a more salient impact on thought disorder quality. It is also possible that it is the configuration of all traits in Cluster 1 which promotes combinatory responses. Further investigation is warranted to better understand the relative contribution of each trait or configuration of traits to specific features of thought disorder.

We also predicted the emergence of a cluster marked by significantly high $\mathrm{O}, \mathrm{A}$, and $\mathrm{C}$ alongside significantly low $\mathrm{N}$. While A did not differ significantly across any of the groups, Cluster 3 had the highest level of A of all of the clusters and was also differentiated from the other cluster by high $\mathrm{O}$, high $\mathrm{C}$, and low $\mathrm{N}$. This cluster did not demonstrate the predicted relationship between cluster features and TDI severity. However, the features of this cluster were consistent with the final cluster prediction that a cluster differentiated from other clusters by higher levels of $\mathrm{C}$ and significantly lower $\mathrm{N}$ (when compared to both the normative sample and the current sample) would demonstrate most scorable instances of thought disorder within the deviant verbalizations category.

Broadly, results of the current study provide partial support for the proposed relationship between personality and thought disorder. Specifically, our results suggest a relationship between personality and the qualitative aspects of thought disorder. In the current study, specific configurations of personality traits showed trends towards specific features of thought disorder. Cluster 1, marked by high N, low C, low E, moderate A, 
and high $\mathrm{O}$, showed trends towards higher frequencies of combinatory responses. Cluster 3, marked by high $\mathrm{C}$, high $\mathrm{A}$, high $\mathrm{O}$, and low $\mathrm{N}$ averaged the highest frequency within the cluster in the deviant verbalizations category. However, Cluster 2 demonstrated the highest frequency of deviant verbalizations out of the clusters.

Combinatory thought processes, though disordered, are often described as highly creative (Holzman, 1986) and have been studied in regards to proposed relationships between creativity and mental illness (Richards, 1997). Research has found that Openness reliably predicts creativity across domains (Feist, 1998) and levels of cognition (Feist\& Barron, 2003). It is possible that Openness itself may be associated with combinatory thinking. However, another cluster in the sample also had high scores on $\mathrm{O}$ which did not significantly differ from this cluster. It is much more likely that $\mathrm{O}$ in combination with another factor or set of factors in a particular configuration contributed to this finding. The cluster also had low scores on $\mathrm{C}$ and though not reliably predictive of creativity, conscientiousness, has frequently been found to correlate negatively with creativity (Batey \& Furnham, 2006).While these relationships did not reach statistical significance, our results suggest the need to further explore these areas and examine potential clinical significance. The inherent complexities in this approach require further research to better understand this relationship. While it may be specific traits which are explicitly related to certain characteristics, it is much more likely that the configuration of traits is relevant.

From a descriptive perspective, when compared to individuals in Cluster 2 and 3, individuals in Cluster 1 are likely to be more prone to negative emotions and may appear anxious or depressed. They may also have difficulty with frustration tolerance and 
excessive self-criticism. These individuals are also likely to demonstrate lower levels of activity and be less talkative and sociable than the other individuals in the sample.

Cluster 1 scores are also consistent with individuals who may have a tendency to be careless and are less organized and motivated than individuals in Cluster 2 and 3. Lastly, individuals in this Cluster are likely to be imaginative and open-minded, and be more curious and willing to try new things than individuals in Cluster 2. Based on mean domain scores, individuals in each of the clusters are likely good-natured, amiable, and willing to help others. Individuals in Cluster 2 are likely to be more person-oriented, sociable, and active than individuals in Cluster 1 . They are also likely to demonstrate more goal-directed behavior and reliability than Cluster 1. While they are not as prone to negative emotions as the individuals in Cluster 1, individuals in Cluster 2 may still be likely to demonstrate maladaptive coping strategies and frustration in response to negative emotions. They are also more likely to experience negative emotions than individuals in Cluster 3. When compared to the other clusters, individuals in Cluster 2 are likely to demonstrate values which are more traditional and may be somewhat rigid and dogmatic in their beliefs. They are likely to be somewhat set in their behavioral and emotional tendencies and may be less likely to make changes. Cluster 3, like Cluster 2, contains individuals who are likely to be much more sociable, outgoing, and talkative than individuals in Cluster 1. These individuals are also likely to demonstrate a high degree of motivation, organization, and reliability. In terms of emotional adjustment and coping, individuals in Cluster 3, in contrast to both other clusters, are likely to be able to tolerate frustration and distress and have a tendency towards general emotional stability. They are also likely to use active positive coping strategies when they do experience 
negative emotions. Similarly to Cluster 1, individuals in Cluster 3 are also likely to be imaginative, curious, and unconventional.

The clinical description of the clusters illustrates a particularly salient example of sample bias. Based on the behavioral correlates of the five factor traits, we can surmise that personality is also likely to be related to the willingness of individuals to engage in a research study. The clusters in our sample did not differ significantly on scores of Agreeableness, suggesting similarities in characteristics such as altruism, kindheartedness, cooperativeness, and helpfulness. It is likely that our sample is comprised largely of individuals demonstrating moderate to high levels of these characteristics. Individuals with low scores on A tend to be uncooperative, irritable, and rude which may make them less likely to participate in a research study. Our results are consistent with these predictions and suggest that individuals with low scores on A are underrepresented in our sample. Although our sample did significantly differ on Openness scores, based on the behavioral correlates of $\mathrm{O}$ as well as scores demonstrated in our sample, it is likely that the range of $\mathrm{O}$ is also fairly restricted in our sample when compared to the schizophrenia population. Individuals who are curious and willing to seek out and appreciate new experiences may have been much more likely to agree to participate in the current study than those who are more behaviorally rigid. While the behavioral characteristics of $\mathrm{O}$ and $\mathrm{A}$ seem particularly relevant to study participation, the correlates of $\mathrm{N}, \mathrm{E}$, and $\mathrm{C}$ as well as the relative trait configuration are all likely to be related to the tendency towards participation and engagement in research. Our sample is quite likely to represent only a limited portion of the larger population in terms of personality as well as thought disorder. 


\section{Limitations and Future Directions}

The results of the study are bound by some limitations. First, the size and composition of our sample limit the generalizability of the results. The sample was fairly small, thus the study should be replicated with a larger sample to assess reliability of findings. This is particularly important given the complex nature of the constructs examined. Our sample was also largely comprised of males. Due to the small number of women within the sample, no gender differences could be explored. Future work should examine potential differences between genders. This work should also expand the sample in terms of other sociodemographic variables, namely ethnicity, SES, and education to explore the potential effect of these factors on personality or thought disorder.

All sample participants were on an inpatient psychiatric unit at the time of study participation. While previous research has suggested self-report personality stability across phases of illness (Horan et al., 2005, Kentros et al., 1997), exacerbations in thought disorder severity are consistently found in the acute phases of illness (Harrow \& Marengo, 1986; Marengo \& Harrow, 1987). The proposed expansion of the study to an outpatient sample was unfortunately not possible. Expanding to an outpatient sample would allow us to examine the relationship between personality traits and thought disorder across illness phases. That the more persistent forms of thought disorder have shown strong relationships with negative functional outcome in several domains highlights the need to specifically examine personality and thought disorder in this context. In order to examine potential interactions among personality, state-like exacerbations in thought disorder, and trait-like thought disorder, longitudinal research 
which assesses for personality and thought disorder at various phases of illness would be optimal.

The measures utilized in the current study also represent potential limitations. The BFI is a self-report measure. While studies have indicated good reliability and validity with self-report personality measures in the schizophrenia population (Horan et al., 2005; Kentros et al., 1997), self-report measures always carry with them several potential sources of biases. Additionally, there are currently no published studies which have utilized the BFI in a schizophrenia population. Strong convergent validity with the NEO has been established, however, the validity of the BFI with this particular diagnostic group has not been formally established. Our sample demonstrated personality characteristics which were not consistent with what would be expected from previous samples using the NEO. Future research could help to clarify whether or not this was an artifact of the measures utilized in the study. This work could also help to establish the utility of the BFI within the schizophrenia population. The TDI is also one of many potential measures of thought disorder which could be utilized to examine thought disorder. The TDI is empirically supported, but the process of evaluating thought disorder is somewhat subjective (McKenna \& Oh, 2005). The TDI is scored in group discussions where trained raters reach a consensus score. Future studies may wish to consider the addition of other measures of thought disorder, or compare TDI scores across multiple scoring groups, allowing for the examination of potential differences in results based on measures and group rating.

The analyses utilized in the current study also present several limitations. Several limitations of cluster analysis were addressed by the use of the two-step method. 
However, there are no stringent guidelines for cluster definition. Cluster analysis should be conducted within other samples to determine replication of clusters. If the clusters are replicable, this provides additional support for cluster validity and may serve as a method for identifying homogenous subgroups within the schizophrenia population which could then be compared across other domains. This approach to the study of personality may be more beneficial than the simple trait-outcome relationships often explored as we cannot overlook the potential interactions of particular trait configurations on outcome.

The previously discussed problem of restricted range in scores also presents limitations related to the analyses in the current study. The use of multiple regression analysis with data representing a restricted range of BFI and likely TDI scores results in a limited view of the potential relationships and underestimates the relationship as it occurs in the population. Given the restricted range in the current study, the strength of our overall model is likely to be underestimated, and our ability to examine the relative contribution of each predictor is limited. Frequency analyses should be conducted with the current data as non-parametric methods may provide us with a more accurate representation of the relationships between personality and thought disorder, given the limited range of the current sample. Future work should explicitly examine the potential relationships among personality, thought disorder, and outcome. Research has found significant associations between thought disorder and outcome as well as personality and outcomes, however, these are only a few of the many potential variables which may influence outcome. Functioning is also likely to be related to a number of factors such as symptom profile, environmental factors, and personal history (Pogue-Geile \& Harrow 1985; Westermeyer \& Harrow, 1984). Future work should focus on disentangling the 
intricate relations between personality, thought disorder, and outcomes. Other potential moderators of relationships should also be the focus of future research such as affect, cognitive variables, substance use, and environmental factors.

As noted previously, we suggest that thought disorder is only one of many variables which could potentially be explored in relation to personality. Future work should continue to build support for the efficacy of the FFT as an explanatory model within the schizophrenia population. The model can then be used as a basis for generating hypotheses related to personality and various other factors, particularly factors which may be of relevance to functional outcome. Some of these factors may include difference in treatment response, the role of personality in etiology, personality as a protective factor, and personality characteristics as strengths which could be utilized in recovery planning. Furthermore, potential changes in personality should be examined. It has been suggested that antidepressants actually change biology thus actually changing personality traits event within the FFM. Perhaps antipsychotics could have the same effect.

\section{Summary and Implications}

To our knowledge, the current study is the first to examine the relationship between personality and thought disorder. While our study failed to find any relationship between personality traits and thought disorder severity, our results do suggest that utilizing personality traits as a framework from which to examine within-schizophrenia heterogeneity may be a fruitful approach to research. The current research identified subgroups within the sample which significantly differed in personality configuration. Thought not statistically significant, these sub-groups demonstrated different 
characteristics of thought disorder, which warrant further exploration to determine potential clinical significance.

The current research offers several unique contributions to the schizophrenia literature, particularly in light of the historical view of personality in schizophrenia. Regardless of whether or not personality can reliably account for the heterogeneity problem, empirical evidence suggests that personality may be of substantial importance to study in schizophrenia for a variety of other reasons (Smith et al., 1995). The participants in our sample all had a diagnosis of schizophrenia or schizoaffective disorder and demonstrated variable personality traits. These findings are consistent with emerging research which has started to emphasize the existence and importance of "normal" personality traits within the schizophrenia population. The finding that personality characteristics have been linked to dimensions relevant to treatment and outcome both within individuals with schizophrenia (Hansson et al., 2001; Kentros, Terkelsen, et al., 1997, Lysakeret al., 2004) and in non-psychiatric individuals (Herbert \& Powell, 1989) suggests that personality may be implicated in guiding clinical interventions.

This highlights the importance of personality traits in day to day clinical interactions. We may strongly benefit from inclusion of personality factors when selecting and planning intervention strategies. This could potentially help clinicians to identify individuals who may receive special benefit from a differing treatment emphasis that complements certain personality traits (Lysaker \& Davis, 2004). Continued research linking personality traits to clinical phenomena may provide a foundation for the study of personality types in response to different treatment modalities. Indeed, personality traits may very well differentiate among groups that respond better or worse to specific 
intervention strategies, particularly in light of the psychosocial nature of the comprehensive treatment modalities often utilized in this population. This information could then be utilized to tailor interventions on an individual basis founded on personality traits or patterns to increase effectiveness.

In the schizophrenia literature, current research emphasizes topics such as genetic mapping, the treatment of positive symptoms, and other factors which distinguish the schizophrenia population from other groups. While there are certain benefits when using this approach, it inherently overlooks the heterogeneous presentation within the schizophrenia population and places diagnosis at the forefront of conceptualization. Evolving views of treatment within the mental health field suggest a need for increased attention in other areas of research. Theory about the etiology of mental illness is not particularly relevant to recovery. It is a unique process influenced by a person's own choices and preferences. By focusing on their uniqueness and ways to enhance/utilize this within the Recovery Model we are better serving these needs. Additionally, recovery can and does occur even though symptoms reoccur, suggesting utility in emphasizing factors other than symptom remission (Anthony, 2000).

Recovery based approaches are person-centered, recognizing that a psychiatric diagnosis is only one facet of the individual. The traditional approaches which emphasize diagnoses fail to recognize the unique presentations that occur within diagnostic categories, thus contributing little to the advancement of recovery-based approaches. Within the Recovery framework, examining factors related to functional outcome, independent of psychiatric status may be a more fruitful approach in determining mechanisms to target in interventions. 
Our results indicate that individuals sharing a diagnosis still differ substantially in the way they think, feel, interpret, and interact with the world. Personality does not cease to exist in the schizophrenia population. Studies such as this remind us that the emergence of schizophrenia does not destroy the personality and that individuals with this diagnosis present with unique individual characteristics that differentiate them from one another. As a final note, by bringing our attention to the individual differences in the schizophrenia population, we are also highlighting the similarities between those with a psychiatric diagnosis to everyone else. A key principle of the Recovery model is the reduction of stigma, which impacts mental health consumers, the general population, and mental health workers alike. As noted by Dr. Patricia Deegan in 1996, the concept of recovery is "rooted in the simple yet profound realization that people who have been diagnosed with mental illness are human beings" (p. 92). Perhaps this study may serve to remind clinicians and researchers alike that when working with this population, we are not simply working with schizophrenia per se, but rather working with people who carry a diagnosis of schizophrenia. Furthermore, these are people who are not all the same, but rather are unique individuals who demonstrate a wide range of characteristics, tendencies, behaviors, thoughts, and numerous other features reflected by their personalities. 


\section{REFERENCES}

American Psychiatric Association(2013). Diagnostic and statistical manual of mental disorders(5th ed.). Arlington, VA: American Psychiatric Publishing.

Andreasen, N. C. (1979a). Thought, language, and communication disorders. I. Clinical assessment, definition of terms, and evaluation of their reliability. Archives of General Psychiatry, 36(12), 1315-1321.

Andreasen, N. C. (1979b). Thought, language, and communication disorders. II. Diagnostic significance. Archives of General Psychiatry, 36(12), 1325-1330.

Andreasen, N. C., \& Carpenter Jr, W. T. (1993). Diagnosis and classification of schizophrenia. Schizophrenia Bulletin, 19(2), 199.

Andreasen, N. C., \& Grove, W. M. (1986). Thought, Language, and Communication in Schizophrenia: Diagnosis and Prognosis. Schizophrenia Bulletin, 12(3), 348-359. doi: $10.1093 /$ schbul/12.3.348

Angst, J., \& Clayton, P. (1986). Premorbid personality of depressive, bipolar, and schizophrenic patients with special reference to suicidal issues. Comprehensive Psychiatry, 27(6), 511-532.

Anthony W. (2000) A recovery-oriented service system: Setting some system level standards, Psychiatric Rehabilitation Journal, 24(2), 159-168.

Asai, T., Sugimori, E., Bando, N., \&Tanno, Y. (2011). The hierarchic structure in schizotypyand the five-factor model of personality. Psychiatry Research, 185, 7883. 
Assaf, M., Rivkin, P.R., Kuzu, C.H., Calhoun, V.D., Kraut, M.A., Groth, K.M., Yassa, M.A., Hart Jr., J., Pearlson, G.D., (2006). Abnormal object recall and anterior cingulate overactivation correlate with formal thought disorder in schizophrenia. Biological Psychiatry, 59, 452-459.

Bagby, R., D. Bindseil, K., Schuller, D. R., Rector, N. A., Trevor Young, L., Cooke, R. G., . . T. Joffe, R. (1997). Relationship between the five-factor model of personality and unipolar, bipolar and schizophrenic patients. Psychiatry Research, 70(2), 83-94. doi: http://dx.doi.org/10.1016/S0165-1781(97)03096-5

Bagby, R.M., Costa, P.T., McCrae, R.R., Livesley, W.J., Kennedy, S.H., Levitan, R.D., Levitt, A.J., Joffe, R.T., Young, L.T., (1999). Replicating the five factor model of personality in a psychiatric sample. Personality and Individual Differences, 27, $1135-1139$.

Barrera, A., McKenna, P.J., \&Berrios, G.E., (2005). Formal thought disorder in schizophrenia: an executive or a semantic deficit? Psychological Medicine, 35, $121-132$.

Bartholomeusz, C.F. \& Allott, K. (2012).Neurocognitive and social cognitive approaches for improving functional outcome in early psychosis: theoretical considerations and current state ofevidence. Schizophrenia Research and Treatment, Article ID 815315, 15 pagesdoi:10.1155/2012/815315

Batey, M. \& Furnham, A. (2006). Creativity, intelligence, and personality: A critical review of the scattered literature. Genetic, Social, and General Psychology Monographs, 132, 355-429. 
Beauchamp, M.-C., Lecomte, T., Lecomte, C., Leclerc, C. and Corbière, M. (2011), Personality traits in early psychosis: relationship with symptom and coping treatment outcomes. Early Intervention in Psychiatry, 5: 33-40.

doi: $10.1111 / \mathrm{j} .1751-7893.2010 .00198 . x$

Benet-Martínez, V., \& John, O. P. (1998). Los Cinco Grandes across cultures and ethnic groups: Multitrait-multimethod analyses of the Big Five in Spanish and English. Journal of Personality and Social Psychology, 75, 729-750.

Berenbaum, H., \& Fujita, F. (1994). Schizophrenia and personality: Exploring the boundaries and connections between vulnerability and outcome. Journal of Abnormal Psychology, 103(1), 148-158. doi: 10.1037/0021-843X.103.1.148

Bleuler, E. Dementia Praecox or e Group of Schizophrenias, Zinkin Journal, trans. Oxford England: International Universities Press, 1950. (Original work published 1911).

Bolinskey,P.K.\& Gottesman, I.I. (2010). Premorbid personality indicators of schizophrenia-related psychosis in a hypothetically psychosis-prone college sample. Scandinavian Journal of Psychology, 51, 68-74.

Bora, E., \& Veznedaroglu, B. (2007). Temperament and character dimensions of the relatives of schizophrenia patients and controls: the relationship between schizotypal features and personality. European Psychiatry, 22(1), 27-31.

Borgin, F.H., \& Barnet, D.C., (1987). Applying cluster analyses in counseling psychology research. Journal of Counseling Psychology, 34, 456-468.

Bowie, C. R., \& Harvey, P. D. (2008). Communication abnormalities predict functional 
outcomes in chronic schizophrenia: Differential associations with social and adaptive functions. Schizophrenia Research, 103(1-3), 240-247. doi:

http://dx.doi.org/10.1016/j.schres.2008.05.006

Buchanan, R. W., \& Carpenter, W. T. (1994). Domains of psychopathology: an approach to the reduction of heterogeneity in schizophrenia. The Journal of nervous and mental disease, 182(4), 193-204.

Burns, R.P. \& Burns, R. (2009). Chapter 24, Cluster Analysis. Business Research Methods and Statistics using SPSS. (pp.552- 567).Thousand Oaks, CA: Sage Publications.

Camisa, K. M., Bockbrader, M. A., Lysaker, P., Rae, L. L., Brenner, C. A., \& O'Donnell, B. F. (2005). Personality traits in schizophrenia and related personality disorders. Psychiatry Research, 133(1), 23-33. doi: 10.1016/j.psychres.2004.09.002

Castaneda, A.E., Tuulio-Henrikkson, A., \&Marttunen, M., et al., (2008) A review of cognitive impairments in depressive and anxiety disorders with a focus on young adults. Journal of Affective Disorders, 106, 1-27.

Coleman, M., Carpenter, J., Waternaux, C., Levy, D., Shenton, M., Perry, J., Medoff, D., Wong, H., Monoach, D., Meyer, P., O’Brian, C., Valentino, C., Robinson, D., Smith, M., Makowski, D., \&Holzman, P. (1993). The Thought Disorder Index: A reliability study. Psychological Assessment, 5(3), 336-342.

Costa Jr., P.T., McCrae, R.R., (1992). Revised NEO Personality Inventory (NEO-PI-R) And NEO Five-Factor Inventory (NEO-FFI) professional manual. Psychological Assessment Resources, Odessa, FL. 
Costa, P.T., \& McCrae, R.R. (2000). Professional Manual: Revised NEO Personality Inventory (NEO-PI-R) and NEO Five-Factor Inventory (FFI) professional manual. Lutz, FL: Psychological Assessment Resources, Inc.

Costa, P.T. Jr.; Terracciano, A.; McCrae, R.R. (2001). Gender Differences in Personality Traits Across Cultures: Robust and Surprising Findings. Journal of Personality and Social Psychology,81(2), 322-331.

Deegan, P. (1996). Recovery as a Journey of the Heart. Psychiatric Rehabilitation Journal, 19(3), 91-97.

DeYoung, C.G., Gray, J.R., Hirsh, J.B., Papademetris, X., Rajeevan, N., \& Shane, M.S. (2010) Testing predictions from personality neuroscience: Brain structure and the Big Five. Psychological Science. 21(6), 820-828.

DiLalla, D. L., \& Gottesman, I. I. (1995). Normal personality characteristics in identical twins discordant for schizophrenia. Journal of Abnormal Psychology, 104(3), 490-499. doi: 10.1037/0021-843X.104.3.490

Dinzeo, T. J., \& Docherty, N. M. (2007). Normal personality characteristics in schizophrenia: A review of the literature involving the FFM. Journal of Nervous and Mental Disease, 195(5), 421-429.

Docherty, N.M.; DeRosa, M.; \& Andreasen, N.C. (1996) Communication disturbances in schizophrenia and mania. Archives of General Psychiatry,53, 358-364.

Dolnicar, S, (2002). A Review of Unquestioned Standards in Using Cluster Analysis for Data-driven Market Segmentation, CD Conference Proceedings of the Australian and New Zealand Marketing Academy Conference 2002 (ANZMAC 2002), Deakin University, Melbourne, 2-4 December 2002. 
Donat, D. C., Geczy, B., Helmrich, J., and Lemay, M. (1992). Empirically derived personality subtypes of public psychiatric patients: Effect on self-reported symptoms, coping inclinations, and evaluation of expressed emotion in caregivers. Journal of Personality Assessment, 58, 36-50.

Exner, J. E. (1993). The Rorschach: A comprehensive system: Vol. 1. Basic foundations (3rd ed.). New York; Wiley.

Eysenck, H. J. \&Eysenck, S. B. G. (1975).Manual for the Eysenck Personality Questionnaire. Educational and Industrial Testing Service.

Feingold, A. (1994). Gender differences in personality: A meta-analysis. Psychological Bulletin, 116, 429-456.

Feist, G.J. (1998). A meta-analysis of personality in scientific and artistic creativity. Personality and Social Psychology Review, 2, 290- 309.

Feist, G.J. \& Barron, F.X. (2003). Predicting creativity from early to late adulthood: Intellect, potential, and personality. Journal of Research in Personality, 37, 62-88.

Field, A. P. (2009). Discovering statistics using SPSS. London, England : SAGE.

Furukawa, T., Hori, S., Yoshida, S. i., Tsuji, M., Nakanishi, M., \& Hamanaka, T. (1998). Premorbid personality traits of patients with organic (ICD-10 F0), schizophrenic (F2), mood (F3), and neurotic (F4) disorders according to the five-factor model of personality. Psychiatry Research, 78(3), 179-187.

Goffman, E. (1963) Stigma: Notes on the Management of Spoiled Identity. Engelwood Cliffs, NJ: Prentice-Hall.

Goldstein, J.M. \& Lewine, R.R.J. (2000). Overview of sex differences in schizophrenia: Where have we been and where do we go from here? In D. Castle, J. McGrath, 
and J. Kulkarni (Eds.).Women and Schizophrenia. Cambridge: Cambridge University Press, 111-143.

Goldstein, J.M. \&Tsuang, M.T. (1988) The process of subtyping schizophrenia: Strategies in the search for homogeneity. In: Tsuang, MT, Simpson, JC (eds.) Handbook of Schizophrenia, Volume 3: Nosology, Epidemiology, and Genetics. Amsterdam: Elsevier Science Publishers B.V. 63-83.

Goodwin, R. D., Fergusson, D. M., \&Horwood, L. J. (2003). Neuroticism in adolescence and the risk of psychotic symptoms in young adulthood. Psychological Medicine, 33, 1089-1097.

Green, M. F. (1996). What are the functional consequences of neurocognitive deficits in schizophrenia? The American journal of psychiatry.

Gurrera, R. J., Nestor, P. G., \& O'Donnell, B. F. (2000). Personality traits in schizophrenia: Comparison with a community sample. Journal of Nervous and Mental Disease, 188(1), 31-35. doi: 10.1097/00005053-200001000-00006

Gurrera, R. J., Nestor, P. G., O'Donnell, B. F., Rosenberg, V., \& McCarley, R. W. (2005). Personality differences in schizophrenia are related to performance on neuropsychological tasks. Journal of Nervous and Mental Disease, 193(11), 714721. doi: 10.1097/01.nmd.0000185938.30783.6b

Haimo, S., \&Holzman, P. S. (1979). Thought disorder in schizophrenics and normal controls: Social class and race differences. Journal of Consulting Clinical Psychology, 47, 963-967.

Hansson, L., Eklund, M., \&Bengtsson-Tops, A. (2001). The relationship of personality 
dimensions as measured by the temperament and character inventory and quality of life in individuals with schizophrenia or schizoaffective disorder living in the community. Quality of Life Research, 10, 133-139.

Harrow, M., \&Marengo, J.T. (1986). Schizophrenic thought disorder at followup: Its persistence and prognostic significance. Schizophrenia Bulletin, 12(3), 373-393.

Harrow, M., Marengo, J., \& McDonald, C. (1986). The Early Course of Schizophrenic Thought Disorder. Schizophrenia Bulletin, 12(2), 208-224. doi:

$10.1093 / \mathrm{schbul} / 12.2 .208$

Harrow, M., Silverstein, M., \& Marengo, J. (1983). Disordered thinking: Does it identify nuclear schizophrenia? Archives of General Psychiatry, 40(7), 765-771. doi: 10.1001/archpsyc. 1983.01790060063008

Hartigan, J.A. \& Wong, M.A. (1979). A K-Means clustering algorithm: Algorithm AS 136, Applied Statistics, 28, 126-130.

Harvey, P. D., Docherty, N. M., Serper, M. R., \& Rasmussen, M. (1990). Cognitive Deficits and Thought Disorder: II. An 8-month Followup Study. Schizophrenia Bulletin, 16(1), 147-156. doi: 10.1093/schbul/16.1.147

Harvey, P., Earle-Boyer, E. A., \& Wielgus, M. S. (1984). The consistency of thought disorder in mania and schizophrenia. The Journal of Nervous and Mental Disease, 172, 458-463.

Heinrichs DW, Hanlon TE, Carpenter WT (1984) The Quality of Life Scale: An instrument for assessing the schizophrenic deficit syndrome. Schizophrenia Bulletin,10, 388-396. 
Herbert, C. M., \& Powell, G. E. (1989). The role of personality factors in rehabilitation. Personality and individual Differences, 10(9), 969-973.

Herrán, A., Sierra-Biddle, D., Cuesta, M. J., Sandoya, M., \& Vasquez-Barquero, J.L. (2006). Can personality traits help us explain disability in chronic schizophrenia? Psychiatry and clinical neurosciences, 60(5), 538-545.

Hiroaki, H., Noguchi, H., Hashimoto, R., Nakabayashi, T., Saitoh, O., Murray, R.M., Okabe, S., \&Kunugi, H., (2008). Personality in schizophrenia assessed with the Temperamentand Character Inventory (TCI). Psychiatry Research, 160, 175-183.

Holzman, P. S., Levy, D. L., \& Johnston, M. H. (2005). The use of the Rorschach technique for assessing formal thought disorder. In R. Bornstein \& J. Masling (Eds.), Scoring the Rorschach: Seven Validated Systems (55-95). Mahwah, New Jersey: Lawrence Erlbaum Associates.

Holzman, P. S., Shenton, M. E., \&Solovay, M. R. (1986). Quality of Thought Disorder in Differential Diagnosis. Schizophrenia Bulletin, 12(3), 360-372. doi:

$10.1093 / \mathrm{schbul} / 12.3 .360$

Horan, W. P., Subotnik, K. L., Reise, S. P., Ventura, J., \&Nuechterlein, K. H. (2005). Stability and clinical correlates of personality characteristics in recent-onset schizophrenia. Psychological Medicine: A Journal of Research in Psychiatry and the Allied Sciences, 35(7), 995-1005. doi: 10.1017/S003329170500440X

Hurt, S. W., Holzman, P. S., \& Davis, J. M. (1983). Thought disorder: The measurement of its changes. Archives of General Psychiatry, 40(12), 1281-1285. doi: 10.1001/archpsyc. 1983.01790110023005

John, O. P., Donahue, E. M., \&Kentle, R. L. (1991). The Big Five Inventory--Versions 
4a and 54. Berkeley, CA: University of California, Berkeley, Institute of Personality and Social Research.

John, O. P., Naumann, L. P., \& Soto, C. J. (2008). Paradigm shift to the integrative Big Five trait taxonomy: History, measurement, and conceptual issues. In O. P. John, R. W. Robins, \& L. A. Pervin (Eds.), Handbook of personality: Theory and research(3rd ed., pp. 114-158). New York, NY: Guilford.

John, O. P., \& Srivastava, S. (1999). The Big-Five trait taxonomy: History, measurement, and theoretical perspectives. In L. A. Pervin \& O. P. John (Eds.), Handbook of personality: Theory and research (Vol. 2, pp. 102-138). New York: Guilford Press.

Johnston, M.H. \& Holzman, P. S. (1979).Assessing schizophrenic thinking. San Francisco, CA: Jossey-Bass.

Johnston, M.H., Holzman, P.S., Solovay, M.R. Shenton, M.E., Gasperetti, C., Coleman, M., Kestnbaum, E., and Carpenter, J.T. (1986). Scoring manual for the Thought Disorder Index. Schizophrenia Bulletin, 12(3), 483-496.

Kentros, M., Smith, T. E., Hull, J., McKee, M., Terkelsen, K., \& Capalbo, C. (1997). Stability of personality traits in schizophrenia and schizoaffective disorder: A pilot project. Journal of Nervous and Mental Disease, 185(9), 549-555. doi: 10.1097/00005053-199709000-00003.

Kentros, M.S.,Terkelsen, K., Hull, J., Smith, T.E., Goodman, M. (1997). The relationship between personality and quality of life in persons with schizoaffective disorder and schizophrenia. Quality of Life Research, 6(2), 118122. 
Krabbendam, L., Janssen, I., Bak, M., Bijl, R. V., de Graaf, R., \& van Os, J. (2002). Neuroticism and low self-esteem as risk factors for psychosis. Social Psychiatry and Psychiatric Epidemiology, 37(1), 1-6. doi: 10.1007/s127-002-8207-y

Kraepelin, E. (1919). Dementia Praecox and Paraphrenia (R.M. Barclay, G.M. Robertson, Trans.). E and S Livingstone, Edinburgh.

Kyziridis, T. C. (2005). Notes on the History of Schizophrenia. German Journal of Psychiatry, 42-48.

Levy, D. L., Coleman, M. J., Sung, H., Ji, F., Matthysse, S., Mendell, N. R., \&Titone, D. (2010). The genetic basis of thought disorder and language and communication disturbances in schizophrenia. Journal of Neurolinguistics, 23(3), 176-192. doi: http://dx.doi.org/10.1016/j.jneuroling.2009.08.003

Lenzenweger, M.F. (2006). Schizotypy: An Organizing Framework for Schizophrenia Research. Current Directions in Psychological Science, 15. 162-166. doi:10.1111/j.1467-8721.2006.00428.x

Lilienfeld, S.O., Wood, J.M. \& Garb, H.N (2000). The Scientific Status of Projective Techniques. Psychological Science in the Public Interest. 1(2), 27-66.

Loehlin, J.C., McCrae, R.R., Costa, P.T., \& John, O.P. (1998). Heritabilities of Common and Measure-Specific Components of the Big Five Personality Factors. Journal of Research in Personality, 32, 431-453.

Lönnqvist, J.-E., Verkasalo, M., Haukka, J., Nyman, K., Tiihonen, J., Laaksonen, I., . . . Henriksson, M. (2009). Premorbid personality factors in schizophrenia and bipolar disorder: Results from a large cohort study of male conscripts. Journal of Abnormal Psychology, 118(2), 418. 
Loughland,C.M., Carr, V.,\&Lewin, T. (2001) The NISAD schizophrenia research register: why do we need a database of schizophreni avolunteers? TheAustralia and New Zealand Journal of Psychiatry, 35, 660-667.

Lysaker, P., Bell, M.D., Kaplan, E., \& Bryson, G (1998). Personality and psychosocial dysfunction in schizophrenia: the association of extraversion and neuroticism to deficits in work performance. Psychiatry Research, 80 (1) 61-68.

Lysaker, P., Bell, M.D., Kaplan, E., Greig, T.C. \& Bryson, G (1999). Personality and psychopathology in schizophrenia: The association between personality traits and symptoms. Psychiatry, 2, 36-48.

Lysaker, P.H., Bryson, G. J.; Marks, K., Greig, T.C., Bell, M.D. (2004). Coping style in schizophrenia: Associations with neurocognitive deficits and personality. Schizophrenia Bulletin, 30(1), 113-121.

Lysaker, P.H., \& Davis, L.W. (2004).Social function in schizophrenia and schizoaffective disorder: Associations with personality, symptoms and neurocognition. Health and Quality of Life Outcomes, 2, 15.

Lysaker, P.H., \& Taylor, A.C. (2007). Personality dimensions in schizophrenia: Associations with symptoms and coping concurrently and 12 months later. Psychopathology, 40, 338-344.

Maeda, K., Kasai ,K., Uetsuki, M., Hata, A., Araki, T., Rogers, M.A., Yamasue, H. \& Iwanami, A. (2007) Increased positive thought disorder with illness duration in patients with schizophrenia. Psychiatry and Clinical Neurosciences, 61, 687-690.

Maj, M., Pirozzi, R., Formicola, A.M., Bartoli, L., Bucci, P., 2000. Reliability and validity of the DSM-IV diagnostic category of schizoaffective disorder: 
preliminary data. Journal of Affective Disorders, 57, 95-98.

Malouff, J. M., Thorsteinsson, E. B., \& Schutte, N. S. (2005). The Relationship Between the Five-Factor Model of Personality and Symptoms of Clinical Disorders: A Meta-Analysis. Journal of Psychopathology and Behavioral Assessment, 27(2), 101-114. doi: 10.1007/s10862-005-5384-y

Marengo, J.T, \& Harrow, M. (1985). Thought disorder: A function of schizophrenia, mania or psychosis? Journal of Nervous and Mental Disease, 173, 35-41.

Marengo, J. T., \& Harrow, M. (1987). Schizophrenic thought disorder at follow-up: A persistent or episodic course? Archives of General Psychiatry, 44(7), 651-659. doi: 10.1001/archpsyc.1987.01800190071011

Marengo, J.T., \&Harrow, M. (1997). Longitudinal courses of thought disorder in schizophrenia and schizoaffective disorder. Schizophrenia Bulletin, 23, 273-285.

Marengo, J.T.; Harrow, M.; Lanin-Kettering, I.; \&Wilson, A. (1986). Evaluating bizarreidiosyncratic thinking. Schizophrenia Bulletin, 12(3):497-511.

Mathalon, D.H., Hoffman, R.E., Watson, T.D., Miller, R.M., Roach, B.J. \& Ford, J.M. (2010). Neurophysiological distinction between schizophrenia and schizoaffective disorder. Frontiers in Human Neuroscience, 3, 70.

McCrae, R. R. (1987). Creativity, divergent thinking and Openness to Experience. Journal of Personality and Social Psychology, 52, 1258-1265

McCrae. R. R., \& Costa, P.T., JI. (1996). Toward a newgeneration of personality theories: Theoretical contexts for the five-factor model. In J. S.Wiggins (Ed.), The five-factor model of personality (pp. 51-87). New York: Guilford Press.

McCrae, R.R. \& Costa, P.T. (1997). Personality trait structure as a human 
universal. AmericanPsychologist, 52, 509-516.

McCrae, R. R., \& Costa, P. T. (1999).A five-factor theory of personality.In L. A. Pervin\& O. P. John (Eds.), Handbook of personality (pp. 139-153). New York: Guilford.

McCrae, R.R. \& Costa, P.T. (2008) The five-factor theory of personality. (reprinted in Funder, D.C. \&Ozer, D.J. (2010) Pieces of the Personality Puzzle $5^{\text {th }}$ Edition. New York: W.W. Norton).

McCrae, R.R. \& John, O.P. (1992). An introduction to the five-factor model and its applications. Journal of Personality, 60, 175-215.

Meehl, P.E. (1962). Schizotaxia, schizotypy, schizophrenia. American Psychologist, 17, $827-838$.

Mertler, C.A., \&Vannatta, R.A. (2009). Path Analysis. In Advanced and Multivariate Statistical Methods: Practical Application and Interpretation. (pp. 199 - 246). Los Angeles, CA: Pyrczak Publishing.

Nigg, J. T. (2000). On inhibition/disinhibition in developmental psychopathology: Views from cognitive and personality psychology and a working inhibition taxonomy. Psychological Bulletin, 126, 220-246.

Nigg, J.T., John, O.P., Blaskey, L.G., Huang-Pollock, C.L., Willcutt, E.G., Hinshaw ,S.P., Pennington, B. (2002). Big five dimensions and ADHD symptoms: Links between personality traits and clinical symptoms. Journal of Personality Social Psychology, 83, 451-469

Pogue-Geile, M.F., \&Harrow, M. (1985) Negative symptoms in schizophrenia and depression: Their longitudinal lcourse and prognostic significance. Schizophrenia 
Bulletin, 11, 427-439.

Racenstein, J. M., Penn, D., Harrow, M., \&Schleser, R. (1999). Thought disorder and psychosocial functioning in schizophrenia :the concurrent and predictive relationships. The Journal of Nervous and Mental Disease, 187, 281-289.

Rapaport, D., Gill, M., \& Schafer, R. (1968). In R. Holt (Ed.).Diagnostic Psychological Testing.New York: International Universities Press.।

Reno, R. M. (2004). Personality characterizations of outpatients with schizophrenia, schizophrenia with substance abuse, and primary substance abuse. Journal of Nervous and Mental Disease, 192(10), 672-681. doi:

10.1097/01.nmd.0000142030.44203.63

Richards, R. (1997). Chapter 32: Conclusions: When Illness Yields Creativity. In Runco, M.A., \& Richards, R. (eds.) Eminent Creativity, Everyday Creativity, and Health, pp. 485- . Greenwich, CT: Ablix Publishing Company.

Rorschach, H. (1942). Psychodiagnostics: A diagnostic test based on perception. Bern, Switzerland: Hans Huber. (Original work published 1921).

Seaton, B. E., Goldstein, G., \& Allen, D. N. (2001). Sources of heterogeneity in schizophrenia: the role of neuropsychological functioning. Neuropsychology Review, 11(1), 45-67.

Shenton, M. E., Solovay, M. R., Holzman, P. S., Coleman, M., \&Gale,H. (1989). Thought disorder in the relatives of psychotic patients. Archives of General Psychiatry, 46, 897-901.

Slater, E. (1968). A review of earlier evidence on genetic factors in schizophrenia. 
Journal of Psychiatric Research, 6, Supplement 1(0), 15-26. doi:

http://dx.doi.org/10.1016/0022-3956(68)90005-8

Smith, T. E., Shea, M. T., Schooler, N. R., \& Levin, H. (1995). Personality traits in schizophrenia. Psychiatry: Interpersonal and Biological Processes.

Solovay, M. R., Shenton, M. E., \& Holzman, P. S. (1987). Comparative studies of thought disorders: I. mania and schizophrenia. Archives of General Psychiatry, 44(1), 13-20. doi: 10.1001/archpsyc.1987.01800130015003

Spohn, H. E., Coyne, L., Larson, J., Mittleman, F., Spray, J., \& Hayes, K. (1986). Episodic and Residual Thought Pathology in Chronic Schizophrenics: Effect of Neuroleptics. Schizophrenia Bulletin, 12(3), 394-407. doi:

$10.1093 / \mathrm{schbul} / 12.3 .394$

Solovay, M. R., Shenton, M. E., Gasperetti, C., Coleman, M., Kestnbaum, E., Carpenter, J. T., et al. (1986). Scoring manual for the Thought Disorder Index. Schizophrenia Bulletin, 12, 483-496.

Soto,C.J. \& John, O.P. (2009). Ten facet scales for the Big Five Inventory: Convergence with NEO PI-R facets, self-peer agreement, and discriminant validity. Journal of Research in Personality, 43, 84-90.

Soto, C. J., John, O. P., Gosling, S. D., \& Potter, J. (2008). The developmental psychometrics of Big Five self-reports: Acquiescence, factor structure, coherence, and differentiation from ages 10 to 20. Journal of Personality and Social Psychology, 94, 718-737.

Streiner, D.L. (2005). Finding our way: An introduction to path analysis. Canadian Journal of Psychiatry, 50(2), 115-122. 
Srivastava, S., John, O. P., Gosling, S. D., \& Potter, J. (2003). Development of personality in early and middle adulthood: Set like plaster or persistent change? Journal of Personality and Social Psychology, 84, 1041-1053.

Tandon, R., Maj, M., (2008).Nosological status and definition of schizophrenia. Some considerations for DSM-V and ICD-11. Asian Journal of Psychiatry, 1, 22-27.

Trull, T.J., \&Sher, K.J. (1994). Relationship between the Five-Factor Model of Personality and Axis 1 disorders in a nonclinical sample. Journal of Abnormal Psychology, 103, 350-355.

Turetsky, B.I., Moberg, P.J., Mozley, L.H., Moelter, S.T., Agrin, R.N., Gur, R.C., \&Gur, R.E. (2002). Memory-delineated subtypes of schizophrenia: relationship to clinical, neuroanatomical, and neuropsychological measures. Neuropsychology, 16(4), 481-490.

U.S. Department of Health and Human Services. National consensus statement on mental health recovery. 2009. Retrieved from http://store.samhsa.gov/shin/content/SMA05-4129/SMA05-4129.pdf

Van Os, J., \& Jones, P. B. (2001). Neuroticism as a risk factor for schizophrenia. Psychological Medicine: A Journal of Research in Psychiatry and the Allied Sciences, 31(6), 1129-1134. doi: 10.1017/S0033291701004044

Waford, R.N. (2013). Understanding thought disorder in schizophrenia-spectrum disorders: Exploring the relation and implications of affect, Unpublished doctoral dissertation, University of Louisville, Louisville, KY. 
Westermeyer, J.F. \& Harrow, M. (1984).Prognosis and outcome using broad (DSM-II) and narrow (DSM-III) concepts of schizophrenia. Schizophrenia Bulletin,10(4), $624-637$.

Zuckerman, M. (1991).Psychobiology of personality. New York: Cambridge University Press. 
CURRICULUM VITAE

Catherine R. Robertson, M.A.

3163 N. HUDSON AVE, APT JB

CHICAGO, IL 60657

(812) $225-1835$

PROFESSIONAL:CATHERINE.ROBERTSON2@VA.GOV

PERSONAL: CATHERINEROBERTSON85@GMAIL.COM

\section{EDUCATION}

Ph.D. Candidate, Clinical Psychology (degree expected, August 2014), University of Louisville, Louisville, KY

Dissertation Title: Putting the Person First: An Examination of Thought Disorder and Personality Heterogeneity in Schizophrenia.

Advisor: Richard R. J. Lewine, Ph.D.

M.A. in Clinical Psychology, 2011, University of Louisville, Louisville, KY

Advisor: Richard R. J. Lewine, Ph.D.

B.A.in Psychology, 2009, University of Louisville, Louisville, KY

Undergraduate Thesis Title: Exploratory Study of Undergraduates Exhibiting

Clinical Perseveration

\section{CLINICAL EXPERIENCE}

$2013-2014$

Edward Hines Jr. VA Hospital (Hines, IL)

Clinical Psychology Intern

The Edward Hines Jr. VA Hospital is one of the largest hospitals in the VA system and serves Veterans in the Chicago area. The Veteranpopulation served by the hospital is diverse in terms of ethnicity, socioeconomic background, presenting clinical issues, and level of functioning.

Primary Care Behavioral Health Rotation (6 months)

Supervisor: Erin Zerth, Ph.D.

Experience included working as a member of the interdisciplinary

Primary Care-Mental Health Integration team, serving as a 
behavioral health specialist for Primary Care's PACTs (Patient Aligned Care Team) throughout the hospital.

This rotation involved providing co-located same-day behavioral health services such as emergency intervention, consultation, assessment, and treatment to Veterans for a wide range of presenting medical and psychiatric problems. Experience also included providing ongoing individual and group interventions for multiple medical and psychiatric presentations including chronic pain, adjustment disorders, health behaviors and lifestyle change, and mood and anxiety spectrum disorders. Rotation included training in the following evidence based psychotherapies: Cognitive Behavioral Therapy for Chronic Pain, Cognitive Behavioral Therapy for Insomnia, Motivational Interviewing and Problem Solving Therapy.

Acute Inpatient Medical Rehabilitation Rotation (3 months) Supervisor: Jennifer Kiebles, Ph.D.

This rotation involved working with Veterans with a wide variety of medical and psychiatric conditions on an inpatient medical rehabilitation unit as a part of the integrative rehabilitation program team. Responsibilities included providing short-term evidence based individual psychotherapy, facilitating weekly groups, conducting psychodiagnostic and neuropsychological assessments for a variety of formal consultation questions, and extensive consultation with the interdisciplinary unit team consisting of physiatrists, nurses, social workers, and various rehabilitation therapists. Groups included coping skills and a psychoeducational group focused on various behavioral health topics such as sleep hygiene, lifestyle changes for stroke prevention, and tobacco use cessation.

Mental Health Service Line Intake Clinic (3 months) Supervisor: Kristin Raley, Ph.D.

Responsibilities include completion of full biopsychosocial evaluation for Veterans interested in services through the Mental Health Service line of the Hines VA. Diagnosis and referral/disposition for each Veteran is provided through collaboration with psychiatrists, nurses, social workers, and pharmacists. 
Psychosocial Rehabilitation and Recovery Center (6 months, beginning January 2014)

Supervisor: Amanda Lyskawa, Ph.D.

Experiences on this rotation will include working with Veterans who have been diagnosed with a serious mental illness (SMI) in an outpatient setting. Treatment is provided within the framework of the Recovery model and seeks to optimize Veteran functioning and quality of life based on personalized recovery goals. Evidencebased interventions will be provided in both individual and group formats.

Psychology Training (3 months, beginning January 2014) Supervisor: Caroline Hawk, Ph.D.

This administrative rotation will provide experiences related to the responsibilities of a Psychology Training Director. There will be a focus on developing and understanding of the various roles of the training director including conceptual program framework, program curricula, policies and procedures related to trainee selection, and regulatory requirements.

Health Promotion Disease Prevention (3 months, beginning January 2014) Supervisor: Erin Zerth, Ph.D.

Experiences on this rotation will include a large behavioral medicine focus. Responsibilities will include evidence-based, time limited individual and group therapy with a focus on health behavior change, education and training of medical staff, consultation with interdisciplinary staff, and the opportunity to participate in program development and evaluation.

Substance Abuse Rehabilitation Residential Treatment Program (3 months, beginning April 2014)

Supervisor: Amber Singh, Ph.D.

Responsibilities will include providing care to Veterans involved in a residential substance abuse treatment program, including intensive group and individual interventions to target substance abuse. This rotation will also include various psychodiagnostic assessment opportunities and extensive collaboration with a multidisciplinary team. 


\section{Clinic assistant}

Supervisor: Bernadette Walter, Ph.D

The Noble H. Kelly Psychological Services center is a community outpatient mental health clinic housed within the University of Louisville Department of Psychological and Brain Sciences. The clinic offers psychotherapy and assessment services on an outpatient basis using a sliding-scale pay basis. Responsibilities as a clinic assistant included conducting bi-weekly intake interviews for potential therapy clients, consultation with a variety of service providers in the community to assist with referrals and community resources, and phone contact with individuals in the community seeking psychotherapeutic and assessment services. Experience also included supervising junior graduate students on intake procedures and clinical interviewing skills.

Noble H. Kelly Psychological Services Center (Louisville, KY) Graduate student therapist/examiner (2010-2013)

The Noble H. Kelly Psychological Services center is a community outpatient mental health clinic housed within the University of Louisville Department of Psychological and Brain Sciences. The clinic offers psychotherapy and assessment services on an outpatient basis using a sliding-scale pay basis.

Cognitive Behavioral Therapy Team (2 years) Supervisor: Janet Woodruff-Borden, Ph.D.

Experience involved providing individual psychotherapy using evidence-based cognitive behavioral treatment approaches. Therapy was conducted for a broad range of presenting problems including mood and anxiety disorders, personality disorders, impulse difficulties, and sexual addiction. Presentation of formal case presentations and supervision of junior graduate students were also responsibilities included in this experience.

Assessment Clinic (3 years) Supervisors: Bernadette Walter, Ph.D., David Winsch, Ph.D.

This experience involved conducting formal psychological testing of both children and adults for a variety of referral questions including, advanced placement testing, ADHD, learning disabilities, and various axis I and II diagnoses. Assessment administration on this rotation included semi-structured interviews, intellectual and achievement tests, neuropsychological testing, and personality tests. 
Integrative and SMI Psychotherapy Team (18 months)

Supervisor: Jay Irby, Ph.D.

Experience involved providing individual psychotherapy to adults with a variety of presenting problems including personality disorders, bipolar disorder, sexual addiction, impulse difficulties secondary to TBI and major depression. Treatment modalities were conducted within an Integrative framework and included Dialectical-Behavior Therapy, Cognitive-Behavior Therapy, Family Systems Therapy, Narrative Therapy, and Gestalt Therapy.

\section{Central State Hospital (Lagrange, KY) Clinical Psychology Extern}

Central State Hospital is a state operated inpatient adult psychiatric hospital serving individuals with a wide range of psychiatric needs from diverse cultural and ethnic backgrounds. Although diagnostic groups varied, the most common diagnoses were psychotic disorders including schizophrenia and schizoaffective disorder, many with co-morbid medical problems and substance abuse.

Secure Care Unit (12 months, 16 hours per week) Supervisors: Rebecca Harvey, Psy.D., Rebecca Asher, Psy.D.

This setting of this rotation wasan all-male secure care unit, housing long-term patients found incompetent to stand trial, individuals in the judicial system requiring acute psychiatric care, and non-forensic patients in acute states at a high risk for violence and/or sexually acting out. Responsibilities included providing long and short term individual psychotherapy, co-facilitating biweekly Social Skills and Coping Skills therapy groups, and program development. Psychodiagnostic and neuropsychological testing for assessment of malingering, cognitive and intellectual functioning, and independent living skills, assisting unit psychologist with weekly court preparation, supervision of other practicum students, training unit staff on individualized behavior management plans for patients, and participation in multidisciplinary treatment team meetings and treatment planning were also responsibilities included in this experience.

Acute Care Units (12 months; 4 hours per week) Supervisors: Susan Brittain, Ph.D., Nancy Schrepf, Psy.D.

Time spent on the general inpatient acute units in the hospital involved providing services for individuals of all genders requiring 
acute psychiatric services. Responsibilities on acute care units included providing short-term individual psychotherapy, conducting frequent suicide risk evaluations, assisting the interdisciplinary team with safety planning for discharge, and administering various psychodiagnostic and neuropsychological test batteries for a variety of indications.

\section{TEACHING, SUPERVISION, AND MENTORING EXPERIENCE}

\section{University of Louisville, Department of Psychological and Brain Sciences (Louisville, KY) Graduate Teaching Assistant}

Spring 2013 \& Introduction to Cognitive Assessment (Graduate)

Spring 2012

Supervised junior graduate students on administration and scoring of the WAIS-IV, WISC-IV, and WJ-III with practice participants in both recorded and live feedback settings. Developed presentation and case example on malingering assessment as well as a lecture supplementing instructor's material on test administration and scoring specific to the clinic site. Provided additional supervision as needed on administration and scoring of various assessments including a full ADHD battery.

Summer 2012 \& Introduction to Clinical Interviewing (Graduate)

Fall 2011

Co-instructed and piloted a restructured format for interviewing course. This was a six week course designed to introduce firstyear graduate students in the clinical psychology doctoral program to basic clinical interviewing skills. Each class period began with a seminar, followed by modeling of specific skills, discussion of modeling, and ended with live feedback role-play modules.

Spring 2010 \& Introduction to Psychology (Undergraduate)

Fall 2009

Teaching assistant for introduction to psychology undergraduate course.

\section{RESEARCH EXPERIENCE}

2009 -present Thought Disorder, Cognition \& Affect Lab: University of Louisville (Louisville, KY)

Research Assistant

Advisor: Richard R. J. Lewine, Ph.D. 
Graduate research assistant with responsibilities including proposal writing, data collection, coding, data analysis, and writing for the following studies:

- Personality and Thought Disorder in Schizophrenia

- Affect and Thought Disorder in Schizophrenia

- Cognitive Perseveration and Academic Performance In Undergraduates

- Mood Induction and Critical Thinking in Undergraduates

- Implications of Symptom Severity Versus Diagnosis

- Dimensional Exploration of Schizoaffective Disorder

\section{Dissertation Project -Putting the Person First: An Examination of Thought Disorder and Personality Heterogeneity in Schizophrenia.}

This study is an exploration of the proposed relationship between personality (as conceptualized by the five-factor model) and thought disorder quality and severity in schizophrenia. All participants had a diagnosis of schizophrenia or schizoaffective disorder and data was collected on an inpatient psychiatric unit. Each participant was administered several measures including a self-report personality inventory, several selfreports of mood and affect, and a Rorschach, which was later scored for thought disorder using the Thought Disorder Index. Data has been collected and is currently being analyzed. It is anticipated that the dissertation will be defended in April of 2014.

2008-2009

KY)

\section{Louisville Twin Study: University of Louisville (Louisville,}

\section{Undergraduate Research Assistant}

Advisor: Deborah Winders-Davis, Ph.D.

Research assistant on a pilot study to re-open the Louisville Twin Study. The Louisville Twin study was one of the largest and most comprehensive longitudinal studies of multiple birth families including extensive data on child factors including health status, temperament, and cognitive abilities. The study had been closed and this project was an attempt to re-open the study by contacting former participants and preserving data. Responsibilities included assisting in locating and recruiting former study participants, transcribing data, managing and organizing data, and organizing mass correspondence.

\section{PEER REVIEWED PUBLICATIONS AND MANUSCRIPTS}

Published Manuscripts

Robertson, C.R.\& Lewine, R. (in press). Sex as a Potential Moderator for the Effects of Perseveration on Academic Performance in Healthy College Undergraduates. Teaching of Psychology, 
Lewine, R., Sommers, A., Waford, R., Bustanoby, H., Robertson, C., Hall, R., \&Eisenmenger, K. (2011). Sex, affect, and academic performance: It's not what you think. International Journal for the Scholarship of Teaching and Learning, 5(2).

Manuscripts in Preparation

Robertson, C.R.\& Lewine, R. (2013). Personality Traits in Schizophrenia: A Neglected Approach to the Heterogeneity Problem. Manuscript in preparation.

Robertson, C., Waford, R. \& Lewine, R. (2013). Dimensional Assessment of Psychopathology: Support from Schizoaffective Disorder.Manuscript in preparation.

Waford, R., Robertson, C.,\&Lewine, R. (2013). Impairment Status is a Useful Method for Examining Performance. Manuscript in preparation.

\section{PROFESSIONAL PRESENTATIONS}

Robertson, C., Lewine, R. , Waford, R., \& Hart, Mara. (2012, October). Examining the Efficacy of Subgrouping by FFM Personality Traits in Schizophrenia: An Exploratory Investigation. Poster session presented at the annual conference of the Society for Research in Psychopathology, Ann Arbor, MI.

Waford, R., Robertson, C., Hart, M. \& Lewine, R. (2012, October). Do Affective Intensity and Valence Moderate Thought Disorder Severity in Schizophrenia and Schizoaffective Disorder?. Poster session presented at the annual conference of the Society for Research in Psychopathology, Ann Arbor, MI.

Robertson, C., Waford, R., \& Lewine, R. (2011, September). Cognitive Perseveration Across Diagnoses: A Dimensional Approach. Poster session presented at the annual conference of the Society for Research in Psychopathology, Boston, MA.

Robertson, C.\& Lewine. R. (2010, October). Individual Differences in WCST Performance in a Schizophrenia Sample. Poster session presented at the annual conference of the Society for Research in Psychopathology, Seattle, WA.

Waford, R.N., Robertson, C.,\& Lewine, R.J. (March, 2010). An Examination of Cognitive Perseveration at the Symptoms Level. Poster presented at annual conference of the Kentucky Psychological Association, Louisville, KY.

Robertson, C.R.\& Lewine, R. J. (September, 2009). Sex Differences in WCST Perseveration in Healthy College Undergraduates. Poster presented at annual conference of the Society for Research in Psychopathology, Minneapolis, MN.

\section{OTHER PROFESSIONAL PRESENTATIONS AND ACTIVITIES}


2013 - MedicalDecision Making Capacity - Presented as a part of Loyola Medical School Geriatric Grand Rounds series.

High Utilization in the VA System - Presented as a part of the Hines VA Integrated Primary Care Team Grand Rounds series.

2011 - Society for Research in Psychopathology, Student Contributor, Publication Committee

\section{MENTORING, SUPERVISION, AND LEADERSHIP EXPERIENCE}

2012-2013

Senior Clinical Graduate Teaching Assistant

- Acted as the senior clinical teaching graduate assistant providing supervision and training to three junior clinical teaching graduate assistants.

- Provided clinical supervision for two junior graduates student for individual therapy clients. This supervision experience was formally supervised.

- Co-designed and piloted new monthly didactic series for graduate students with a focus on discussion of clinical issues which may be particularly relevant to new therapists.

2012- Peer mentor for incoming graduate student.

2011- Peer mentor for incoming graduate student.

\section{RELEVANT WORK EXPERIENCE}

2006-2007

2005-2006

2004-2005
Central State Hospital (LaGrange, KY) Mental Health Technician

Provided support and milieu therapy to an inpatient adult population. Assisted patients with multiple daily needs.

\section{Harrison Health and Rehabilitation (Corydon, IN)} Certified Nursing Assistant

Provided extensive care to individuals in a nursing home setting.

Kentuckiana Nursing Association (Louisville, KY) Home Health Aide

Provided in home care to older adults and adults with severe physical disabilities. 


\section{PROFESSIONAL MEMBERSHIPS}

\section{Professional Affiliations}

Kentucky Psychological Association

Society for Research in Psychopathology

\section{REFERENCES}

\section{Rich Lewine, Ph.D.}

Licensed Clinical Psychologist, Professor, Undergraduate Chair Department of

Psychological and Brain Sciences, University of Louisville, Louisville, KY

Phone: (502)852-3243

E-mail: rich.lewine@louisville.edu

Erin O'Neill Zerth, Ph.D.

Licensed Clinical Psychologist, Primary Care Behavioral Health Program Manager, CoHealth Behavior Coordinator, Edward Hines Jr. VA Hospital

Phone: (708)202-8387 ext. 25142

E-mail: erin.zerth@va.gov

\section{Janet Woodruff-Borden, Ph.D.}

Licensed Clinical Psychologist, Director of Clinical Training, Clinical Psychology

Program, Department of Psychological and Brain Sciences, University of

Louisville, Louisville, KY

Phone: (502)852-6070

E-mail: j.woodruff-borden@louisville.edu

\section{Bernadette Walter, Ph.D.}

Licensed Clinical Psychologist, Clinic Director of the Noble H. Kelly Psychological

Services Center, Department of Psychological and Brain Sciences, University of Louisville, Louisville, KY

Phone: (502)852-8270

E-mail: bernadette.walter@louisville.edu 